\title{
Behavioral Effects of Inhibition of Cyclic Nucleotide Phosphodiesterase 2 (PDE2) in Mice
}

Lindsay M. Lueptow

Follow this and additional works at: https://researchrepository.wvu.edu/etd

\section{Recommended Citation}

Lueptow, Lindsay M., "Behavioral Effects of Inhibition of Cyclic Nucleotide Phosphodiesterase 2 (PDE2) in Mice" (2015). Graduate Theses, Dissertations, and Problem Reports. 6121.

https://researchrepository.wvu.edu/etd/6121

This Dissertation is protected by copyright and/or related rights. It has been brought to you by the The Research Repository @ WVU with permission from the rights-holder(s). You are free to use this Dissertation in any way that is permitted by the copyright and related rights legislation that applies to your use. For other uses you must obtain permission from the rights-holder(s) directly, unless additional rights are indicated by a Creative Commons license in the record and/ or on the work itself. This Dissertation has been accepted for inclusion in WVU Graduate Theses, Dissertations, and Problem Reports collection by an authorized administrator of The Research Repository @ WVU.

For more information, please contact researchrepository@mail.wvu.edu. 


\title{
Behavioral Effects of Inhibition of Cyclic Nucleotide Phosphodiesterase 2 (PDE2) in Mice
}

\section{Lindsay M Lueptow}

\author{
Dissertation submitted to the School of Medicine \\ At West Virginia University
}

In partial fulfillment of the requirements for the degree of

Doctor of Philosophy in

Neuroscience

James M O’Donnell, Ph.D., Chair

Visvanathan Ramamurthy, Ph.D.

Adrienne Salm, Ph.D.

Usha Sambamoorthi, Ph.D.

Hanting Zhang, Ph.D.

Department of Behavioral Medicine \& Psychiatry

Morgantown, WV

2015

Keywords: cognition; learning and memory; anxiety; phosphodiesterase inhibitors; phosphodiesterase 2 (PDE2); object recognition test (ORT); cyclic GMP; cyclic AMP; nitric oxide synthase (NOS); protein kinase G (PKG) 


\title{
ABSTRACT \\ Behavioral Effects of Inhibition of Cyclic Nucleotide Phosphodiesterase 2 (PDE2) in Mice
}

\author{
Lindsay M Lueptow
}

Cyclic nucleotide phosphodiesterases (PDEs) are a super-family of enzymes that regulate intracellular levels of the second messengers, cyclic AMP and cyclic GMP. Multiple PDEs have been shown to play vital roles in the central nervous system, with involvement in mood, reward mechanisms, and learning and memory. PDE2 is of special interest due to its high level of expression in forebrain regions, which are specifically implicated in mood and memory processes. In the first set of experiments, the potential role of PDE2 in depression- and anxiety-like behaviors was investigated using the forced swim test, tail suspension test, elevated plus maze, hole-board and step-through passive avoidance tests, as well as the object recognition test (ORT). The PDE2-selective inhibitor, Bay 60-7550 (3 mg/kg) did not significantly alter any of the depression- or anxiety-like behaviors, but did significantly enhance memory in the ORT. In the next set of experiments, the ORT was used to investigate the effect of PDE2 inhibition on various stages of learning and memory. Bay 60-7550 was administered 30120 min prior to training, 0,1 , or $3 \mathrm{hrs}$ after training, or $30 \mathrm{~min}$ prior to recall testing. Next, inhibitors of the CAMP or cGMP signaling pathways were administered $30 \mathrm{~min}$ prior to the PDE2 inhibitors Bay 60-7550 or ND7001, to assess the role cyclic nucleotide signaling on PDE2 inhibitor-enhanced memory. Finally, changes in the phosphorylation of CREB at Ser-133 and VASP at Ser-239 were determined to confirm activation of cAMP and cGMP signaling by PDE2 inhibition at behaviorally relevant doses. Bay 60$7550(3 \mathrm{mg} / \mathrm{kg}$ ) significantly enhanced memory of mice in the ORT when given $30 \mathrm{~min}$ prior to training, immediately after training, or $30 \mathrm{~min}$ prior to recall. Inhibitors of the cGMP pathway blocked the memory-enhancing effects of both Bay $60-7550$ (3 mg/kg) and ND7001 (3 mg/kg). Bay 60-7550 (3 mg/kg) significantly enhanced the phosphorylation of CREB and VASP, both targets of PKG. While PDE2 inhibition did not appear to play a major role in depression- and anxiety-like behaviors in these tests, future research will further elucidate the role of PDE2 in other mood-related behavior tests. Additionally, PDE2 does appear to play a major role in learning and memory, as seen in the ORT. Developing a greater understanding of the role of PDE-2 in these memory processes will allow for potential drug development for the intervention of a variety of human diseases related to cognitive decline and memory impairment, which plague millions of individuals each year. 


\section{DEDICATION}

To all of the people I love that have been there for me every step of the way.

$\overline{(\text { iii })}$ 


\section{ACKNOWLEDGEMENTS}

I owe a debt of gratitude to all of the people that have helped me along the way: friends, family, and scientists, alike. My time at WVU has been uniquely challenging, and I couldn't have made it through without all of your support, both in and out of the lab.

I would like to specifically thank my advisor, Dr. Jim O'Donnell, for sticking with me through all the years of technical difficulties and negative data. l'd like to thank my committee members, Dr. Adrienne Salm, Dr. Hanting Zhang, Dr. Vishy Ramamurthy, and Dr. Usha Sambamoorthi (and Dr. Rae Matsumoto, prior to her departure from WVU) for offering all of their time and expertise in helping me finish. I would like to thank all of the professors that offered me your valuable time, advice, and technical skills following Dr. O'Donnell's departure from WVU, including Dr. Al Berrebi for agreeing to takeover my animal protocol, allowing me to finish my work in Dr. O'Donnell's absence.

I would also like to thank the former members of the Zhang and O'Donnell labs that were always willing to lend a helping hand.

I would like to thank the staff of OLAR including Frank Ali and Dr. Wimsatt for helping allocate animal resources, including space, after my mentor left. Also, special thanks to the Behavior Core and Dr. Liz Engler-Chiurazzi for your patience and help with my experiments. A very special thanks to Holly Legleiter for her invaluable administrative support, especially after the departure of Dr. O'Donnell.

I absolutely must thank my fellow Neuroscience members and graduate students. All of you have offered immeasurable support when I needed it the most. From taking time out of your busy schedules to attend my talks and offer helpful feedback, to our extensive hallway chats about the difficulties in lab (and life), to summer BBQs and Christmas parties, l'm forever thankful and appreciative

Last, but certainly not least, I have to thank the rest of my close friends and family. Though there aren't enough pages to list you all individually, you should know that I'm elated to have you all in my life. To my friends here in WV (including those that have since moved on from WVU), as well as those in Wisconsin, you have been a continuing source of encouragement and, of course, entertainment, that I couldn't live without. To my parents, Barb and Randy, you have taught me, through your own actions, the invaluable skills of perseverance, hard work, and dedication. To my Grandma Pat and Grandpa Ron, you have demonstrated the value of unconditional love and support. You have been there celebrating each of my milestones with more enthusiasm and excitement than I could have ever asked for. To my best friend and partner in life, Chris Bostick, there aren't really words for how important you've been to my success over the last few years. You've embodied patience, love, tough love, and support, whatever I needed when I needed it. I'm so happy to have shared this experience with you. 


\section{TABLE OF CONTENTS}

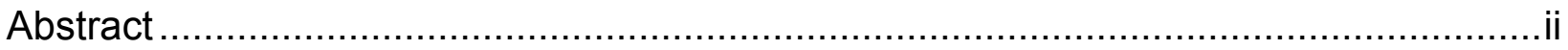

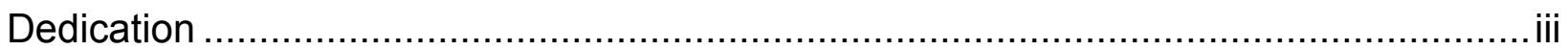

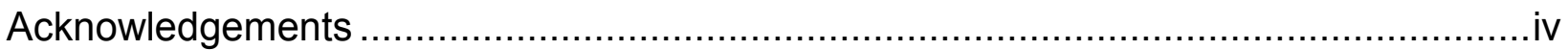

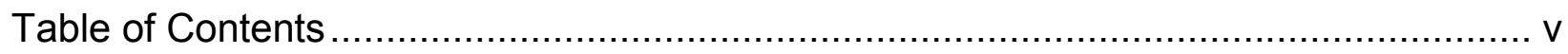

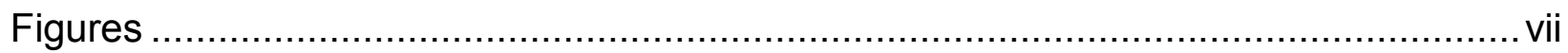

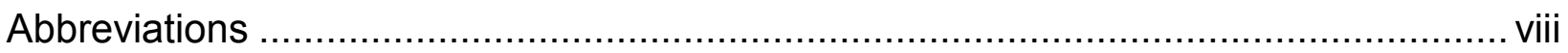

Chapter 1: Background and Objectives ............................................................... 1

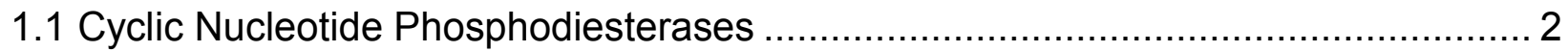

1.2 Clinical Relevance of Phosphodiesterase Inhibitors for CNS Dysfunction ............... 6

1.3 Biology and Current Treatments for Mood and Cognitive DisordersPDE2: Promising

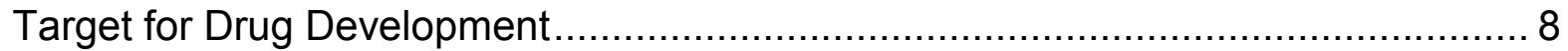

1.3.1 Biology of Anxiety and Depression ............................................................. 9

1.3.2 Current Limitations of Pharmacological Treatments for Anxiety and

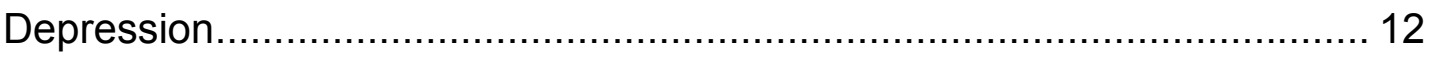

1.3.3 Biology of Learning and Memory \& Cognitive Dysfunction ........................ 14

1.3.4 Current Limitations of Pharmacological Treatments for Cognitive

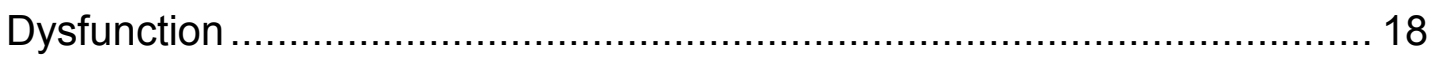

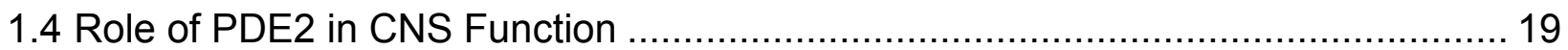

1.4.1 PDE2 in Anxiety and Depression ............................................................ 21

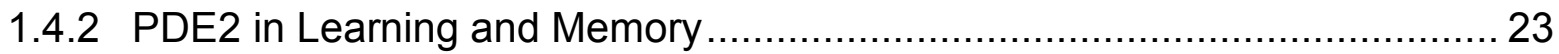

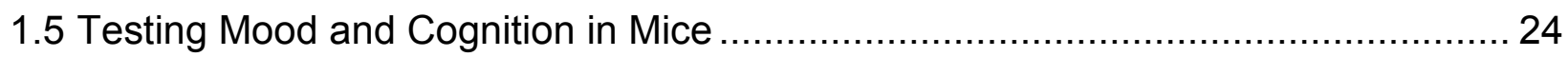

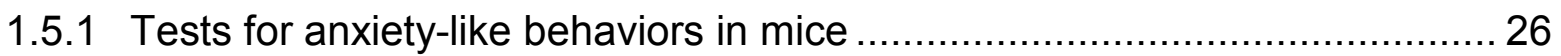

1.5.2 Tests for depression-like behaviors in mice ........................................ 27

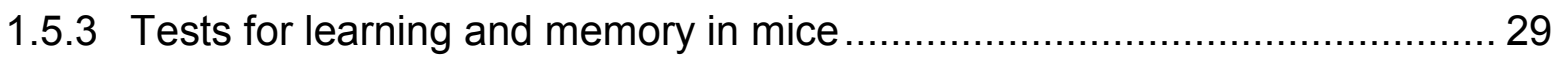


Chapter 2: Exploring the potential role of Cyclic Nucleotide Phosphodiesterase-2 in depression- and anxiety-like behaviors in mice ................................................. 35

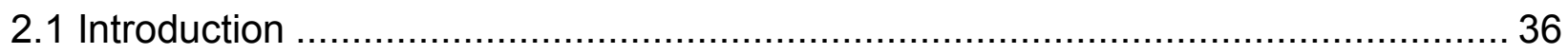

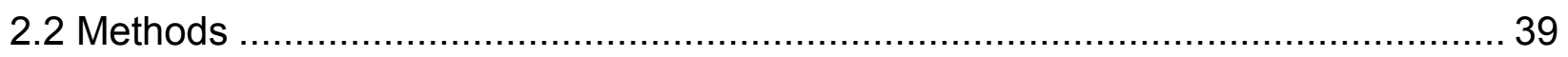

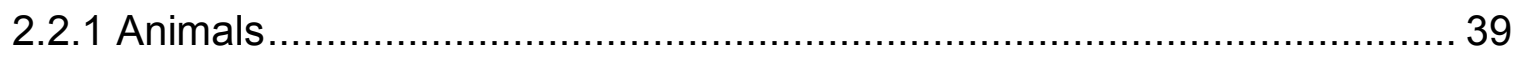

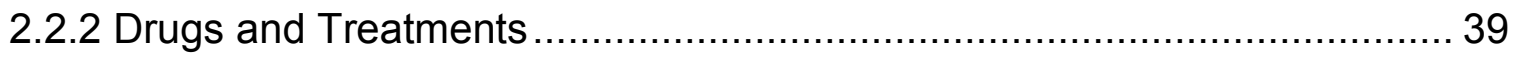

2.2.3 Cannula Surgery and ICV Drug Treatment......................................... 40

2.2.4 Forced Swim Test....................................................................... 41

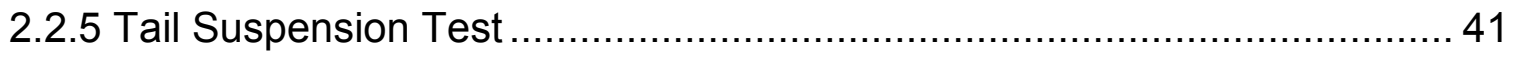

2.2.6 Elevated Plus Maze ...................................................................... 41

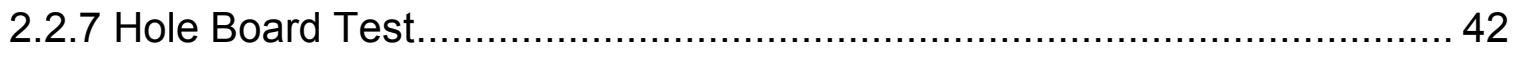

2.2.8 Step-through Passive Avoidance........................................................ 42

2.2.9 Object Recognition Test ............................................................ 43

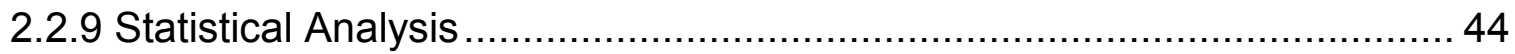

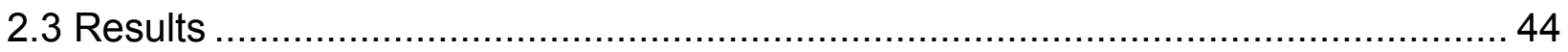

2.3.1 Chronic Bay 60-7550 did not decrease depression-like behavior in the forced swim test or tail suspension test ..................................................... 44

2.3.2 Chronic Bay 60-7550 did not decrease anxiety-like behavior in the elevated plus maze or hole board test .................................................................. 45

2.3.3 Neither central nor peripheral administration of Bay 60-7550 decreased depression-like behavior in the tail suspension test...................................... 46

2.3.4 Neither central nor peripheral administration of Bay 60-7550 decreased anxiety-like behavior in the elevated plus maze ........................................... 46

2.3.5 Neither central nor peripheral administration of Bay 60-7550 enhanced memory in the step-through passive avoidance test...................................... 47

2.3.6 Both central and peripheral administration of Bay 60-7550 enhanced memory in the object recognition test ........................................................ 48 


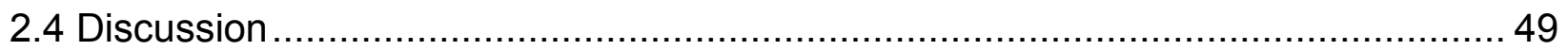

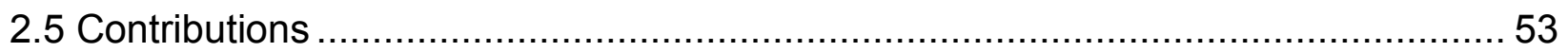

Chapter 3: Cyclic GMP-Mediated Memory Enhancement in the Object Recognition Test by Inhibitors of Phosphodiesterase-2 in Mice..............................................54

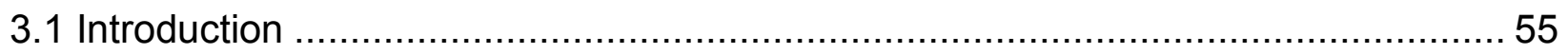

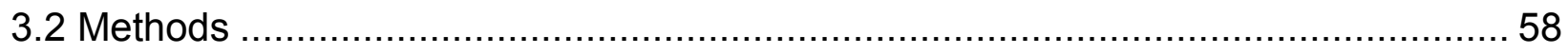

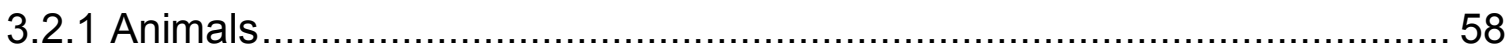

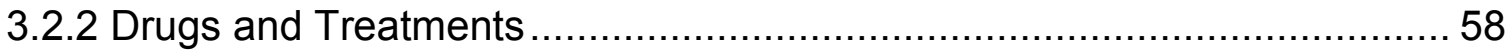

3.2.3 Cannula Surgery and ICV Drug Treatment......................................... 59

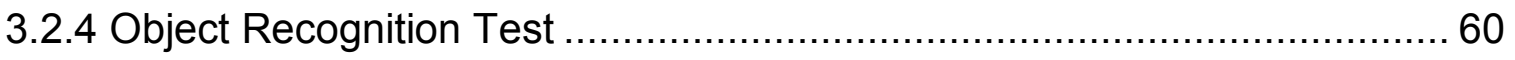

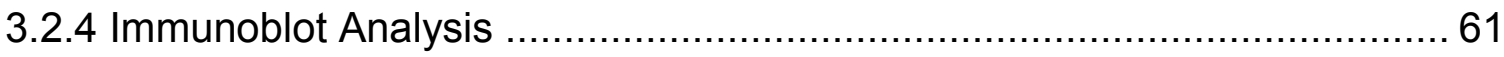

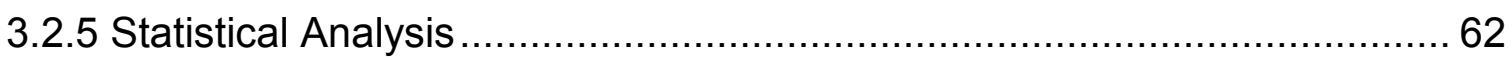

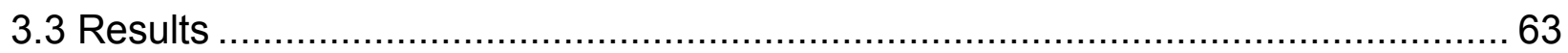

3.3.1 Dose-dependent memory enhancement using PDE2 inhibitors ............... 63

3.3.2 PDE2 inhibition during acquisition, early consolidation, or recall significantly

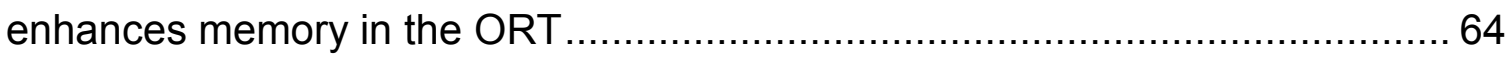

3.3.3 Enhancement of memory in the ORT following PDE2 inhibition during early consolidation is mediated via NOS/cGMP/PKG pathway ................................ 65

3.3.4 Bay 60-7550 enhanced CREB and VASP phosphorylation ..................... 67

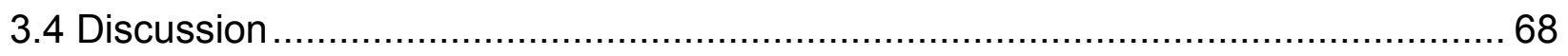

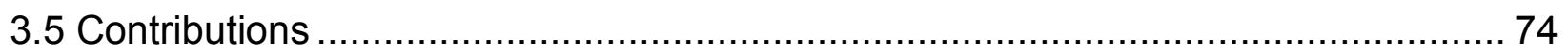

Chapter 4: Conclusions and Future Studies......................................................... 75

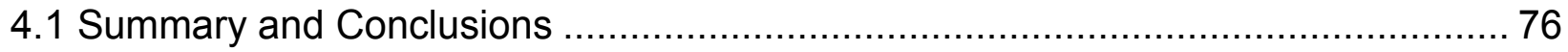

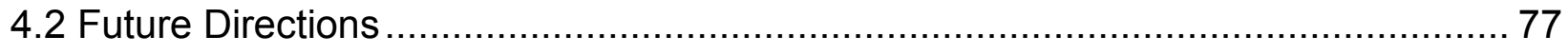

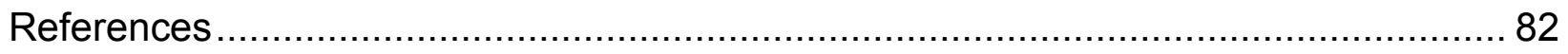




\section{LIST OF FIGURES AND TABLES}

$\begin{array}{lll}\text { Figure } 1.1 & \text { The PDE family } & 6\end{array}$

$\begin{array}{lll}\text { Table 1.1 FDA approved PDE inhibitors for clinical application } & 10\end{array}$

Figure 1.2 The human brain and the mouse brain 20

Table 1.2 Expression of PDE2 in peripheral and CNS tissue 26

Figure 1.3 Tests for anxiety-like behaviors in mice 28

Figure 1.4. Tests for depression-like behaviors in mice 29

Figure 1.5 Testing Parameters for the Object Recognition Test (ORT)

Figure 2.1 Repeated treatment with Bay 60-7550 does not induce antidepressant-like behavior in the forced swim test (FST) or tail 44 suspension test (TST).

Figure 2.2 Repeated treatment with Bay 60-7550 does not decrease anxiety-like behavior in the hhole board (HB) or elevated plus maze (EPM).

Figure 2.3 Neither peripheral nor central administration of Bay $60-7550$ induces antidepressant-like behavior in the tail suspension test $\quad 46$ (TST).

Figure 2.4 Neither peripheral nor central administration of Bay 60-7550 alters anxiety-like behavior in the elevated plus maze (EPM)

Figure 2.5 Neither peripheral nor central administration of Bay 60-7550 increased the latency to enter the dark side in the STPA

Figure 2.6 Both peripheral and central administration of Bay 60-7550 enhanced memory in the ORT. 
Figure 3.1 PDE2 inhibitors enhanced memory in the ORT.

Figure 3.2. PDE2 inhibition during acquisition, early consolidation, or recall significantly enhanced memory in the ORT.

Figure 3.3. Inhibitors of the NOS/sGC/cGMP/PKG pathway blocked the memory-enhancing effects of PDE2 inhibition in the ORT

Figure 3.4. Bay 60-7550 significantly enhanced phosphorylation of CREB at Ser-133.

Figure 3.5. Bay 60-7550 significantly enhanced phosphorylation of VASP at Ser-239. 


\section{LIST OF ABBREVIATIONS}

$\begin{array}{ll}\text { 5HT } & \text { Serotonin } \\ \text { AD } & \text { Alzheimer's disease } \\ \text { BNST } & \text { Bed nucleus of the stria terminalis } \\ \text { cAMP } & \text { cyclic 3'5' adenosine monophosphate } \\ \text { cGMP } & \text { cyclic 3'5' guanosine monophosphate } \\ \text { CREB } & \text { Cre response element binding protein } \\ \text { ED/ID } & \text { Extradimensional//ntradimensional test } \\ \text { EPM } & \text { Elevated plus maze } \\ \text { FST } & \text { Forced swim test } \\ \text { HB } & \text { Hole Board } \\ \text { ICV } & \text { Intracerebrolventricular } \\ \text { IP } & \text { Intraperitoneal } \\ \text { LTM } & \text { Long term memory } \\ \text { MAOI } & \text { Monoamine oxidase inhibitor } \\ \text { MCI } & \text { Mild cognitive impairment } \\ \text { mPFC } & \text { Medial prefrontal cortex } \\ \text { MWM } & \text { Morris Water Maze } \\ \text { NAC } & \text { Nucleus accumbens } \\ \text { NE } & \text { Norepinephrine } \\ \text { NO } & \text { Nitric oxide } \\ \text { NOS } & \text { Nitric oxide synthase } \\ \text { OLT } & \text { Object location test } \\ \text { ORT } & \text { Object recognition test } \\ \text { pCREB } & \text { Phosphorylated CREB } \\ \text { PD } & \text { Parkinson's disease } \\ \text { PDE } & \text { Phosphodiesterase } \\ \text { PHR } & \text { Perirhinal region } \\ \text { PKA } & \text { Protein kinase A } \\ \text { PKG } & \text { Protein Kinase G } \\ \text { pVASP } & \text { Phosphorylated VASP } \\ \text { SNRI } & \text { Serotonin and norepinephrine reuptake inhibitor } \\ \text { SGC } & \text { Soluble guanylyl cyclase } \\ \text { SSRI } & \text { Selective serotonin reuptake inhibitor } \\ \text { STM } & \text { Short term memory } \\ \text { STPA } & \text { Step-through passive avoidance } \\ \text { TCA } & \text { Tri/Tetra-cyclic antidepressant } \\ \text { TST } & \text { VASP }\end{array}$




\section{Chapter 1}

\section{Background and Objectives}




\subsection{Cyclic Nucleotide Phosphodiesterases}

Over 6 decades ago, Earl Sutherland uncovered what we now understand to be one of the most important second messenger signaling systems in a cell, with the characterization of the synthesis of 3',5'-cyclic adenosine monophosphate (cAMP) via adenylyl cyclases and degradation via cyclic nucleotide phosphodiesterases (PDEs; Beavo and Brunton, 2002; Sutherland and Rall, 1958). Subsequently, a parallel "sister" system involving cyclic guanosine 3'5'- monophosphate (cGMP) was described (Ashman et al., 1963; Beavo and Brunton, 2002; Beavo et al., 1970). However, it wasn't until the 1970s that the idea of targeting this "cyclic nucleotide system" for drug development was put forth (Amer, 1977; Ignarro et al., 1987; Keravis and Lugnier, 2012). Since then, researchers have discovered that this seemingly simple signaling pathway is incredibly diverse and complicated.

The original discovery and characterization of CAMP was carried out in liver homogenates for the study of glycogen metabolism (Rall et al., 1956; Sutherland and Rall, 1958). Though Sutherland and colleagues discovered this second messenger system in a fairly narrow context, an incredible amount of research has since shown cAMP, and subsequently cGMP, to be expressed ubiquitously throughout the body, in every cell type, and involved in numerous signaling cascades. Additionally, as researchers have continued to parse the diversity of the cyclic nucleotide signaling cascades, they have also characterized another very important super-family of enzymes, which have proven to be invaluable regulators of cAMP and cGMP: the cyclic nucleotide phosphodiesterases (PDEs). 


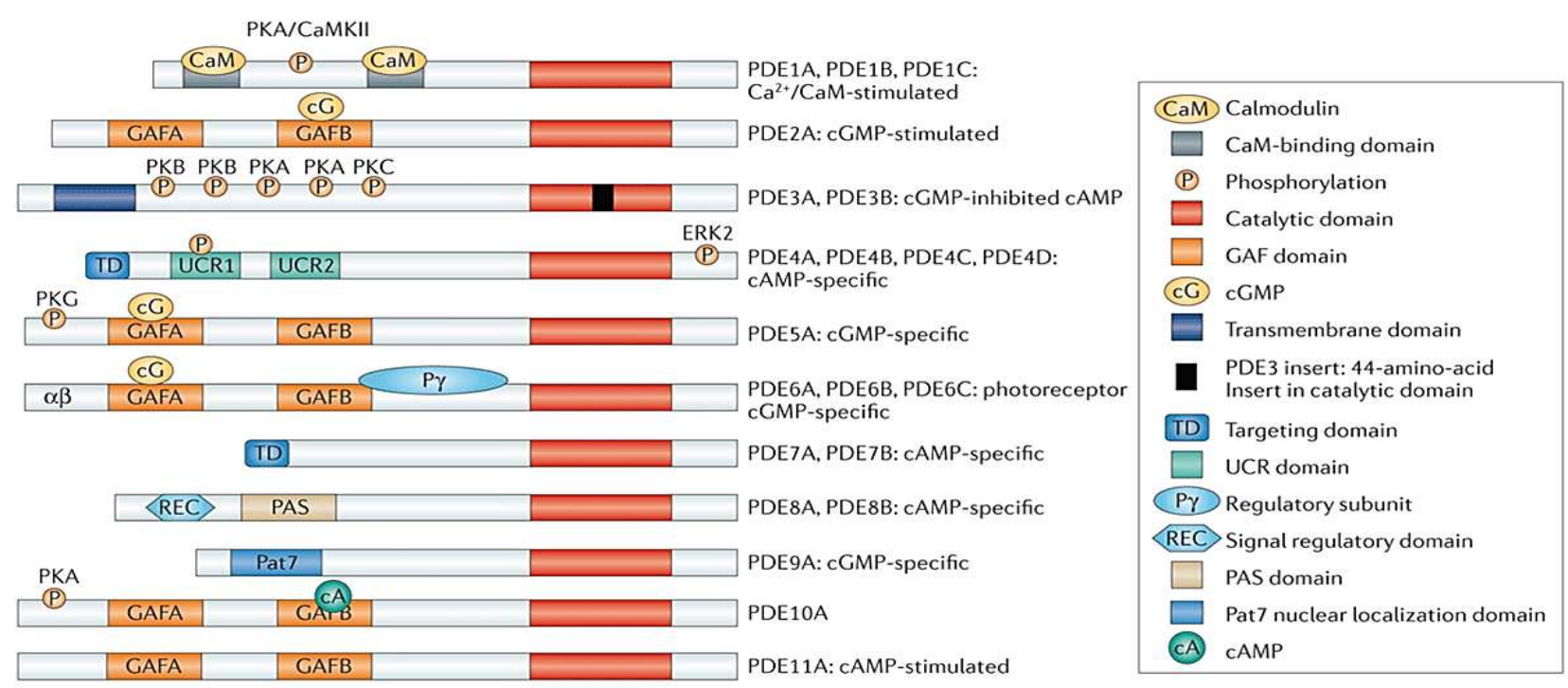

Figure 1.1 The PDE family. The conserved catalytic domain (shown in red) is located in the carboxyterminal portion of the phosphodiesterases (PDEs). The catalytic domain of PDE3 contains a unique 44amino-acid insert (shown in black). Many of the PDE families1, 2, 3 contain amino-terminal subdomains (such as GAF domains, transmembrane domains, targeting domains, upstream conserved regions (UCRs), PAS domains and REC domains) and $\mathrm{N}$-terminal hydrophobic regions that are important in subcellular localization, in the incorporation of PDEs into compartmentalized signalosomes, in interactions with signaling molecules and molecular scaffolds, and in the regulation of PDE activity. GAF domains regulate the allosteric binding of CGMP (to PDE2, PDE5, PDE6 and PDE11), the allosteric binding of CAMP (to PDE10) and the regulation of catalytic activity (in PDE2, PDE5 and PDE6). Phosphorylation sites are labelled on the figure. CaMKII, calcium/calmodulin-dependent protein kinase II; ERK2, extracellular signal-regulated kinase 2; PKA, protein kinase A; Pat7, 7-residue nuclear localization signal.

(Reprinted by permission from Macmillan Publishers Ltd: Nature Reviews Drug Discovery Maurice et al., 2014 copyright 2014)

While cAMP and cGMP signaling can be controlled through regulation of their synthesis via adenylyl and guanylyl cyclases, once activated, inherent control over the spatial and temporal signal becomes very important. The PDE family, which serves as the off switch for these cyclic nucleotides, is encoded by 21 genes in humans and has over 100 splice variants that offer an incredible amount of diversity in terms of overall expression patterns, on/off mechanisms, post-translational modifications and subcellular targeting. As shown in Fig 1.1, the catalytic domains of all PDEs are relatively similar, but the N-terminal of each of the 11 PDE family members varies widely, with even further diversification amongst the splice variants. The PDEs are broadly grouped based on 
their ability to catalyze the hydrolysis of cAMP and/or cGMP. While PDEs $1,2,3,10$, and 11 are able to hydrolyze and inactivate both cAMP and cGMP, PDEs 4, 7, 8 only hydrolyze cAMP, and PDEs 5, 6, 9 only hydrolyze cGMP. All of these factors contribute to the tight control of both CAMP and CGMP signaling.

PDE expression patterns within the CNS are an important consideration when looking for potential targets for drug development. The relatively restricted expression of certain splice variants provides an opportunity for selective targeting of certain tissues or brain regions, thereby minimizing off-target effects seen with a more global approach. PDE expression in the CNS varies by splice variant, but general expression patterns are as follows: PDE1A is primarily in the hippocampus and cortex; PDE1B is primarily in the hippocampus and striatum; and PDE1C is exclusively expressed in the olfactory neuroepithelium (Lakics et al., 2010; Menniti et al., 2006); PDE2A is found primarily in cortex, hippocampus, amygdala, striatum, and medial habenula (Lakics et al., 2010; Stephenson et al., 2009; Van Staveren et al., 2003); PDE3 is expressed throughout the brain at very low levels; PDE4A is in the hippocampus, cortex olfactory bulb, striatum, thalamus, hypothalamus, amygdala, midbrain, and cerebellum, PDE4B \& D are in the cortex, striatum, hypothalamus, midbrain, and cerebellum (Keravis and Lugnier, 2012; Lakics et al., 2010); PDE5A is expressed in the hippocampus, cortex, and cerebellum (Francis et al., 2011a; Keravis and Lugnier, 2012; Lakics et al., 2010); PDE6 is selectively expressed in the pineal gland and the rod and cone cells of the retina; PDE7A is expressed in the hippocampus, cortex, olfactory bulb, and striatum, while PDE7B is expressed in hippocampus, cortex, striatum and midbrain; PDE8B is expressed in hippocampus, cortex, olfactory bulb, striatum, and midbrain; PDE9A is in the 
hippocampus, cortex, olfactory bulb, striatum, thalamus, hypothalamus, amygdala, midbrain, and cerebellum; and PDE10 is in the hippocampus, cortex, striatum, midbrain, and cerebellum; PDE11 has not been detected in brain (Keravis and Lugnier, 2012; Lakics et al., 2010; Menniti et al., 2006).

Overall, there is a considerable amount of overlap in the expression patterns of individual PDE splice variants, not only within each brain region, but also on a subcellular level. While this may appear as redundancy within the systems, research has shown that each PDE splice variant provides distinct and important control over a select pool of cyclic nucleotides and can be dynamically regulated under different conditions (Francis et al., 2011b; Maurice et al., 2014). A broad example of this from Suvarna and O'Donnell shows that although PDE2 is able to hydrolyze both cAMP and cGMP, in primary rat cerebral cortex and hippocampus cultures, PDE4 is primarily involved in cAMP catalysis, while PDE2 is primarily involved in cGMP catalysis (Suvarna and O'Donnell, 2002). A more specific example of the dynamic regulation of PDE expression and function is seen with changes in the subcellular expression of PDE1. In an injury model of vascular smooth muscle cells, during the uninjured, quiescent phase, PDE1 is primarily found in the cytosol, while during the injured, proliferation phase, PDE1 is primarily found the nucleus (Nagel et al., 2006). These are only two examples the dynamic range of PDEs, and the importance of developing a thorough understanding of the most basic role of each PDE splice variant in physiological and behavioral processes, in hopes of the development of novel pharmaceuticals that are faster acting with fewer side effects. 


\subsection{Clinical Relevance of Phosphodiesterase Inhibitors for}

\section{CNS Dysfunction}

The development of more selective PDE inhibitors, as well as more targeted genetic tools, has provided a greater understanding of the role of individual PDE splice variants in specific biological processes and has renewed interest in PDEs as potential novel therapeutic drug targets. Currently, the only PDE inhibitors with FDA approval for clinical use target PDE3, PDE4 and PDE5 (Table 1.1). The PDE5 inhibitor sildenafil (Viagra; Pfizer) was originally investigated in clinical trials for the potential treatment of angina and coronary artery disease. While there were no robust effects for either

\begin{tabular}{|c|c|c|c|}
\hline $\begin{array}{c}\text { Generic name } \\
\text { (Brand name; original company) }\end{array}$ & $\begin{array}{l}\text { PDE } \\
\text { Targeted }\end{array}$ & FDA Approved Indication & $\begin{array}{l}\text { Original } \\
\text { Year of } \\
\text { Approval }\end{array}$ \\
\hline $\begin{array}{l}\text { Cilostazol } \\
\text { (Pletal; Otsuka Pharmaceutical) }\end{array}$ & PDE3 & Intermittent claudication & 1999 \\
\hline $\begin{array}{l}\text { Milrinone } \\
\text { (Primacor; Astellas } \\
\text { Pharma/Sanofi) }\end{array}$ & PDE3 & Refractory heart failure & 1987 \\
\hline $\begin{array}{l}\text { Apremilast } \\
\text { (Otezla; Celgene) }\end{array}$ & PDE4 & Psoriatic arthritis & 2014 \\
\hline $\begin{array}{l}\text { Roflumilast } \\
\text { (Daliresp; Forest } \\
\text { Pharmaceutical) }\end{array}$ & PDE4 & $\begin{array}{l}\text { Chronic obstructive pulmonary } \\
\text { disease with chronic bronchitis }\end{array}$ & 2011 \\
\hline $\begin{array}{l}\text { Avanafil } \\
\text { (Stendra; Vivus) }\end{array}$ & PDE5 & Erectile dysfunction & 2012 \\
\hline $\begin{array}{l}\text { Sildenafil } \\
\text { (Viagra; Pfizer) }\end{array}$ & PDE5 & Erectile dysfunction & 1998 \\
\hline $\begin{array}{l}\text { Sildenafil } \\
\text { (Revatio; Pfizer) }\end{array}$ & PDE5 & $\begin{array}{l}\text { Pulmonary arterial } \\
\text { hypertention }\end{array}$ & 2005 \\
\hline $\begin{array}{l}\text { Tadalafil } \\
\text { (Cialis; Lilly) }\end{array}$ & PDE5 & Erectile dysfunction & 2003 \\
\hline $\begin{array}{l}\text { Tadalafil } \\
\text { (Adcirca; Lilly) }\end{array}$ & PDE5 & $\begin{array}{l}\text { Pulmonary arterial } \\
\text { hypertension }\end{array}$ & 2009 \\
\hline $\begin{array}{l}\text { Vardenafil } \\
\text { (Levitra; Bayer) }\end{array}$ & PDE5 & Erectile dysfunction & 2003 \\
\hline
\end{tabular}

Table 1.1 FDA approved PDE inhibitors for clinical application 
disease, reports of efficacy for erectile dysfunction launched sildenafil, and subsequent PDE5 inhibitors, into popular use. Subsequently, because of the fairly high expression of PDE5 in vascular smooth muscle, PDE5 inhibitors have shown efficacy in the treatment of pulmonary arterial hypertension (Maurice et al., 2014). Early generation PDE4 Inhibitors, including rolipram, showed great promise in the treatment of plaque psoriasis and inflammatory diseases, as well as depression; however, clinical application was halted due to unpleasant side effects including nausea and vomiting (Maurice et al., 2014). The new generation of PDE4 inhibitors has been designed to mitigate these side effects, and both apremilast and roflumilast are now FDA approved for both psoriatic arthritis and COPD with chronic bronchitis (Table 1.1).

Despite the relatively limited number of PDE inhibitors with FDA approval, there are over 20 novel PDE inhibitor compounds, either discovered or newly synthesized, in various stages of clinical trials, targeting numerous disease (for a full list as of 2014, see Maurice et al., 2014). For example, resveratrol, a polyphenol found in red wine, is a panPDE inhibitor that has shown promising results in animal models for the treatment of glucose intolerance and Alzheimer's disease and is now in Phase II clinical trials for both. While resveratrol does have numerous putative targets, the main therapeutic actions are thought to be mediated via PDE4 (Maurice et al., 2014; Park et al., 2012). Many of the previously approved PDE3, 4 and 5 inhibitors are also undergoing clinical trials for potential efficacy in other diseases, including PDE3 inhibitor cilostazol for fertility, dementia, and ischemic stroke, PDE4 inhibitor apremilast for acne, and PDE5 inhibitors sildenafil and tadalafil for diabetes and other endocrine functions, muscular dystrophy, schizophrenia, and heart failure (Maurice et al., 2014). 
Though these compounds have been used with varying degrees of success, all of the currently FDA approved PDE inhibitors are non-selective in regards to subtypes within their enzyme family and have some off-target effects for other family members, which often results in a narrow therapeutic range, as well as severe side effects and toxicities. Many PDE inhibitors have failed clinical trials for these reasons. Rolipram was a very promising PDE4 inhibitor developed in the 90s, with robust antidepressant-like effects in preclinical studies (Maurice et al., 2014). However, despite its efficacy in some clinical trials, it has not advanced to approval due to dose-limiting side effects of nausea and emesis. These effects have been suggested to be mediated by the PDE4D subtype, which is highly expressed in the area postrema, an emetic trigger site (Maurice et al., 2014). Because of this, researchers have been working to develop drugs with an alternate mechanism of action or isoform selective inhibitors to increase the safety profile and efficacy. PDE4 inhibitors, specifically, have been redesigned to act as allosteric modulators at specific splice variants, and have resulted in significantly fewer gastrointestinal side effects, allowing for higher doses and a safer therapeutic range (Burgin et al., 2010).

\subsection{Biology and Current Treatments for Mood and Cognitive}

\section{Disorders}

It is because of the high level of expression of certain PDEs, such as PDE2 and 4, in limbic and cortical regions of the brain that PDE inhibitors have generated much interest for the treatment of neuropsychiatric disorders such as depression, anxiety, as well as disorders affecting learning and memory (Beavo and Brunton, 2002; Bolger et al., 1994; Francis et al., 2011b; Menniti et al., 2006; Xu et al., 2011). Anxiety and depression 
are two of the most prominent mood disorders reported in the United States and worldwide each year (Kessler et al., 2005; Norquist, 1998; Services, 2009) and the incidences of cognitive impairment, ranging from mild cognitive decline, to late stage dementia and Alzheimer's disease, are reaching all-time highs with an aging baby boomer population (Hebert et al., 2003). Current treatment options are limited, often falling short of full clinical relief and/or resulting in unpleasant or intolerable side effects. This raises a great need for a deeper, more complete understanding of the etiology and biology of mood and cognitive disorders, for identification of novel drug targets for safer, more efficacious treatment options.

\subsubsection{Biology of Anxiety and Depression}

According to the DSM-V, generalized anxiety disorder is classified by excessive anxiety and worries occurring most days over a 6 month period, and is difficult for an individual to control (American Psychiatric Association, 2013). Additional symptoms may include: restlessness or feeling on edge, fatigue, irritability, difficulty concentrating, muscle tension, or sleep disturbances. Depression is classified by an impaired mood or loss of interest in daily activities for at least 2 weeks, with impaired social, occupational or educational function. Additional symptoms may include: feeling irritable, significant weight gain/loss, insomnia/hypersomnia, psychomotor agitation or retardation, loss of energy, feelings of worthlessness, difficulty concentrating, or suicidal ideation (American Psychiatric Association, 2013). Symptoms experienced among patients may vary widely, making diagnosis and treatment difficult and often requiring multiple approaches before a full therapeutic effect is possible. Part of the lack of successful treatment options stems from the limited understanding of not only the etiology of anxiety and depression, but 
also, a very limited understanding for how current treatment options result in a therapeutic effect.

Currently, researchers have identified a few key brain regions involved in anxiety and anxiety-like behaviors. Imaging researchers have identified a "fear circuitry" within the human limbic system of the brain, which includes the amygdala, hippocampus, anterior cingulate cortex, and insula, which are hyperactive during anxiety provoking situations (Engel et al., 2009; Holzschneider and Mulert, 2011; Kheirbek et al., 2013; Tye et al., 2011). Many of these brain regions, including the hippocampus and amygdala, are conserved in the mouse brain and have also been implicated in anxiogenic-like behaviors in mice (see Fig 1.2). More specifically, the ventral hippocampus has been implicated in anxiety

behaviors in mice, and its function is correlated with activity in the medial prefrontal cortex (mPFC;

Adhikari et al., 2010;

Deacon and Rawlins, 2005;

Engin and Treit, 2007). The

amygdala, which has

classically been considered

the epicenter of fear and

anxiety, has numerous

inputs and targets, some
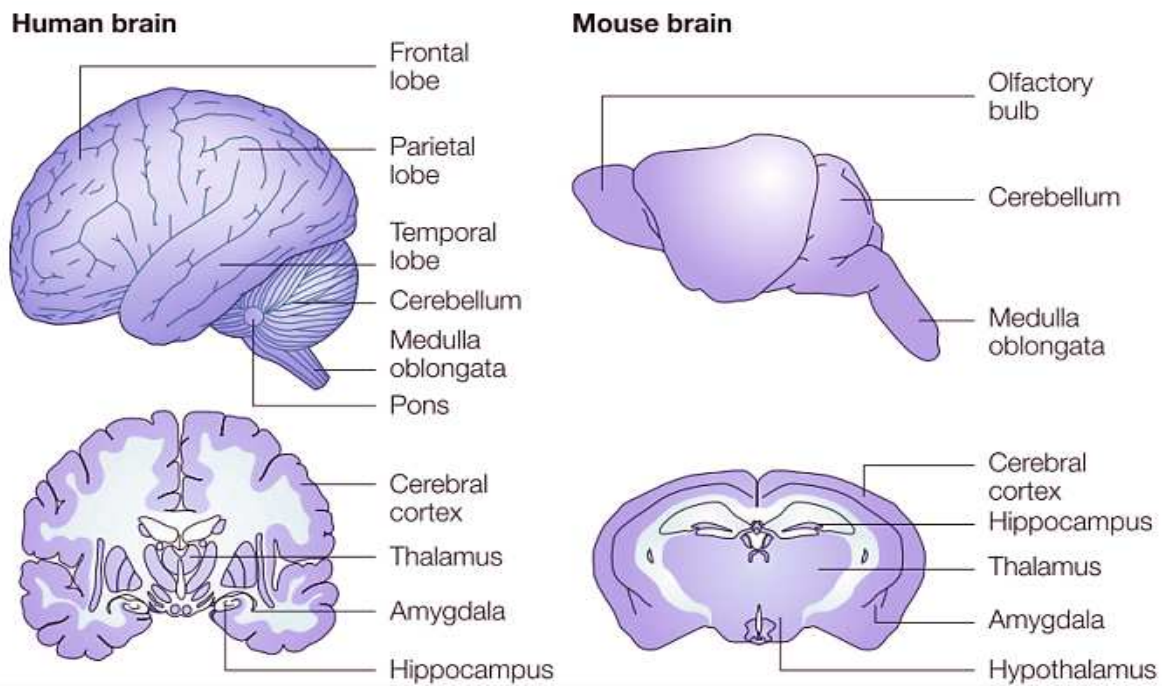

Figure 1.2 The human brain and the mouse brain. As well as having a mass of about 2,700 times greater than that of the mouse brain (right), it is the convoluted folds of an extensive cerebral cortex that distinguish the human brain (left) from the brains of lower species, such as the mouse. The potential functional significance of these species differences to emotional regulation and the implications for modelling emotional states in mice is yet to be fully under - stood. However, it is clear that many brain structures involved in limbic regulation of emotion, such as the hippocampus and amygdala, are evolutionarily conserved from mouse to man.

(Reprinted by permission from Macmillan Publishers Ltd: Nature Reviews Drug Discovery, Cryan and Holmes, 2005 copyright 2005) 
reciprocating, including glutamatergic output to the bed nucleus of the stria terminalis (BNST), nucleus accumbens (NAc), hippocampus and cortex, with concurrent GABAergic output from the central-medial nucleus of the amygdala to many of the same brain regions (Engin and Treit, 2007; Etkin, 2012; Holzschneider and Mulert, 2011; Petrovich et al., 2001; Tye et al., 2011). These complicated signaling connections only suggest a role in the etiology and regulation of anxiety-like behavior. Further research is required to truly understand the functional role of these brain regions in both the onset and treatment of anxiety disorders.

These same brain regions have also been implicated in depressive behaviors in both humans and rodents. Though, because patients suffering from depression present with a wide variety of different and often contradictory symptoms, the underlying biological and physiological processes of depression are likely complex and heterogeneous. Postmortem studies have attempted to identify pathological anomalies, and have shown decreased neuronal size, a decreased glial population, and shorter dendrites in cortical and hippocampal regions (Hercher et al., 2009; Karege et al., 2005; Krishnan and Nestler, 2010). Imaging techniques have shown decreased volume in these same brain regions, as well as hypermetabolism in the subgenual cingulate cortex and amygdala, as well as hypometabolism in the dorsal prefrontal cortex and striatal regions (Krishnan and Nestler, 2010; Videbech and Ravnkilde, 2004). However, correlating any of these biological changes with behavior changes has been difficult, and despite the wealth of available research, definite conclusions regarding the etiology of behavior or biological subtypes of depression have yet to be made. 


\subsubsection{Current Limitations of Pharmacological Treatments for Anxiety and Depression}

Part of the interest in developing novel therapeutics for the treatment of a variety of CNS diseases stems from the unfortunate reality that currently available pharmaceuticals have limited efficacy, side-effects, and in some cases, abuse liability. Currently, the first-line treatment for anxiety and depression are antidepressants. Selective serotonin reuptake inhibitors (SSRIs) are one of the most commonly used, second-generation antidepressants that work by blocking the reuptake of serotonin $(5 \mathrm{HT})$ in the synaptic cleft. While all classes of antidepressants have shown some efficacy in treating depression and anxiety disorders, SSRIs have shown reliable efficacy and tolerability (Linden et al., 2012). Venlafaxine and other serotonin and norepinephrine reuptake inhibitors (SNRIs) are also frequently used for the treatment of depression and anxiety. As with the SSRIs, SNRIs are well tolerated and are safe to use in higher risk populations, such as children or the elderly (Koen and Stein, 2011; Ravindran and Stein, 2010; Shelton, 2004). Antidepressants, however, take weeks to months of repeated use before the onset of a therapeutic effect, and they also carry undesired side effects such as weight gain, somnolence, and agitation, which can be counter indicative for treating anxiety and depression (Reinhold et al., 2011).

Benzodiazepines are another option for the treatment of anxiety disorders. While these were once considered a first-line treatment, their safety profile is somewhat more limited, and the side effects, including drowsiness and decreased alertness, can be impairing (Ravindran and Stein, 2010; Reinhold et al., 2011). Additionally, their maximal efficacy is only seen with short duration treatments of less than 4 weeks, as patients can 
develop tolerance and dependence with prolonged use. Antidepressants do not lead to tolerance, and can be safely discontinued with proper tapering.

For anxiety, and certain cases of depression, less widely used treatments include atypical antidepressants, bupropion (norepinephrine and dopamine reuptake inhibitor), nonbenzodiazepine anticonvulsants, atypical antipsychotics, and busiprone (5-HT1A receptor partial agonist) (Gorman, 2003; Linden et al., 2012; Ravindran and Stein, 2010; Reinhold et al., 2011; Rudolph and Knoflach, 2011). These classes of drugs are generally not considered until the first line of treatment has shown to be ineffective or not well tolerated. Many of these classes have the same disadvantages as the first lines of treatment, including limited or delayed efficacy, side effects, and poor tolerability in certain vulnerable populations (Hettema, 2008; Koen and Stein, 2011; Lenze and Wetherell, 2011; Ravindran and Stein, 2010; Reinhold et al., 2011).

Older generations of antidepressants may also be used for first-line treatmentresistant cases of anxiety and/or depression. Tri- and tetra-cyclic antidepressants (TCAs) were the first-generation of reuptake inhibitors, originally synthesized in the late1950s (Kuhn, 1958; Ravindran and Stein, 2010). While TCAs do show efficacy for both anxiety disorders and depression, their clinical use is discouraged due to significant anticholinergic and antiadrenergic side effects, including dry mouth, constipation, palpitations, orthostatic hypotension, and risk of toxicity in overdose (Schatzberg et al., 2007). The very first antidepressant was the monoamine oxidase inhibitor (MAOI) iproniazid, which was originally used to treat tuberculosis (Lopez-Munoz and Alamo, 2009). While it was found to have limited efficacy for its intended purpose, patients reported elevated mood, and it was subsequently found to increase norepinephrine (NE) 
and $5 \mathrm{HT}$ levels in the brain (Schildkraut, 1965). This led to the synthesis of additional MAOIs. However, they are now considered a third-line treatment option for both depression and anxiety due to undesirable side effects and the potential for a hypertensive crisis due to interaction with certain foods and drugs (Schatzberg et al., 2007). While they lack the anticholinergic effects seen with TCAs, they do cause orthostatic hypotension, insomnia at night, and sedation during the day (Schatzberg et al., 2007).

\subsubsection{Biology of Learning and Memory \& Cognitive Dysfunction}

Cognitive dysfunction is a hallmark of numerous psychiatric illnesses, with the most common being mild cognitive impairment $(\mathrm{MCl})$, with or without turnover to Alzheimer's Disease (AD), and Parkinson's Disease (PD). $\mathrm{MCl}$ is defined as cognitive capacity below what is expected from a normal person that age and affects approximately $10-25 \%$ of individuals over the age of 70 (Kumar et al., 2015; RóżykMyrta, 2015). There is a turnover rate of approximately $10 \%$ per year from $\mathrm{MCl}$ to full dementia, including AD (Różyk-Myrta, 2015). Alzheimer's disease currently affects over 4.5 million Americans and had a global economic impact of $\$ 605$ billion in 2010 alone (Kumar et al., 2015; Różyk-Myrta, 2015). By the year 2050 it is estimated that 1 in 85 people globally will suffer from AD (Dzirasa et al., 2010). Concurrently, while motor dysfunction is the classical symptom of PD, dementia is often overlooked, despite affecting approximately three-fourths of patients with PD (Aarsland et al., 2003; Hely et al., 2008). The statistics for any one of these forms of cognitive impairment alone are cause for concern. Taken together, the need for a greater understanding of cognitive 
processing (and therefore cognitive impairment) and potential treatments is more than critical.

Interestingly, cognitive processing is done by many of the same brain regions discussed above (see section 1.3.1). One of the main brain regions repeatedly implicated in the formation of new memories is the hippocampus and surrounding structures, or the para-hippocampal region (PHR), which includes the subiculum and rhinal cortical areas (Strien et al., 2009). The complex interplay among these various subregions is responsible for the bulk of learning, including acquisition and consolidation, as well as for memory retrieval.

The underlying biological processes of different forms of memory can vary greatly, but the main phases of learning and memory can be grouped into three broad categories: memory acquisition, consolidation (early and late phases), and recall (Kandel, 2012; Mayr and Montminy, 2001; Muller, 2012; Wang et al., 2006). From here, there are many ways to classify learning and memory based on task (i.e., spatial memory vs object memory), duration of memory (i.e., short term vs long term memory; STM \& LTM, respectively), as well as the manner of memory acquisition (i.e., explicit vs implicit memory) (Kandel, 2012; Muller, 2012; Wang et al., 2006; Winters et al., 2010). Because the underlying biological processes of these different forms memory can vary greatly (despite utilizing similar brain regions), the following will focus on one form of memory, object recognition memory.

Object recognition memory is considered a crucial component of one's ability to successfully survive and navigate a very complex world. Object recognition memory is a key component of human declarative memory, which is defined as the conscious 
memory for facts and events, and is one of the first, and most severely affected forms of memory by various diseases that lead to cognitive impairment, such as PD or AD (Desgranges, 1998; Gabrieli et al., 1995; Golby et al., 2005). Various object recognition tests have been used across species to develop a greater understanding of biology of recognition memory, and therefore, aspects of declarative memory, in hopes of identifying novel drug targets for the treatment of various forms of declarative memory loss (Akkerman et al., 2012; Winters et al., 2010, 2008).

Our current understanding of the neuroanatomical correlates of object recognition memory stems mainly from ablation studies. For both rodents, non-human primates, and humans, the putative brain regions responsible for object recognition memory are the rhinal cortical areas, including the perirhinal and entorhinal cortices, as well as the remaining PHR (Antunes and Biala, 2012; Balderas et al., 2013; Brown et al., 2012; Clark and Squire, 2010; Dere et al., 2007; Jobim et al., 2012; Seoane et al., 2012; Suzuki, 1996; Wan et al., 1999; Warburton and Brown, 2010; Weible et al., 2012; Winters and Bussey, 2005; Winters et al., 2010, 2008). Many lesion studies for both nonhuman primates and rodents repeatedly demonstrate the importance of the entorhinal and perirhinal cortical areas, specifically in object recognition memory tasks (Balderas et al., 2013; Brown et al., 2012; Dere et al., 2007; Wan et al., 1999; Warburton and Brown, 2010; Winters et al., 2008), while evidence for the necessity of hippocampal regions remains somewhat mixed (Brown et al., 2012; Stupien et al., 2003; Wan et al., 1999; Warburton and Brown, 2010). However, one likely source of inconsistency stems from the apparatus and testing conditions used, as these tend to vary greatly between research groups. Those that make use of more spatially-cued arenas are possibly 
shifting the cognitive task from one that is purely object-related to one that is more spatially-related, and the hippocampus is required for spatial memory tasks (Warburton and Brown, 2010).

Additionally, meta-analysis of lesion studies in monkeys shows that, while there is a positive correlation between the size of perirhinal lesion and recognition memory impairment, a negative correlation is found between the size of the hippocampal lesion and recognition memory impairment (Baxter and Murray, 2001). This means that the smaller the lesion in the hippocampus, the greater the memory impairment. While there is no definitive answer to why or how this inverse relationship exists, the authors suggest that the hippocampus has competing processes for recognition memory, and a small lesion leads to disruption of these competitive processes, leading to overall inhibition, whereas a larger lesion would fully prevent any competitive inhibition from the hippocampus (Baxter and Murray, 2001). Other analysis of similar studies failed to find this inverse relationship between hippocampal lesion size and argued that testing conditions, rather than lesion size, contributed to study performance (Zola and Squire, 2001). They suggest that perhaps there is a positive correlation size with hippocampal lesion and memory deficit up until the lesion is able to fully disable the structure, which, according to their analysis, may only be around $20 \%$ damage (Zola and Squire, 2001). This means any further damage would not increase the memory deficit. Nonetheless, no matter how large the lesion in the hippocampus, lesions to the perirhinal cortex always resulted in larger recognition memory deficits (Baxter and Murray, 2001; Warburton and Brown, 2010; Zola and Squire, 2001). 
In the context of cognitive decline, the brain regions most profoundly affected by $\mathrm{MCl}$ and dementia in $\mathrm{AD}$ and $\mathrm{PD}$ are fairly similar. The first and most severely affected brain region in $A D$ is the medial temporal lobe, which encompasses the amygdala, hippocampus, and the entire PHR (Desgranges, 1998; Golby et al., 2005; Ossenkoppele et al., 2015). While the primary locus of PD has always been considered the substantia nigra, recent studies show widespread cortical thinning in medial temporal cortical areas in patients with PD, and further thinning in patients with PD that suffer from dementia (Aarsland et al., 2003; Hely et al., 2008; Mak et al., 2015). As previously mentioned, these are the very regions of the brain necessary for learning and memory processing. Early damage to these structures profoundly affects declarative memory processing, which is what is seen across these various cognitive diseases (Aarsland et al., 2003; Goldman and Weintraub, 2015; Hampstead et al., 2015; Mak et al., 2015; Ossenkoppele et al., 2015).

\subsubsection{Current Limitations of Pharmacological Treatments for Cognitive Dysfunction}

Like our current understanding of cognitive disorders, treatment options are extremely limited. The first FDA approved drug for the treatment of AD was an acetylcholinesterase inhibitor (AChel), tacrine (Cognex), which was discontinued in 2013 due to safety concerns. Currently approved treatments for AD include three AChels, donepezil (Aricept; Esai, Tokyo, Japan), galantamine (Razadyne; Janssen Research Foundation), and rivastigmine (Excelon; Novartis), as well as one n-methyl-d-aspartate receptor (NMDAR) antagonist, memantine (Namenda; Forest Laboratories) and one combination AChel/NMDAR antagonist (donepezil and memantine; Namzaric; Forest Laboratories) (Goldman and Weintraub, 2015; Kumar et al., 2015; Rafii and Aisen, 
2015). Currently, only one drug has FDA approval for the treatment of dementia in PD, and that is the AChel rivastigmine (Goldman and Weintraub, 2015).

The primary and most obvious drawback of all of these drugs is the fact that they are mere symptom stop-gaps, and are not able to reverse or stop disease progression. Additionally, because our current understanding of many of these cognitive diseases lies only in the actual disease processes and not their etiology, the mechanism of drug action for most of these disorders, including AD and PD, addresses dementia only after substantial neuronal loss has occurred. This means that drugs such as AChels only attempt to restore what has already been lost in terms of boosting neuronal signaling, and are unable to stop or reverse the neuronal loss that has already occurred. Therefore, it is vital to gain a deeper understanding of cognitive processing on a basic level, and subsequently in a disease state, to gain a thorough understanding of the etiology of cognitive disorders and identify appropriate targets for drug development to stop and/or reverse these debilitating conditions.

\subsection{Role of PDE2 in CNS Function}

While almost all of the PDEs have been found to have some level of expression in the brain, PDE2 has exceptionally high levels in frontal cortical regions, the hippocampus, and the amygdala, brain regions responsible for mood and cognition (Table 1.2; Bolger et al., 1994; Deng et al., 2007; Gomez and Breitenbucher, 2013; Stephenson et al., 2009). Though there is much to understand regarding the role of PDE2 in behavior, researchers have demonstrated a role of PDE2 in both mood and cognition. Research has primarily utilized pharmacologic tools, as the constitutive PDE2 
knockout is embryonic lethal (Stephenson et al., 2009). While a conditional knockout is in development, no work has been published regarding a genetic knockout of PDE2.

In terms of drug development, PDE2 is of particular interest due to its high expression in cortical and limbic regions of the brain, which are responsible for the regulation of mood and cognition. This interest is 2 -fold. Firstly, as selective inhibitors for PDE2 have only been developed in the last decade, the current understanding of the basic biological role of PDE2 in rodent behavior is fairly limited. Secondly, PDE2 is a potential drug target for the treatment of mood and/or cognitive disorders, based on its pattern of expression in the brain. Therefore, researchers are interested in not only developing a deeper understanding of PDE2 in behavior, but also targeting PDE2 for potential drug development for a variety of diseases.
Peripheral Expression
CNS Expression
Endothelial Cells:
Hippocampus (+++)
Stomach (+)
Frontal Cortex (++)
Small/Large Intestines (+)
Vasculature (+)
Amygdala (++)
Striatum $(++)$
Heart/Lung (+)
Medial Habenula (+++)
Adrenal Cortex (+++)
(aldosterone secretion)
Little to no detectable expression in mid or hind brain

Table 1.2 Expression of PDE2 in peripheral and CNS tissue. + = low expression, $++=$ moderate expression, $+++=$ high expression

PDE2 was first identified in a rat liver by Beavo, Hardman and Sutherland in 1971 (Beavo et al., 1970). Three different splice variants of mammalian PDE2 are encoded by a single gene (PDE2A) and differ only in their N-terminal, which determines intracellular 
localization to either the membrane (PDE2A2 and PDE2A3) or the soluble fraction (PDE2A1). PDE2A2 was originally cloned from rat brain cDNA (Repaske et al., 1992; Yang et al., 1994), while PDE2A1 and 2A3 were cloned from bovine heart cDNA (Sonnenburg et al., 1991; Tanaka et al., 1991). An identical PDE2A3 variant was also cloned from human brain tissue (Rosman et al., 1997). Expression of a similar GAFcontaining PDE2, PDE2B, is found in the parasite Trypanosoma brucei, but has yet to show significant cGMP activity (Laxman et al., 2005; Rascón et al., 2002).

The first and, as of now, only commercially available PDE2-selective inhibitor was patented in 2003 by Bayer (Niewohner et al., 2003). Unfortunately, the compound, Bay 60-7550 has solubility issues and has limited ability for crossing the blood brain barrier (BBB). Nonetheless, the synthesis of Bay 60-7550 has allowed researchers to move forward in developing a better understanding of the role of PDE2 in rodent behavior. Since then, a few additional compounds have been synthesized, including ND7001 patented in the US in 2008, and very recently Lu AF64280 (Abarghaz et al., 2005; Redrobe et al., 2014). However, behavioral research has relied on only 2 compounds, Bay 60-7550 and ND7001, for our current understanding of PDE2 in mood and cognition. While the current literature shows a promising role for PDE2 as a potential therapeutic drug target, much more research is needed to fully understand PDE2 and its signaling partners in both mood and cognition.

\subsubsection{PDE2 in Anxiety and Depression}

The O'Donnell group first looked at the possible role of PDE2 in the reversal of stress-induced anxiety- and depression-like behaviors in mice. Using Bay 60-7550, they showed PDE2 inhibition could block oxidative stress induced by the chemical L- 
buthionine-(S,R)-sulfoximine (BSO) in mice (Masood et al., 2008; Niewohner et al., 2003). Firstly, they were able to show that BSO did, in fact, induce oxidative stress in neurons, and also resulted in anxiety-like behaviors in mice in the elevated plus maze (EPM) and hole board test (HB), both reliable screens for anxiety-like behavior. Pretreatment with Bay 60-7550 was able to prevent both BSO-induced cellular oxidative stress and anxiety-like behavior (Masood et al., 2008).

From here, the O'Donnell group moved on to explore the role of PDE2 inhibition in various other models of stress-induced anxiety and depression, including acute restraint stress (Masood et al., 2009) and chronic unpredictable stress (Ding et al., 2014; Xu et al., 2015, 2013). The findings consistently point to a role of PDE2 inhibitors, both Bay 607550 and a second selective inhibitor ND7001, in preventing stress-induced changes on a cellular and behavioral level. More specifically, restraint stress and/or chronic unpredictable stress leads to increases in depression- and anxiety-like behavior in the TST and FST (Ding et al., 2014) and EPM and HB (Ding et al., 2014; Masood et al., 2009), respectively, decreases in cognitive function in the MWM and ORT (Xu et al., 2015), as well as decreases in neuronal spine density and altered spine morphology (Xu et al., 2015). All of these stress-induced changes were blocked by inhibitors of PDE2. Additionally, it was consistently demonstrated that the protective effects of PDE2 inhibition were mediated via the NOS/cGMP/PKG pathway rather than the cAMP/PKA pathway (Masood et al., 2009, 2008; Xu et al., 2015, 2013). These results demonstrate that PDE2 inhibition plays a role in stress-induced anxiety and depression, and suggest that PDE2 may be a viable drug target for the treatment of stress-induced anxiety and depression. 


\subsubsection{PDE2 in Learning and Memory}

The potential for PDE2 inhibition in cognitive enhancement was first shown by Boess and colleagues in 2004. They demonstrated that Bay 60-7550 significantly enhanced long-term memory in both the ORT and social recognition tests (Boess et al., 2004). From there, researchers showed that the memory enhancing effects of PDE2 inhibition were time-dependent, and only seen when Bay 60-7550 was given either immediately after training or $3 \mathrm{hrs}$ after training, but not when given $1 \mathrm{hr}$ or $6 \mathrm{hrs}$ after training (Bollen et al., 2014; Rutten et al., 2007). Interestingly, these effects were differentially mediated by cAMP and cGMP signaling pathways. A PKG inhibitor was able block the memory-enhancing effects of PDE2 inhibition when Bay 60-7550 was given immediately after training, but not 3 hrs after training. Alternatively, a PKA inhibitor was able to block the memory-enhancing effects of PDE2 inhibition when Bay 60-7550 was given 3 hrs after training, but not immediately after training (Bollen et al., 2014). Interestingly, this suggests a time-dependent role for both cAMP and cGMP in PDE2mediated memory enhancement. This differs from previous literature involving the protective effects of PDE2 inhibition from stress-induced changes in anxiety and depression, which show cGMP/PKG primarily, and solely, mediates the effects (Masood et al., 2009, 2008; Xu et al., 2015, 2013).

Additional studies show PDE2 inhibition to be protective against various rodent models of cognitive impairment. The NMDAR antagonist MK-801 and the muscarinic acetylcholine receptor antagonist scopolamine both are shown to impair memory in the ORT. Bay 60-7550, given with either MK-801 or scopolamine 30 min prior to training, significantly prevents the drug-induced memory deficits (Reneerkens et al., 2013b). Bay 
60-7550 also prevented PCP-induced memory deficits in an extradimensionalintradimensional (ED/ID) task of cognitive flexibility in rats (Rodefer et al., 2012), and prevented cognitive impairment in the ORT following tryptophan depletion (van Donkelaar et al., 2008). In a mouse-model of AD, chronic Bay 60-7550 ameliorated deficits in the object location test, a variant of ORT that focuses on spatial memory over object recognition (Sierksma et al., 2012). One newly synthesized selective PDE2 inhibitor, Lu AF64280, was also protective against PCP-induced memory deficits in both the ORT and ED/ID cognitive task (Redrobe et al., 2014). These results suggest a role for PDE2 inhibition in cognitive enhancement in both normal and challenged systems.

\subsection{Testing Mood and Cognition in Mice}

Rodents provide a relatively easy and effective means for assessing potential clinical relevance of novel drug compounds whose safety and efficacy in a human population are unknown. While researchers cannot directly assess the "depression" or "anxiety" levels in mice, there are many behavioral tests available for analysis of certain domains of these disorders that are considered to be depression- or anxiety-like. Most of these tests do not actually mimic depression or anxiety, and are therefore not considered models of either, but instead, many of these tests have shown high predictive validity for efficacy of a compound in a human population, and are therefore considered screens for antidepressant or anxiolytic activity. While there are currently no models or screens that can mimic or test all domains of anxiety or depression, each test offers various pros and cons for different aspects of each. However, because of this, interpretation of findings in these tests must be carefully considered. 
Testing changes in learning and memory in rodents is somewhat less ambiguous. However, because rodents have a limited cognitive capacity, and, of course, lack certain brain structures necessary for higher cognitive function, these tests also tend to focus on one aspect or domain of memory, such as spatial memory, and again, interpretation of results should be carefully considered, as changes in one domain of rodent memory may not translate into changes in a more complex species, such as humans.

Though these drawbacks may make it difficult to fully understand the etiology of complex human diseases, carefully designed and controlled experiments of rodent behavior offer a more simplified system to begin to understand the basic mechanisms of more complex behaviors. Many of the most commonly used rodent behavioral tests exploit stereotyped or innate tendencies of mice and rats to detect changes or aberrations following an experimental manipulation, such as a drug administration or a genetic alteration. Because these simple behaviors are easily observed, any changes or deviations indicate that the experimental manipulation is having an effect. Quantifying these changes not only allows researchers to gain a better understanding of an unknown molecule or signaling pathway of interest in regards to behavior, but also allows for the identification of novel drug targets for the development of faster acting, more efficacious therapeutics with fewer side effects. The following highlights some of the most commonly used tests for anxiety- and depression-like behaviors, as well as tests for learning and memory. 


\subsubsection{Tests for anxiety-like behaviors in mice}

Numerous behavioral assays exist for testing anxiety-like behaviors in mice. Each test exploits slightly different behaviors in rodents, which must be considered when analyzing results in different rodent strains.

Most anxiety-related tests place mice in a somewhat stress-inducing environment to elicit avoidance or resilient behaviors. The following highlights the most frequently used test for anxiety-like behaviors in mice.

First introduced in the mid-80s, the EPM is among the most commonly used tests for anxiety-like behavior in mice (Haller and Alicki, 2012; Handley and Mithani, 1984; Pellow et al., 1985). The EPM consists of an elevated apparatus with 2 closed arms and 2 open arms (Fig 1.3a). The amount of time a)

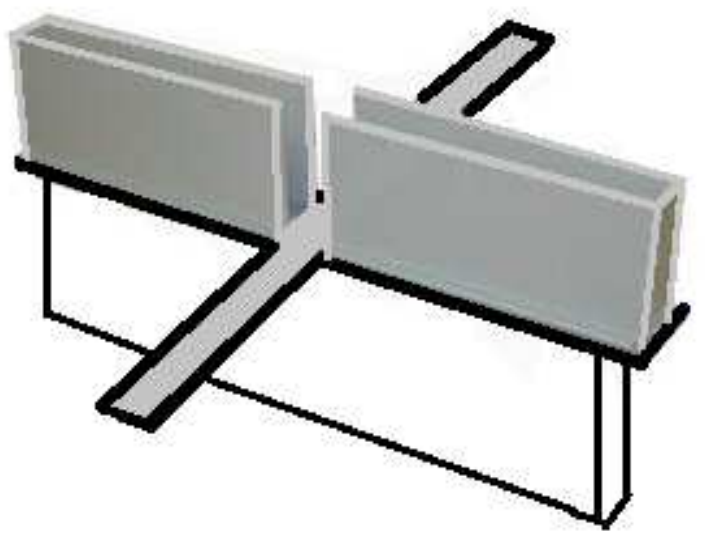

b)

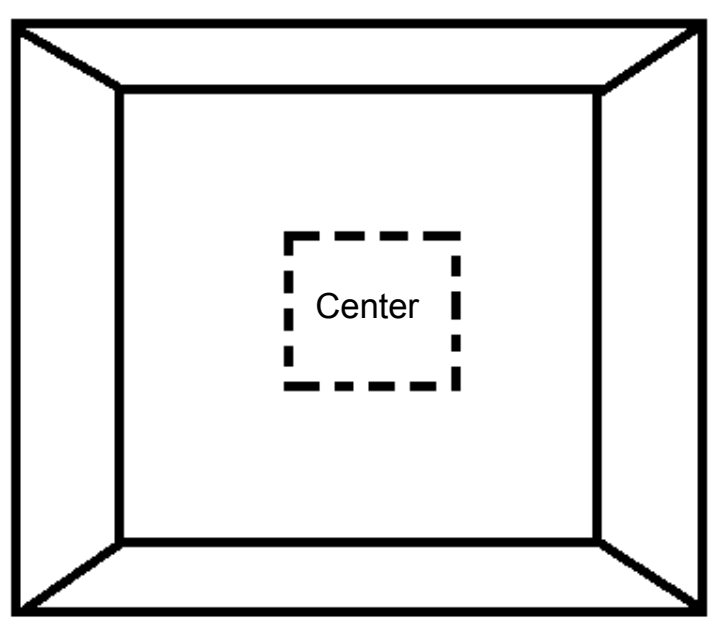

Figure 1.3. Tests for anxiety-like behaviors in mice. a, the EPM consist of 2 open arms and 2 closed arms. The mouse is placed in the center and allowed to explore. Time in the open arms is used as a measure of anxiety-like behavior. $b$, In the open field test, mice are placed in the center and allowed to explore. Time spent in the center is used as a measure of anxiety-like behavior.

spent in each arm, as well as the number of entries into each arm is quantified. This test exploits a balance between two different behaviors in mice: their preference for a closed, darker environment (i.e., the closed arms) and their innate exploratory or novelty-seeking behavior, which compels them onto the open, more exposed areas (i.e., the open arms). Anxiety-like behavior would be indicated by a decrease in the amount of time and entries 
into the open arms relative to control. Anxiolytic-like behavior would be indicated by an increase in the amount of time and entries into the open arms relative to control. This test has high predictive validity for anxiolytic drugs in humans and is commonly used as a screen for potential novel anxiolytics.

The HB test exploits somewhat similar behaviors in mice. This test consists of a board with small holes drilled in the center regions. The time the rodent spends dipping its head into the hole and the number of dips is quantified. The more time dipping and the greater number of dips is indicative of anxiolytic-like behavior (Boissier and Simon, 1964, 1962; Takeda et al., 1998). This test is sensitive to known anxiolytic agents and to stress-inducing anxiogenic behavior (Takeda et al., 1998).

A third frequently used measure of anxiolytic behavior is the open field test. This again places the mouse in a somewhat stressful environment, consisting of an open field, brightly illuminated in the center. Mice are allowed to explore for 5 minutes, and the amount of time spent in the center area is quantified (Fig 1.3b). The more time spent in the center area is indicative of anxiolytic-like response (Cryan and Holmes, 2005). One benefit of this test is that center time can be quantified for the first five minutes of a longer run to quantify overall locomotor behavior. This allows proper analysis of both overall locomotor changes between treatments and potential anxiolytic properties.

\subsubsection{Tests for depression-like behaviors in mice}

Testing depression-like behaviors in mice is somewhat more difficult due to the heterogeneity of the disease in humans. One of the most commonly used tests for depression-like behaviors is the forced swim test (FST), which was described by Porsolt in 1977 (Porsolt, 1977). This test consists of placing a rodent in a cylinder of water and 
timing 3 main behaviors: immobility, swimming, and climbing (Fig 1.4a). Immobility is defined as the minimum movement required keeping the head above water. Swimming is active movement through the water, and climbing is attempting to escape up the wall of the cylinder. After a period of attempted escape, which consists of swimming and climbing, rodents will enter a period of immobility in which they "give up", sometimes referred to as behavioral despair. Increases in immobility time are indicative of increased depression-like behavior, while a decrease in immobility is indicative of decreased depression-like behavior, as compared to controls. The FST is sensitive to standard antidepressant treatments and is used as a screen for antidepressant efficacy of novel putative antidepressants.

The tail suspension test (TST) is similar to the FST in that it also measures

a)

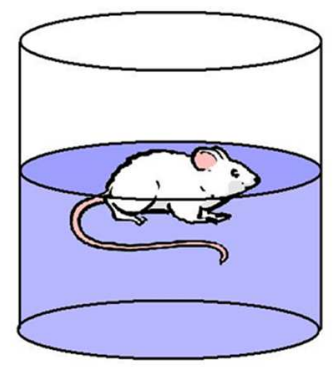

b)

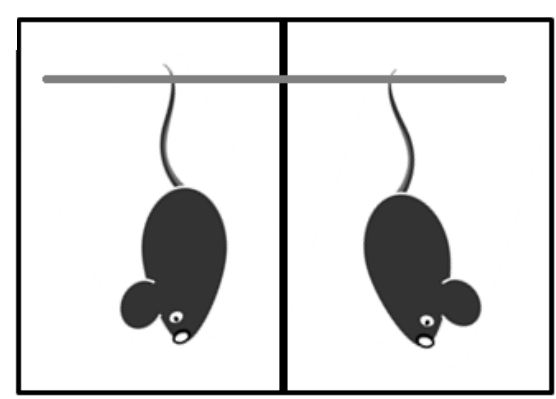

Figure 1.4. Tests for depression-like behaviors in mice. a, the FST consist of a beaker filled with temped water. The mouse is placed in the water and observed for swimming, climbing and immobility. Decreased immobility is indicative of anti-depressant-like behavior. b. For the TST, mice are taped to a bar and observed for immobility time. Decreased immobility time is indicative of anti-depressant-like behavior. immobility time and is considered to be an indication of behavioral despair (Steru et al., 1985). Mice are suspended from a bar by their tail and immobility time is quantified (Fig 1.4b). As with the FST, the mice will initially try to escape before eventually giving up and becoming immobile. Immobility is defined as little to no movement of body or limbs, or the absence of a struggle to escape. Increases or decreases in immobility time are considered depression- or antidepressant-like, respectively. As with the FST, it is a reliable screen for antidepressant efficacy in humans. 


\subsubsection{Tests for learning and memory in mice}

As with tests of anxiety and depression, tests of memory in mice often focus on one general aspect of memory, such as "spatial" memory or "object" memory. However, the parameters of any single memory test can often be manipulated to analyze numerous aspects of this memory domain, such as increasing or decreasing the intertrial intervals during training to assess acquisition, or the interval from training to testing to assess short- vs long-term memory. Additionally, when a drug manipulation is involved, treatment can be

given at any stage ranging

from prior to training to prior to testing, in order to manipulate acquisition, consolidation, or recall.

The object recognition test (ORT) is a relatively quick and efficient test of learning and memory that can be easily altered to assess different aspects of learning and memory (Ennaceur and Delacour, 1988; Leger et al., 2013). The ORT has quite a a)
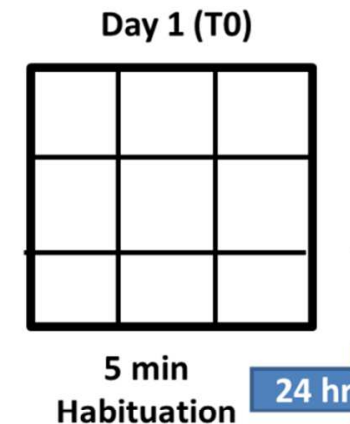

Day 2 (T1)

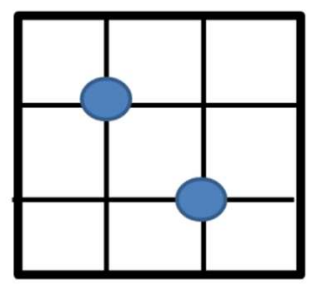

$10 \mathrm{~min}$ Training

\section{$24 \mathrm{hr}$}

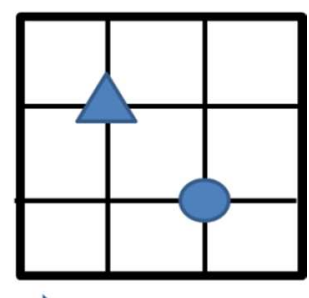

$10 \mathrm{~min}$ Testing

b)

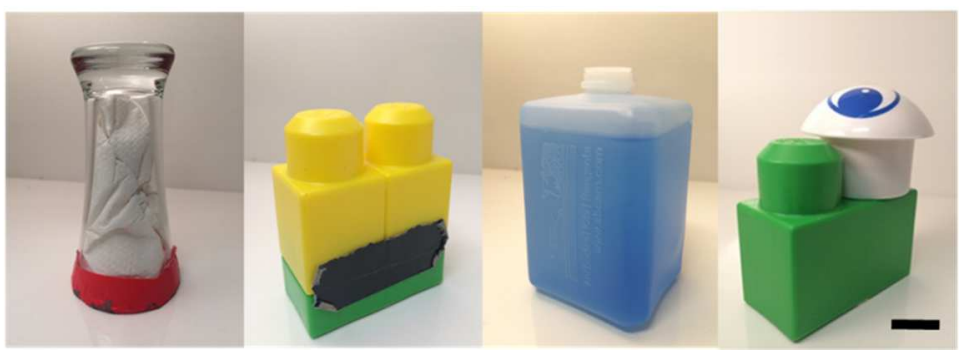

Figure 1.5 Testing Parameters for the Object Recognition Test (ORT). a, Mice were tested over the course of three days. On day 1 (TO), mice were placed in the open field for $5 \mathrm{~min}$. On day 2 (T1), mice were placed in the open field with 2 identical objects and allowed to explore for $10 \mathrm{~min}$. On day 3 (T2), mice were placed in the open field with one familiar object from $T 1$ and one novel object and allowed to explore for $10 \mathrm{~min}$. $b$, The following objects were used randomly as familiar or novel objects: small beer tasting glass, lego with duct tape, ice pack, lego with eye piece.

few advantages over other tests of memory, one of the more important being that it does 
not require any lengthy or stressful training or reinforcement schedules. It also doesn't require any form of food or water deprivation. This means that mice can be tested from a fairly natural baseline, absent from any unusual stressors. Additionally, the ORT exploits a rodent's natural interest in exploring novelty, again negating the need for any external interference. Additionally, the test takes place over 2-3 days, which is much shorter than other common memory tests with extensive training that can take weeks or months.

For tests of long-term memory, the ORT takes place over 3 days. Day 1 (T0) is merely habituation to the test chamber. Day 2 is training (T1) with 2 identical objects. Day 3 is $24 \mathrm{hr}$ after training, and is the testing day (T2), in which the mouse is exposed to one of the familiar objects and one novel object (1.5a). Because mice like to explore novel objects over familiar ones, a mouse that "remembers" the object from T1 will spend a proportionally greater amount of time exploring the novel object. At $24 \mathrm{hr}$, most rodents show equal preference for the familiar and novel object, indicating no memory for the familiar object. For optimal exploration, objects used should be approximately mousesized with simple, but distinct features (Fig 1.5b). Any drug that enhances memory will increase the preference to explore the novel object, indicating the rodent remembered the familiar object.

For assessing short-term memory, a shorter delay can be used. Rodents with unimpaired memory should show preference for the novel object if tested $1 \mathrm{hr}$ or less after T1. These parameters would be used when testing changes to short-term memory, such as with the possibility of cognitive enhancing drugs in a population of rodents that have genetic or chemically impaired learning and memory that are unable to remember the familiar object at $1 \mathrm{hr}$ post T1. 
Another commonly used test of memory, the step-through passive avoidance (STPA), is also fairly quick and efficient. However, this test makes use of somewhat more stressful testing parameters, including bright light and a shock, shifting more into the domain of fear memory. It was first described in 1960 by Jarvik and Essman and has since been used for numerous applications (Jarvik and Essman, 1960; Jarvik and Kopp, 1967). The apparatus consists of a small dark chamber and a larger, brightly lit chamber connected by a guillotine door. Similar to the anxiety test mentioned above, this test exploits a mouse's desire to be in a smaller, dark place over a bright open area. For training, mice are placed in the brightly lit chamber. When the mouse crosses into the dark chamber, the door is closed, and a shock is administered. This process is repeated until the mouse suppresses its desire to enter the dark chamber, indicating an association was made between the dark chamber and the inescapable shock. Testing is often done $24 \mathrm{hr}$ after this training period and simply involves placing the mouse back into the brightly lit side of the chamber and measuring the amount of time until the mouse enters the dark side. The longer a mouse suppresses the desire to enter the dark side, the stronger the memory for the dark-shock association.

The advantages of STPA are the relative quickness and simplicity of training and testing. As with the ORT, many of the experimental variables can be manipulated as necessary, including inter-trail intervals and delay to testing, as well as the shock duration and strength. Additionally, this test is a simple measure of stress or fear- related memory without having to do days or weeks of conditioning that significantly stress or even depress the rodents. 


\subsection{Objectives}

Several members of the PDE family have shown great potential as targets for drug development for the treatment of numerous mood and cognitive disorders. The study of PDE2, specifically, has thus demonstrated a protective role of PDE2 against behavioral and biological changes associated with stress-induced anxiety, depression, and impaired learning and memory. Additionally, PDE2 inhibition has been shown to significantly enhance recognition memory in the ORT and similar memory tests.

However, the research presented above has been primarily demonstrated in "challenged" systems, limiting our understanding of the role of PDE2 in these behaviors from baseline. Research into the role of PDE2 in anxiety and depression has focused on its protective effects from changes following both chemically and physically induced stress (Ding et al., 2014; Masood et al., 2009, 2008; Xu et al., 2015, 2013). Research into the role of PDE2 in learning and memory has made use of singly-housed rats, which is known to significantly alter behavior, as well as induce stress and impair memory in rodents (Akkerman et al., 2014b; Bianchi et al., 2006; Douglas et al., 2003; Hall, 1998; Lapiz et al., 2003; Thorsell et al., 2006; Weiss et al., 2004). Therefore, the main objective of the following studies is to understand the basic role of PDE2 in anxiety-and depression- like behaviors and learning and memory in mice through the following aims:

1. Compare the effects of acute vs chronic treatment of the PDE2 inhibitor, Bay 60-7550 on anxiety- and depression-like behaviors

a. In order to compare the effects of acute inhibition of PDE2 vs repeated inhibition, which may result in more chronic neurobiological changes, PDE2 inhibitor Bay 60-7550 will be administered either acutely or 
repeatedly for 14 days and mice will be tested in various tests for anxiety- and depression- like behavior, including the EPM, HB, FST, and TST.

2. Compare the effects of peripherally vs centrally administered Bay $60-7550$ on anxiety- and depression-like behaviors, and learning and memory.

a. In order to parse the potential role/interference of peripherally expressed PDE2 on tests of mood and cognition, mice will be given Bay 60-7550 either peripherally via IP injection or centrally via injection into the lateral ventricles and tested for anxiety-like behavior in the EPM, depression-like behavior in the TST, and effects on learning and memory in the STPA and ORT.

3. Asses the role of PDE2 in learning and memory using the ORT

a. In order to develop a more thorough understanding of the role of PDE2 in different phases of learning and memory, PDE2 inhibitor Bay 60-7550 will be administered during the ORT. Bay $60-7550$ will be given $30-120$ min prior to training to assess the role of PDE2 inhibition in memory acquisition, immediately after training, and up to $3 \mathrm{hrs}$ after training, to assess its role in memory consolidation, as well as 30 min prior to testing, to assess its role in memory recall

b. In order to understand the molecular pathways that underlie PDE2mediated memory consolidation enhancement, various inhibitors of the cAMP/cGMP pathways will be administered prior to PDE2 inhibitor administration, in an attempt to block the memory-enhancing effects of 
either Bay $60-7550$ or ND7001. This includes inhibitors to nitric oxide synthase (NOS), soluble guanylyl cyclase (sGC), protein kinase $G$ (PKG) and protein kinase $A(P K A)$.

Our central hypothesis in these studies is that PDE2 inhibition, acutely and chronically, peripherally and centrally, will result in anxiolytic-like and antidepressant-like effects as well as enhanced memory in the ORT. 


\section{CHAPTER 2}

Effects of Phosphodiesterase-2 Inhibition on Depression- and Anxiety-like Behaviors in Mice 


\subsection{Introduction}

Mood disorders represent a large and growing mental health concern not only in the United States, but also around the world. Anxiety and depression are two of the most prominent mood disorders, with anxiety affecting approximately $18 \%$ of American adults in a given year, and a lifetime prevalence of $28.8 \%$, and depression affecting approximately $7 \%$ of American adults in a given year, with a lifetime prevalence of approximately 17\% (Kessler et al., 2005; Norquist, 1998; Services, 2009). While depression and anxiety are frequently found to be comorbid (50-70\% lifetime comorbidity), symptoms of each of these diseases can vary widely, making successful treatment often difficult for physicians (Hettema, 2008). Although a number of pharmacological treatment options are available, successful treatment of anxiety and/or depression remains limited due to suboptimal or delayed efficacy, side effects, and toxicity in certain populations. Additionally, though individual symptoms often vary widely within and between these mood disorders, the same classes of drugs, all with similar mechanisms, are the main pharmacologic treatment option for either diagnosis, regardless of the individual symptomology. Moreover, this first line treatment, the antidepressants, cause a number of undesirable side effects, and require continued treatment for many weeks in order to ease symptoms (Hirschfeld, 2000). These limitations reveal the great need that exists for the development of novel, more efficacious antidepressants and anxiolytics.

One of the limiting factors for the development of novel antidepressants and anxiolytics is our insufficient understanding of the etiology and underlying mechanisms of these disorders. The current generation of antidepressants, which are considered 
first-line treatments for both anxiety and depression, primarily target the serotonergic and noradrenergic systems. These drugs work via inhibition of the respective reuptake transporter, thereby increasing the concentration and duration of serotonin and/or norepinephrine signaling within the synapse. While this molecular effect is seen immediately, a therapeutic effect may take weeks to manifest (Hirschfeld, 2000). Therefore, researchers are interested in identifying other potential mechanisms within similar brain regions that may allow for a faster onset of symptom relief.

The super-family of phosphodiesterases (PDEs) has over 100 splice variants grouped into 11 gene-related families. Such diversity allows for tight regulation of cell signaling through cell and/or microdomain specificity. This, in combination with their widespread expression in the CNS, makes them prime targets for drug development for the treatment of mood disorders. PDE2 is of special interest due to its high expression in the limbic system, which is a key brain region for emotional processing.

PDE2 is highly expressed in the forebrain, specifically in the isocortex, entorhinal cortex, striatum, hippocampus, amygdala, medial habenula , basal ganglia, and the substantia nigra (pars compacta) (Gesellchen and Zaccolo, 2011; Stephenson et al., 2009). PDE2s expression in these areas suggests an important role for PDE2 in mood and emotion.

Following NMDA receptor activation in rat cortical and hippocampal neuronal cultures, PDE2 was shown to be the primary PDE for the hydrolysis of cGMP (Suvarna and O'Donnell, 2002), and nitric oxide-induced accumulation of cGMP in striatal cell culture also revealed PDE2 as the PDE responsible for cGMP hydrolysis (Wykes et al., 2002). Early exploration of the role of PDE2 in behavior indicated a protective role of PDE2 in oxidative stress-induced anxiety (Masood et al., 2008). Mice that received 
BSO, a drug that induces oxidative stress, showed increased anxiety-like behavior. Pretreatment with the PDE2 inhibitor Bay 60-7550 prevented the BSO-induced increase in anxiety-related behaviors (Masood et al., 2008). PDE2 inhibitors have also shown to be protective against chronic unpredictable stress (Ding et al., 2014; Masood et al., 2009; Xu et al., 2013). Mice subjected to daily stressors are likely to develop anxiogenic-like behaviors. Administration of PDE2 inhibitors Bay 60-7550 and ND7001 was shown to reverse these deficits and produce anxiolytic-like responses (Ding et al., 2014; Masood et al., 2009; Xu et al., 2013).

While much has been shown regarding the protective role of PDE2 in stressinduced changes in behavior, researchers have yet to fully uncover the basic role of PDE2 in anxiety and depression. Therefore, the present study investigated the effect of PDE2 inhibition on anxiety- and depression-like behavior in mice. First, mice were treated daily with Bay $60-7550$ for 14 days and then tested in the forced swim test (FST), the tail suspension test (TST), the elevated plus maze (EPM), and the hole board (HB) test. This chronic treatment did not result in antidepressant- or anxiolytic-like behavior in any of these tests. Next, to assess any potential interference of peripherally expressed PDE2 on changes in anxiety- or depression- like behavior, mice were given Bay 60-7550 either via IP injection or directly into the brain via an ICV injection into the lateral ventricles. Mice treated with Bay 60-7550 via IP or ICV did not show any changes in anxiety or depression-like behaviors, as tested in the TST, the EPM, or the step-through passive avoidance (STPA) test. However, mice treated with Bay 60-7550 both centrally and peripherally did show enhanced memory, as measured in the object recognition test (ORT). 


\subsection{Methods}

\subsubsection{Animals}

Male ICR mice (Harlan, Indianapolis, IN, USA) weighing 25-35 g (6-8 weeks old) were housed 5 per cage in standard polycarbonate cages, with food and water available ad libitum. Mice were maintained on a $12 \mathrm{hr}$ light-dark cycle (lights on at 06:00 h) with constant temperature $\left(22 \pm 2{ }^{\circ} \mathrm{C}\right)$ and humidity $(55 \pm 10 \%)$. Animals were randomly assigned to experimental conditions, with each animal being used only once for each behavioral test to prevent habituation and crossover testing effects. All mice were acclimated to the testing room and handled daily for 5-7 days prior to testing. All animal procedures in this study were reviewed and approved by the Animal Care and Use Committee of West Virginia University.

\subsubsection{Drugs and Treatments}

Bay 60-7550 (Caymen Chemical, Ann Arbor, MI) was dissolved in 5\% ethanol, 10\% Kolliphor (Sigma Chemicals, St. Louis, MO), 85\% saline. When given ICV, Bay 60-7550 was dissolved in 50\% DMSO. Diazepam (Med-Vet International, Mettawa, IL) was diluted to working concentration in saline. Rolipram (Enzo Life Sciences, Farmingdale, NY) was dissolved in 5\% DMSO and 95\% saline. All drugs were given IP, with the exception of Bay 60-7550, which was also administered into the lateral ventricle via implanted cannulae. For control treatments, mice were administered the corresponding drug vehicle.

For chronic drug treatments, mice were given a daily IP injection of either Bay $60-7550$ or vehicle for a minimum of 14 days prior to the start of behavior, with additional daily injections through the end of behavior testing. On day 14 , behavior 
testing began with the HB test followed immediately by the EPM. On day 15, mice were tested in the TST. On day 16, mice were tested in the FST. Testing was done independent of the time of the drug injection.

For acute IP vs ICV testing, each cohort of mice (IP or ICV) was exposed to each behavior test in the following order from least to most stressful: EPM, ORT, TST, STPA. Each test had a minimum washout period of 2 days and mice were randomly assigned to different treatment groups for each test. Injections were given 30 min prior to testing (EPM, TST) or training (ORT, STPA).

\subsubsection{Cannula Surgery and ICV Drug Treatment}

Mice were anesthetized with ketamine $(100 \mathrm{mg} / \mathrm{kg})$ and xylazine $(8 \mathrm{mg} / \mathrm{kg})$ and placed in a stereotaxic apparatus (Stoelting Instruments, Wood Dale, IL). A 26 gauge guide cannula (Plastics One, Roanoke, VA) was implanted unilaterally (AP - $0.2 \mathrm{~mm}$ from Bregma, $\mathrm{ML}+1 \mathrm{~mm}$ from the midline, DV $-2 \mathrm{~mm}$ from skull surface using the atlas of Paxinos and Franklin (Paxinos and Franklin, 2008) and secured with a single skull screw and cranioplastic cement. Mice were allowed to recover for 7 days before testing.

On the day of training or testing, a 33 gauge injection cannula was inserted, and mice were administered vehicle or Bay 60-7550 using a syringe pump (KD Scientific, Holliston, MA) dispensing 5 ul over 5 min. The guide cannula was left in place for at least one additional min to allow diffusion and to minimize backflow into the guide cannula. At the end of the experiment, mice were injected with dye to confirm placement of the cannula; mice with incorrect cannula placement were excluded from analysis. 


\subsubsection{Forced Swim Test}

The forced swimming test (FST) was carried out as previously described (Ding et al., 2014). Briefly, mice were individually placed in glass cylinders (height: $25 \mathrm{~cm}$; diameter: $10 \mathrm{~cm}$; containing $10 \mathrm{~cm}$ depth of water at $24 \pm 1{ }^{\circ} \mathrm{C}$ ) for $6 \mathrm{~min}$. The sessions were recorded and at a later time, the last 4 min were scored for immobility by a blind experimenter. A mouse was determined to be immobile when there were only small movements necessary to keep its head above water. A decrease in immobility time is considered to be an anti-depressant like behavior.

\subsubsection{Tail Suspension Test}

The tail-suspension test (TST) for depressive behavior in mice was carried out as described previously (Ding et al., 2014). Mice were suspended from a stand arm by a $1.9 \mathrm{~cm} \times 15 \mathrm{~cm}$ with masking tape loop attached to the end of their tail, leaving the last $1 \mathrm{~cm}$ of tail exposed. Mice were recorded for 6 -min before returning to their home cage. The sessions were recorded and, at a later time, the last 4 min were scored for

immobility time by a blind experimenter. A mouse was considered immobile when there was no struggle and there was little to no movement of fore or hind legs. A decrease in immobility time is considered to be an anti-depressant like behavior.

\subsubsection{Elevated Plus Maze}

Behavior in the elevated plus-maze test (EPM) was assessed as described previously (Ding et al., 2014; Masood et al., 2008). The EPM (San Diego Instruments, San Diego, CA) consisted of two open arms $(30 \mathrm{~cm} \times 5 \mathrm{~cm})$ and two closed arms $(30 \mathrm{~cm} \times 5 \mathrm{~cm} \times 15 \mathrm{~cm})$ that extended from a central platform $(5 \mathrm{~cm} \times 5$ $\mathrm{cm})$. The entire maze was elevated $40 \mathrm{~cm}$ above the floor. Mice were placed in the 
center platform facing an open arm and allowed to explore for $5 \mathrm{~min}$. All sessions were recorded and later scored by a blind experimenter. During the 5-min of free exploration, the number of entries into and the time spent in open and closed arms were noted. An entry was defined as all four paws in an arm. Percent of total entries into the open arms and percent of total time spent in the open arms was calculated to control for differences in locomotor activity between mice. Significant increases in percent entries and time in the open arm is considered to be decreased anxiety-like behavior.

\subsubsection{Hole Board Test}

The hole-board (HB) test was conducted as described previously (Masood et al., 2008). The hole-board apparatus consisted of a Perspex box $(60 \times 60 \times 35 \mathrm{~cm})$ with four equidistant holes, $4 \mathrm{~cm}$ in diameter in the floor, with a small black box underneath to catch any mice that crawl through the hole. Each animal was placed in the center of the hole-board and allowed to freely explore the apparatus for $5 \mathrm{~min}$. All sessions were recorded and later scored by a blind experimenter. The number of head-dips and total time spent in head- dipping were recorded. A head dip was counted when the animal extended its head into the hole past the ears. Significant increases in time dipping and number of dips is considered to be decreased anxiety-like behavior.

\subsubsection{Step-through Passive Avoidance}

The step-through passive avoidance (STPA) test was conducted as previously described. The apparatus consisted of 2 equal size chambers, 1 dark chamber with an electrified grid floor and 1 brightly illuminated chamber, connected by a guillotine door. With the guillotine door open, mice were placed in the illuminated chamber and allowed to freely explore. As soon as the mouse entered the dark side, the guillotine door was 
closed and a foot shock was delivered. Mice were left in the dark chamber for $30 \mathrm{sec}$, and then placed back into the light chamber. This process was repeated until the mouse stayed in the light chamber for 300 seconds, indicated it had learned the association between the dark side and the shock. Twenty-four hours later, the mouse was placed back into the light chamber, and the latency to enter the dark side was recorded.

\subsubsection{Object Recognition Test}

Behavior in the Object Recognition Test (ORT) was assessed as previously described (Leger et al., 2013).On the first day, mice were acclimated to the empty, square open field chamber for 5 min (T0: habituation). The next day, mice were injected with vehicle or drug. Thirty minutes later, mice were placed in the field with 2 identical objects and allowed to explore for 10 min (T1: training). Twenty-four hrs later, mice were placed back into the open field with one familiar object (i.e., object used in T1) and one novel object and allowed to explore for $10 \mathrm{~min}$ (T2: testing). All objects used were of a size appropriate for exploration by mice (e.g., LEGO blocks, small glass filled with paper, small freezer pack) and were placed at a diagonal in the box. Objects and object locations were counterbalanced for novel vs familiar use and orientation in the box. All testing was done under low light conditions. Both T1 and T2 sessions were video recorded and time spent exploring the objects was later scored by an experimenter blinded to treatment conditions. For the testing phase, only the first 5 min of exploration were scored, or until the mouse reached the minimum exploration time. Mice that did not reach a minimum exploration time of 20 seconds during T1 or T2 were excluded from analysis. The discrimination index (DI) was calculated for each mouse during T2: 
$[D I=($ novel object exploration time - familiar object exploration time $) /($ novel object exploration time + familiar object exploration time)].

\subsubsection{Statistical Analysis}

Data are expressed as means \pm S.E.M. Comparisons among groups were first analyzed via one-way analysis of variance (ANOVA) followed by Bonferroni's multiple comparisons tests. A p value of less than 0.05 was considered significant.

\subsection{Results}

\subsubsection{Repeated treatment with Bay 60-7550 did not decrease depression-like behavior in the forced swim test or tail suspension test.}

Bay 60-7550, given daily for 14 days, did not result in significant changes in depression-like behavior. Neither dose $(0.5 \mathrm{mg} / \mathrm{kg}$ or $1 \mathrm{mg} / \mathrm{kg})$ changed immobility time when compared to vehicle treated mice in the $\operatorname{FST}(F(2,26)=2.59$; ns; Fig 2.1a) or TST $(F(2,22)=1.55$; ns; Fig 2.1b), both screens for antidepressant-like behavior.
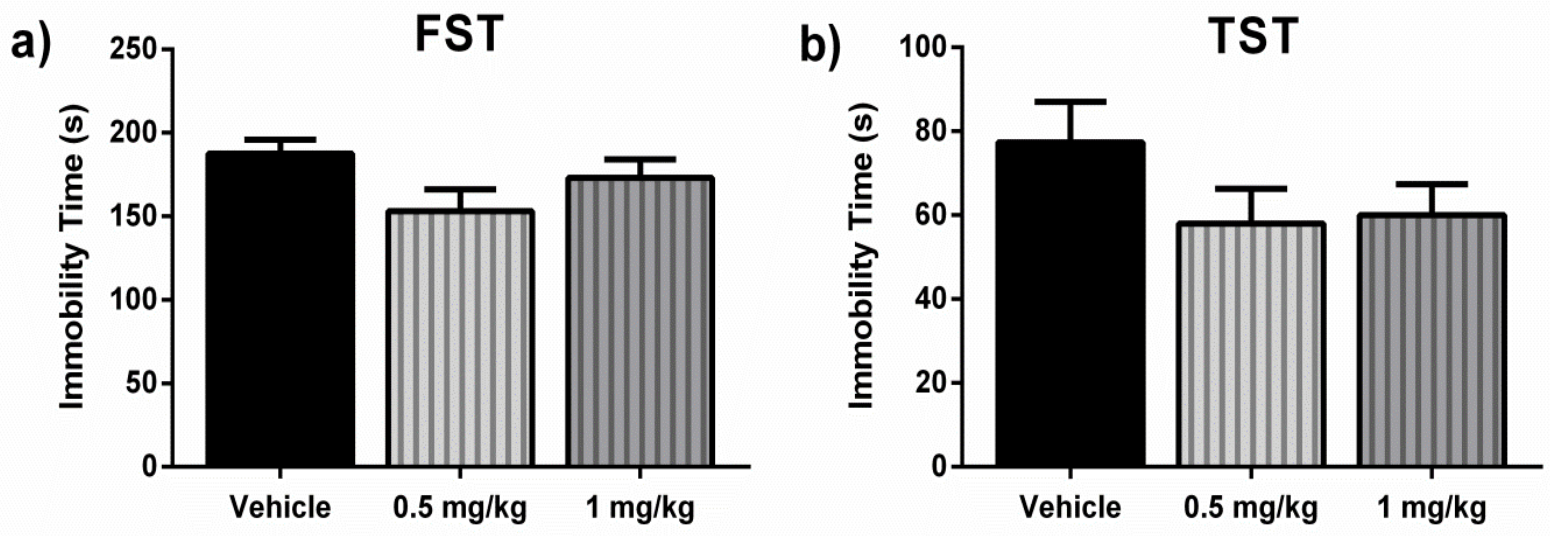

Figure 2.1 Repeated treatment with Bay 60-7550 does not induce antidepressant-like behavior in the forced swim test (FST) or tail suspension test (TST). a, Compared to vehicle, mice treated with Bay 60$7550(0.5 \mathrm{mg} / \mathrm{kg}$ or $1 \mathrm{mg} / \mathrm{kg})$ daily for 14 days did not show significantly decreased immobility time in the FST. b. Mice treated with Bay 60-7550 (0.5 mg/kg or $1 \mathrm{mg} / \mathrm{kg})$ daily for 14 days did not show significantly decreased immobility time in the TST. Bars represent means \pm S.E.M. $n=8-10$ mice/group 


\subsubsection{Repeated treatment with Bay 60-7550 did not decrease anxiety-like behavior}

in the elevated plus maze or hole board test

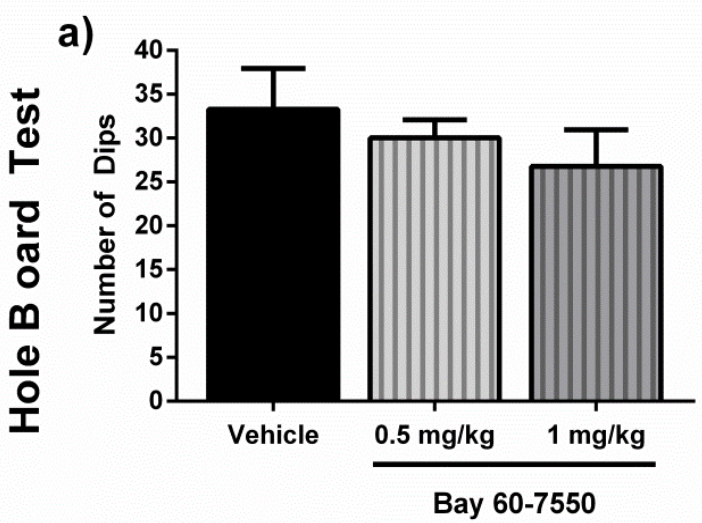

b)

c)

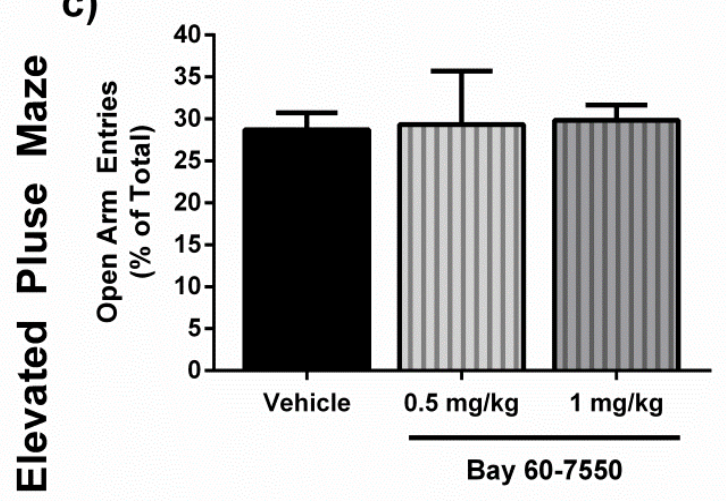

d)

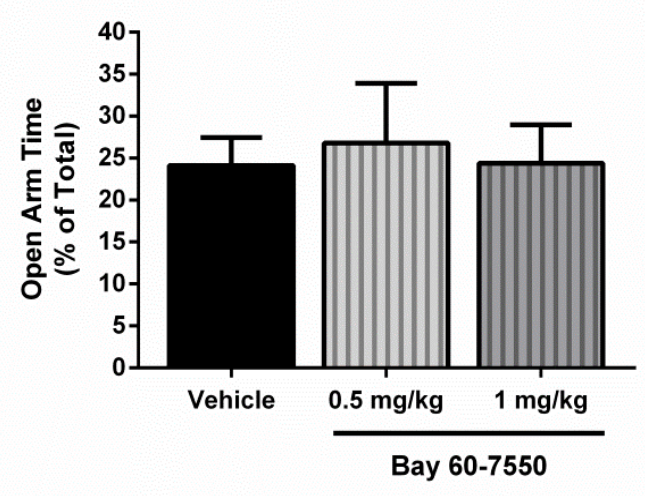

Figure 2.2 Repeated treatment with Bay 60-7550 does not decrease anxiety-like behavior in the hole board (HB) or elevated plus maze (EPM). a, Compared to vehicle, mice treated with Bay 60-7550 $(0.5 \mathrm{mg} / \mathrm{kg}$ or $1 \mathrm{mg} / \mathrm{kg})$ daily for 14 days did not significantly increase the number of dips, $b$, or time dipping in the HB test. c, Mice treated with Bay 60-7550 (0.5 mg/kg or $1 \mathrm{mg} / \mathrm{kg})$ daily for 14 days did not increase the percent of open arm entries, $d$, or increase the percent time in the open arms of the EPM. Bars represent means \pm S.E.M. $n=8-10$ mice/group

Bay 60-7550, given daily for 14 days, did not result in significant changes in anxiety-like behavior. Neither dose $(0.5 \mathrm{mg} / \mathrm{kg}$ or $1 \mathrm{mg} / \mathrm{kg})$ changed the number of dips $(F(2,24)=0.70 ; n s ; F i g$ 2.2a) nor time dipping $(F(2,24)=0.18$; ns; Fig 2.2b) in the HB test, when compared to vehicle treated mice. Additionally, neither dose $(0.5 \mathrm{mg} / \mathrm{kg}$ or 1 $\mathrm{mg} / \mathrm{kg})$ changed the percent of entries into the open arm $(F(2,26)=0.02 ; n s ; F i g 2.2 \mathrm{c})$ nor the percent of time spent in the open $\operatorname{arm}(F(2,26)=0.08$; ns; fig $2.2 d)$, when compared to vehicle treated. 


\subsubsection{Neither central nor peripheral} administration of Bay 60-7550 decreased depression-like behavior in the tail suspension test

No change in depression-like behavior was observed with either IP (peripheral injection) or ICV (central injection) administration of Bay 60-7550. A single IP injection of Bay $60-7550$ (3 mg/kg) did not alter immobility time in the TST (Fig 2.3a; ns) A single ICV injection of Bay 60-7550 (30ug) 30 min prior to testing did not alter immobility time in the TST (Fig 2.3b; ns).

\subsubsection{Neither central nor peripheral}

\section{administration of Bay 60-7550 decreased}

anxiety-like behavior in elevated plus maze

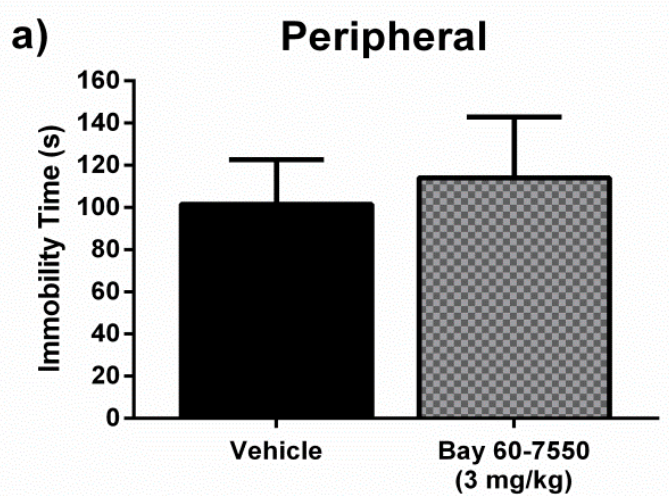

b)

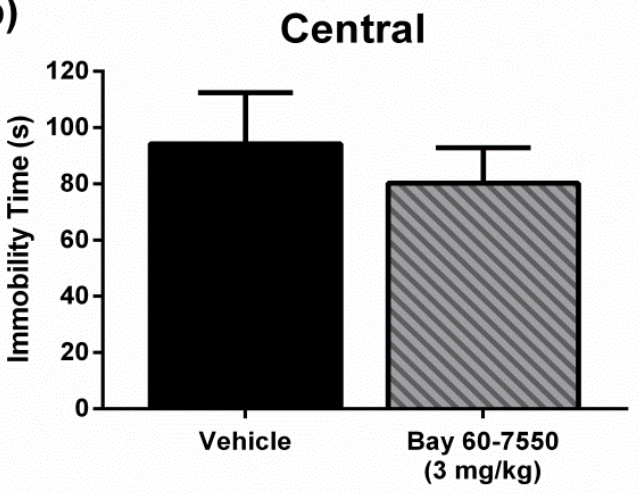

Figure 2.3 Neither peripheral nor central administration of Bay 60-7550 induces antidepressant-like behavior in the tail suspension test (TST). a, Compared to vehicle, mice treated with Bay 60-7550 (3 $\mathrm{mg} / \mathrm{kg}$ ) either via IP injection or $\mathrm{b}$, Mice treated with Bay 60-7550 (30 ug) via ICV injection did not show changes in immobility time in the TST. Bars represent means \pm S.E.M. $n=10-14$ mice/group

No change in anxiety-like behavior was observed with either ICV or IP administration of Bay 60-7550. A single IP injection (peripheral) of Bay 60-7550 (3 $\mathrm{mg} / \mathrm{kg}$ ) $30 \mathrm{~min}$ prior to testing did not alter percent of entries into the open arms (Fig 2.4a; ns) or percent of time spent in the open arms (Fig 2.4b; ns) when compared to vehicle treated mice in the EPM. A single injection of the anxiolytic diazepam (2 mg/kg) 30 min prior to testing did significantly increase the percent of entries into the open arm $(F(2,33)=4.88, p<0.01 ; F i g 2.4 a)$ and percent of time spent in the open arm $(F(2,33)$ 
$=5.71, \mathrm{p}<0.01 ;$ Fig 2.4b). A single ICV injection (central) of Bay 60-7550 (3 mg/kg) 30 min prior to testing did not alter percent of entries into the open arm (Fig 2.4c; ns) or percent of time in the open arm (Fig 2.4d; ns).

a)

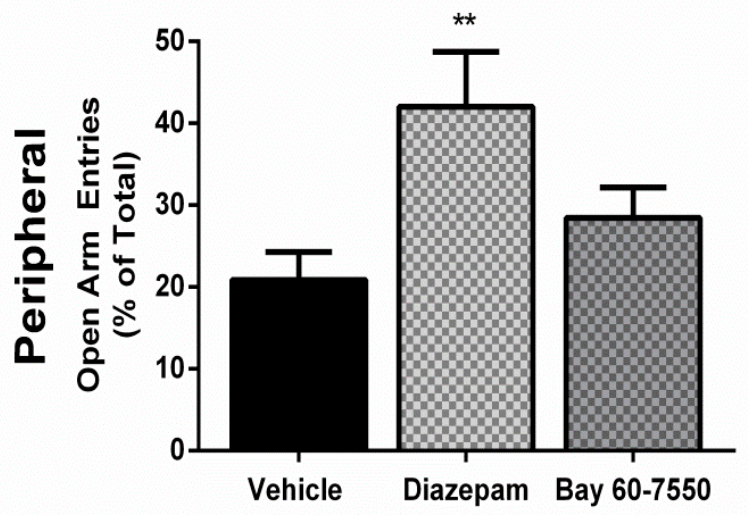

c)

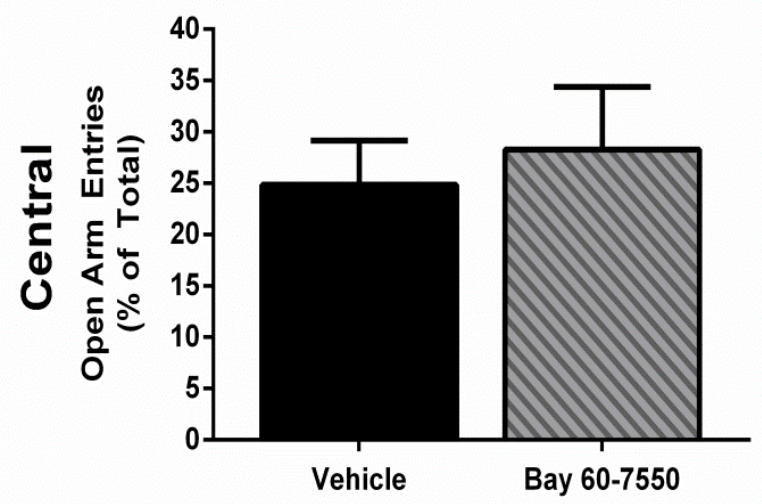

b)

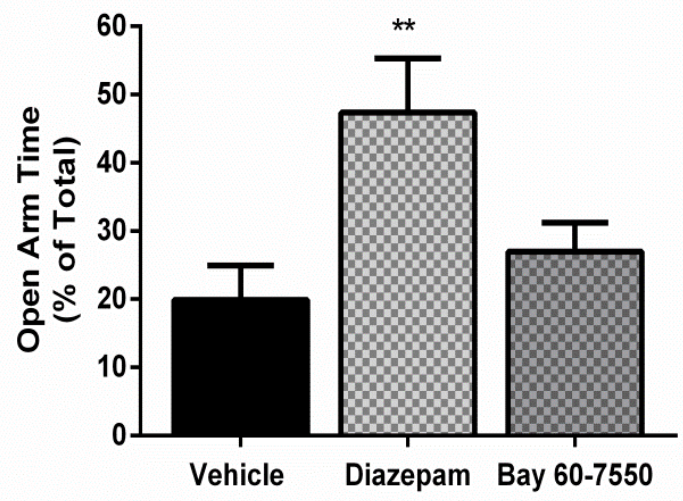

d)

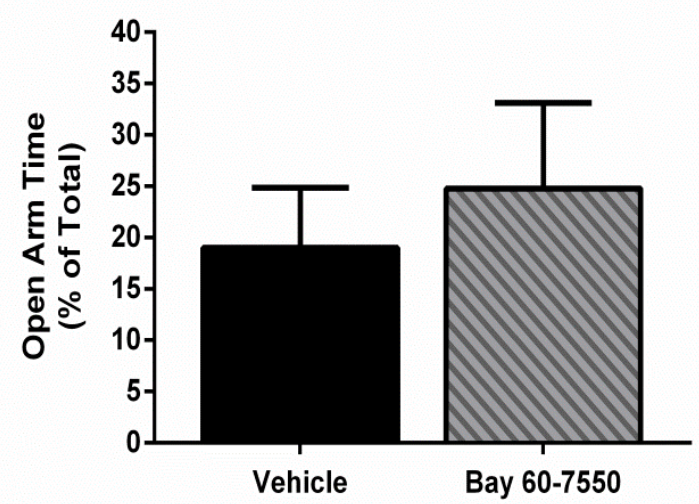

Figure 2.4 Neither peripheral nor central administration of Bay 60-7550 alters anxiety-like behavior in the elevated plus maze (EPM). a, Compared to vehicle, mice treated with Bay 60-7550 (3 mg/kg) via a peripheral, IP injection did not show changes in percent open arm entries or, b, percent open arm time. Mice treated with diazepam (2 mg/kg), showed an increase in the percent entries and time in the open arm (a \&b). c, Compared to vehicle, mice treated with Bay 60-7550 (3 mg/kg) via a central, ICV injection did not show changes in percent open arm entries or, $b$, percent open arm time. Bars represent means \pm S.E.M. $n=8-10$ mice/group. ${ }^{* *} p<0.01$ vs vehicle

\subsubsection{Neither central nor peripheral administration of Bay 60-7550 enhanced memory in the step-through passive avoidance test}

No change in the latency to enter the dark side of the test chamber (i.e., the side where electric footshock was delivered during training) was observed with either ICV or 

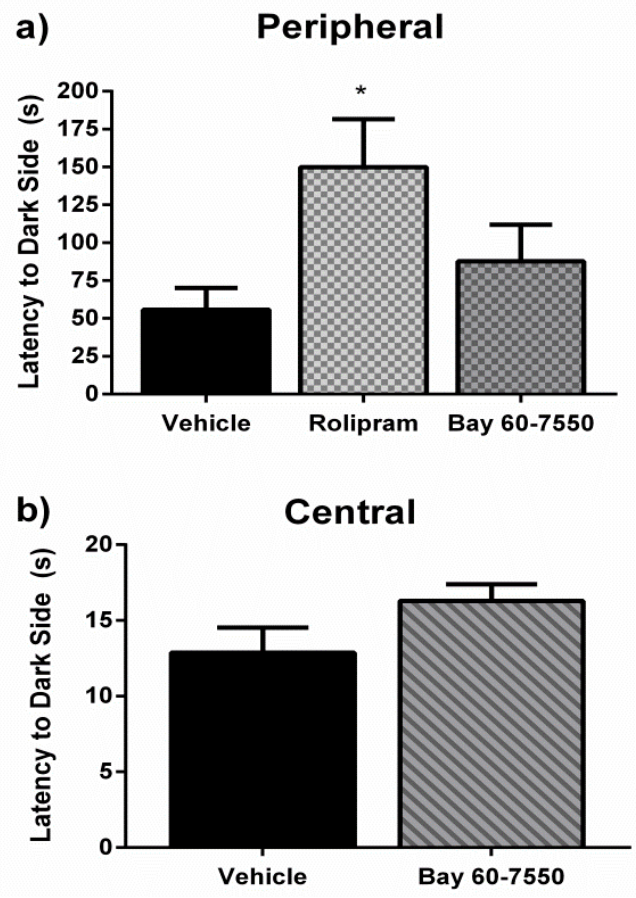

Figure 2.5 Neither peripheral nor central administration of Bay 60-7550 increased the latency to enter the dark side in the STPA. a, Compared to vehicle, mice treated with Bay 60-7550 (3 mg/kg) either via IP injection or b, Mice treated with Bay 60-7550 (30 ug) via ICV injection did not show changes latency to enter the dark side. Rolipram (1 $\mathrm{mg} / \mathrm{kg}$ ) did increase the latency to enter the dark side (a). Bars represent means \pm S.E.M. $n=6-9$ mice/group. ${ }^{*} p<0.05$
IP administration of Bay 60-7550. A single IP injection of Bay $60-7550(3 \mathrm{mg} / \mathrm{kg}) 30 \mathrm{~min}$ prior to training did not alter the latency to enter the dark chamber (Fig 2.5a; ns). While a single injection of rolipram (1 mg/kg) $30 \mathrm{~min}$ prior to testing did significantly increase the latency to enter the dark side $(F(2,35)=$ 3.66, $p<0.05$; Fig 2.5b), a single IP injection of Bay $60-755030$ min prior to testing did not alter the latency to enter the dark side (Fig $2.5 b ; n s)$.

\subsubsection{Central and peripheral administration} of Bay 60-7550 enhanced memory in the object recognition test.

Both ICV and IP administration of Bay

60-7550 resulted in significant enhancement of memory in the ORT. A single IP injection of either rolipram (1 mg/kg; $p<0.01$; Fig 2.6a) or Bay 60-7550 (3 mg/kg; $p<0.01$; Fig 2.6a) given 30 min prior to training significantly enhanced ORT memory when tested $24 \mathrm{hr}$ later $(\mathrm{F}(2,39)=7.633 ; \mathrm{p}=0.001)$. A single IP injection of Bay $60-7550(30 \mathrm{ug}) 30$ min prior to training significantly enhanced memory in the ORT when tested $24 \mathrm{hr}$ later, as compared to vehicle treated mice $(F(2,39)=7.63$, Fig 2.6b). 

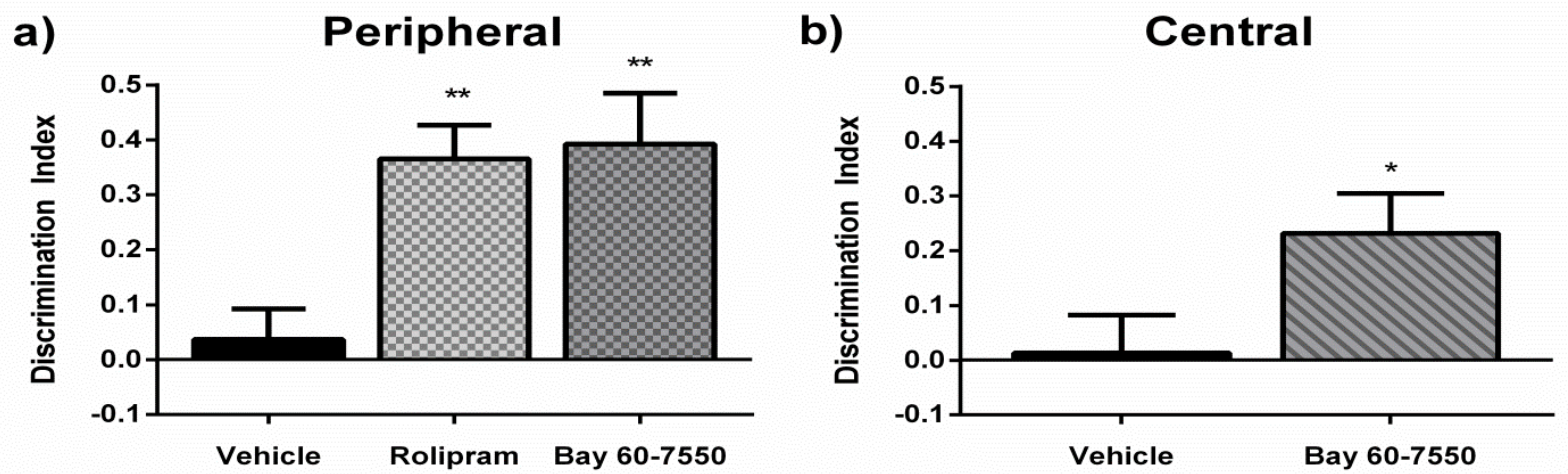

Figure 2.6 Both peripheral and central administration of Bay 60-7550 enhanced memory in the ORT. a, Compared to vehicle, mice treated with Bay 60-7550 (3 mg/kg) either via IP injection or $b$, Mice treated with Bay 60-7550 (30 ug) via ICV injection $30 \mathrm{~min}$ prior to training showed enhanced memory in the ORT. Rolipram (1 mg/kg) also increased memory in the ORT (a). Bars represent means \pm S.E.M. $n=10-14$ mice/group. ${ }^{*} p<0.05,{ }^{* *} p<0.01$ vs vehicle

\subsection{Discussion}

The PDE2 inhibitor Bay 60-7550, when administered repeatedly for 14 days or when administered acutely via IP or ICV injection did not significantly alter depressionor anxiety-like behaviors. Mice treated with Bay 60-7550 (0.5 or $1 \mathrm{mg} / \mathrm{kg})$ daily for 14 days did not show changes in immobility time in either the FST or the TST, nor did mice show increased time or entries into the open arm of the EPM, or increases in time dipping or number of dips in the HB test.

In order to assess any potential interference of peripherally expressed PDE2 vs PDE2 in the CNS, mice were given a single injection of Bay 60-7550 either via IP (peripheral administration) or ICV (central administration). Mice treated with Bay 607550 either IP or ICV (3 mg/kg and 30 ug, respectively) did not show changes in immobility time in the TST or changes in open arm time/entries in the EPM. Additionally, neither IP nor ICV administration of Bay 60-7550 (3 mg/kg and $30 \mathrm{ug}$, respectively) altered the latency to enter the dark side in the STPA. However, both IP and ICV administration of Bay 60-7550 significantly enhanced memory in the ORT. These results suggest that PDE2 inhibition does not significantly mediate antidepressant- or 
anxiolytic-like behaviors in mice, regardless of the duration of treatment or route of administration. PDE2 inhibition does appear to enhance memory, as seen in the ORT. While memory was not enhanced in the STPA, the use of a stressful or fearful element, the foot shock, is certainly testing a different domain of memory (fear memory vs object memory) and therefore, may be altering the underlying molecular cascades responsible for mediating learning and/or memory. One explanation could be that the inclusion of a stressor may be shifting the brain regions responsible for learning and memory to those that rely less on PDE2. Alternatively, it is possible that the critical periods for PDE2 inhibition are shifted for fear memory. Bay $60-7550$ was only given 30 min prior to training. It is possible that PDE2 inhibition is more important during consolidation or recall events, rather than acquisition.

While a few studies have previously shown Bay 60-7550 to be protective against stress-induced mood and cognitive changes, little has been done to investigate the effect of PDE2 inhibition on non-stress related anxiety and depressive behaviors in mice (Ding et al., 2014; Masood et al., 2009, 2008; Xu et al., 2015, 2011). Early studies showed that Bay 60-7550 was protective against increases in anxiety from chemically induced oxidative stress (Masood et al., 2008). Additionally, Bay 60-7550 protected against physical stress-induced anxiety- and depression-like effects, including daily restraint stress and chronic unpredictable stress (Ding et al., 2014; Xu et al., 2013). These studies also provided evidence that the behavioral and neuronal changes seen were mediated via cGMP/PKG pathway. They were able to block the protective effects of PDE2 inhibition by pretreating with a PKG inhibitor, KT5823, but not a PKA inhibitor, H89. 
Based on these previous findings, it was hypothesized that PDE2 inhibition would lead to antidepressant- and anxiolytic-like effects in non-stressed mice. The FST and TST are reliable screens for antidepressant-like efficacy. Drugs that are known to have antidepressant properties in humans significantly increase immobility time in both of these tests. The EPM and HB are reliable screens for anxiolytic efficacy, also with high predictive validity. Drugs that have anxiolytic properties increase the entries/time spent in the open arm of the EPM and increase the number of dips and time dipping in the HB test. However, no significant change in behavior was observed in any of these tests.

From a signaling point of view, the lack of efficacy may arise from the low basal activity of cGMP often observed in neurons (Domek-Łopacińska and Strosznajder, 2010; Kawamoto et al., 2013; Masood et al., 2009, 2008). While active PDE2 does bind and inactivate both cAMP and cGMP with similar affinity, inactive PDE2 binds CGMP with a much higher affinity than cAMP, and requires the binding of cGMP to induce positive cooperativity. Therefore, if the concentration of cGMP is low under normal conditions, PDE2 will likely not be activated, and, consequently, inhibition of PDE2 would not affect cAMP signaling. On a behavioral level, this would mean that in an unstressed or unchallenged system, as was the case here, inhibition of PDE2 was ineffective due to the lack of an on switch, i.e., cGMP, for PDE2 in the first place. This means that stress may be altering the expression of cGMP, cAMP, or both.

Previous research has shown that following repeated stress, either restraint stress or unpredictable stress, results in increases in NOS-NO levels in numerous brain regions, including the cortex and hippocampus (Gao et al., 2014; Harooni et al., 2009; Hu et al., 2012; Zhou et al., 2011). It is likely these increases in NO lead to increases in 
cGMP levels as well (Meyerhoff et al., 1985; Southam and Garthwaite, 1993). At the same time, research has also showed cAMP-PKA-pCREB to be significantly decreased following chronic stress (Hill et al., 2012; Li et al., 2009). Though the exact mechanism has yet to be fully understood, when considering how a PDE2 inhibitor may be able to exert antidepressant/anxiolytic effects following chronic stress, but have limited to no efficacy in a non-stressed system, it's important to take this cGMP/cAMP imbalance into consideration. Perhaps, the elevated cGMP leads to increased activation of PDE2, which would further decrease cAMP levels. While increasing cGMP is often associated with anxiety and depression (though studies are somewhat mixed), using a PDE2 inhibitor would prevent any further degradation of cAMP levels, potentially allowing cAMP to accumulate and restore a balance. Alternatively, in a non-stressed system, low levels of cGMP and perhaps normal levels of cAMP would not afford PDE2 inhibitors the opportunity to have a meaningful effect.

While the PDE2 inhibitor Bay 60-7550 did not appear to have antidepressant- or anxiolytic-like effects here, in terms of a clinical application, this may actually be a positive. Drugs that do not affect baseline behavior, but instead are protective against stress-induced changes in mood, may actually be preferable to an intervention that alters mood or cognition from baseline. Anxiety and depression might represent, in part, pathologies that result from flawed mechanisms for coping with stress. Of course, our understanding of the mechanism differential efficacy in stressed vs. nonstressed situations is limited and further research is necessary before any possible clinical application could be explored. 


\subsection{Contributions}

Lindsay Lueptow performed all behavioral testing, surgical procedures, and drug administrations. Special thanks to members of the Zhang and O'Donnell labs for assistance during surgeries. Dr. James O'Donnell and Lindsay Lueptow were involved in the design of all experiments. 


\section{CHAPTER 3}

\section{Cyclic GMP-Mediated Memory Enhancement in the Object}

Recognition Test by Inhibitors of Phosphodiesterase-2 in Mice 
The following is reprinted from Lueptow, L.M., Zhan, C.-G., O'Donnell, J.M., 2015. Cyclic GMP-mediated memory enhancement in the object recognition test by inhibitors of phosphodiesterase-2 in mice. Psychopharmacology (Berl).

doi:10.1007/s00213-015-4129-1., with kind permission from Springer Science and Business Media

\subsection{Introduction}

Second messenger cyclic nucleotides, 3'5'-cyclic adenosine monophosphate (cAMP) and 3'5'-cyclic guanosine monophosphate (cGMP), are important mediators of learning and memory in a variety of species (Beavo and Brunton, 2002; Bollen et al., 2014; Bourtchuladze et al., 1994; Castellucci et al., 1980; Greengard, 1976). They are expressed throughout the brain and involved in the propagation of numerous signaling cascades, and therefore, require tight regulation (Beavo and Brunton, 2002). One mechanism for this is the off switch, i.e., the cyclic nucleotide phosphodiesterase(PDE) catalyzed hydrolysis of the cyclic nucleotide 3'-phosphodiester bond resulting in the inactive 5'-monophosphate forms. As a superfamily of 11 different PDEs, with over 100 splice variants differentially expressed throughout the brain, these enzymes are able to exert tight, selective control over cyclic nucleotide signaling.

Phosphodiesterase-2 (PDE2), which catalyzes the hydrolysis of both cAMP and cGMP, is expressed in forebrain regions of the brain, including the cerebral cortex and hippocampus, regions known to be involved in learning and memory, as well as in peripheral organs (Stephenson et al., 2009; Van Staveren et al., 2003). The expression pattern of PDE2 in the brain suggests it as a prime target for the 
development of cognitive enhancing drugs for variety of diseases such as age-related cognitive decline, vascular dementia, or Alzheimer's disease.

While the cellular cascades responsible for mediating each of the phases involved in learning and memory have yet to be fully elucidated, increases in cAMP, cGMP, or some combination of both, are known to play roles. Activation of adenylyl cyclase increases production of cAMP, leading to activation of cAMP-dependent protein kinase (PKA) and subsequent phosphorylation and activation of the transcription factor cAMP-response-element-binding protein (CREB), which in turn initiates the production of other growth factors and cytoskeletal proteins necessary for memory stabilization. Similarly, activation of nitric oxide synthase (NOS) increases production of nitric oxide (NO), which, in turn, activates soluble guanylyl cyclase (sGC) and increases production of cGMP. This leads to activation of cGMP-dependent protein kinase (PKG), which is also able to phosphorylate and activate CREB. Importantly, both cAMP and cGMP are effectors for NMDA receptor-mediated signaling, which is important in the regulation of learning and memory; PDE2 is a component of this signaling pathway as a regulator of cGMP (Suvarna and O'Donnell, 2002).

Memory-enhancing effects following increases in either cAMP or cGMP are time-dependent and vary depending on tasks and brain regions involved (Bernabeu et al., 1996; Bollen et al., 2014; Bourtchouladze et al., 1998; Lee et al., 2005; Nonaka et al., 2014). Inhibition of PDE2 may lead to increases in either cAMP, cGMP, or both. Therefore, it is important to not only understand the role of PDE2 inhibition during different phases of memory formation and recall, but also to develop a better 
understanding of the underlying pathways that are involved in PDE2 inhibitor-induced changes in memory.

The object recognition test (ORT) is a simple and efficient means for evaluation of various stages of memory (i.e., acquisition, consolidation, and recall). As compared to other rodent memory tests, the ORT is able to assess short- and long-term memory without stressful training or reinforcement conditions or a prolonged training schedule (Ennaceur and Delacour, 1988; Leger et al., 2013). Furthermore, the ORT assesses mouse memory under more natural conditions, exploiting the mouse's innate tendency to explore novelty. Previous research has shown that PDE2 inhibition during early consolidation (i.e., 0 - 3 hrs after training) significantly enhances object memory in rats (Boess et al., 2004; Bollen et al., 2014; Reneerkens et al., 2013a; Rutten et al., 2009). However, this effect was demonstrated in rats that were socially isolated, which is known to result in persistent changes in behavioral and biochemical states, including hyper-reactivity to novel environments and altered behavioral responses to psychoactive drugs (Bianchi et al., 2006; Douglas et al., 2003; Hall, 1998; Lapiz et al., 2003; van Goethem et al., 2012). Additionally, this research has focused on early consolidation mechanisms and has been limited to investigation of the role of hippocampus, which is not considered the primary locus of memory processing in the ORT (Balderas et al., 2013; Bollen et al., 2014; Brown et al., 2012; Dere et al., 2007; Prickaerts et al., 2002; Rutten et al., 2007; Winters et al., 2008).

The present study examined the effects of PDE2 inhibition on behavior of mice in the ORT, assessing the extent to which effects depend on the phase of memory, i.e., acquisition, consolidation, and recall. Further, since previous work has demonstrated 
the importance of the NOS/sGC/cGMP/PKG pathway in effects of PDE2 inhibition, the effects of inhibitors of this pathway on PDE2 inhibitor-mediated enhancement of memory were determined. Finally, evidence for the ability of behaviorally relevant doses of a PDE2 inhibitor to activate relevant signaling in rhinal cortex was obtained by quantifying phosphorylation of CREB (Ser-133) and vasodilator-stimulated phosphoprotein (VASP; Ser-239).

\subsection{Materials and Methods}

\subsubsection{Animals}

Male ICR mice (Harlan, Indianapolis, IN, USA) weighing 25-35 g (6-8 weeks old) were housed 5 per cage in standard polycarbonate cages, with food and water available ad libitum. Mice were maintained on a $12 \mathrm{hr}$ light-dark cycle (lights on at 06:00 h) with constant temperature $\left(22 \pm 2{ }^{\circ} \mathrm{C}\right)$ and humidity $(55 \pm 10 \%)$. Animals were randomly assigned to experimental conditions, with each animal being used only once for each behavioral test to prevent habituation and crossover testing effects. All mice were acclimated to the testing room and handled daily for 5-7 days prior to testing. All animal procedures in this study were reviewed and approved by the Animal Care and Use Committee of West Virginia University

\subsubsection{Drugs and Treatments}

The PDE2 inhibitors Bay 60-7550 (Caymen Chemical, Ann Arbor, MI) and ND7001 (synthesized by Chang-Guo Zhan, University of Kentucky) were dissolved in $5 \%$ ethanol, $10 \%$ Kolliphor (Sigma Chemicals, St. Louis, MO), 85\% saline. Bay $60-$ 7550 has a Ki of about $4 \mathrm{nM}$ and is 50 fold selective for PDE2 over PDE1, and 100 fold or more selective over other PDEs (Boess et al., 2004; Masood et al., 2009). ND7001 has a Ki of $114 \mathrm{nM}$ and is 100 fold selective for PDE2 over other PDEs (Masood et al., 
2009). The sGC inhibitor ODQ (1H-[1,2,4]oxadiazolo[4,3-a]quinoxalin-1-one), PKA inhibitor H-89 (N-[2-[[3-(4-bromophenyl)-2-propen-1-yl]amino]ethyl]5isoquinolinesulfonamide) \& PKG inhibitor KT5823 (2,3,9,10,11,12-hexahydro-10Rmethoxy-2,9-dimethyl-1-oxo-9S,12R-epoxy-1H-diindolo[1,2,3-fg:3',2',1'-kl]pyrrolo[3,4i] $[1,6]$ benzodiazocine-10-carboxylic acid, methyl ester; Caymen Chemical, Ann Arbor, MI) were dissolved in 25\% DMSO, 75\% saline. The NOS inhibitor L-NAME (N5[imino(nitroamino)methyl]-L-ornithine, methyl ester, monohydrochloride; Caymen Chemical, Ann Arbor, MI) was dissolved in saline. Drug doses were selected based on effective doses used previously in the literature (Almeida et al., 2006; Chien et al., 2005; Chijiwa et al., 1990; Cunha et al., 2014; Lee et al., 2003; Wu et al., 2006; Xu et al., 2015, 2013). All drugs were given IP, with the exception of H-89 and KT5823, which were administered into the lateral ventricle via implanted cannulae. For control treatments, mice were administered the corresponding drug vehicle.

\subsubsection{Cannula Surgery and ICV drug administration}

Mice were anesthetized with ketamine $(100 \mathrm{mg} / \mathrm{kg})$ and xylazine $(8 \mathrm{mg} / \mathrm{kg})$ and placed in a stereotaxic apparatus (Stoelting Instruments, Wood Dale, IL). A 26 gauge guide cannula (Plastics One, Roanoke, VA) was implanted unilaterally (AP -0.2 mm from Bregma, $\mathrm{ML}+1 \mathrm{~mm}$ from the midline, DV $-2 \mathrm{~mm}$ from skull surface using the atlas of Paxinos and Franklin (Paxinos and Franklin, 2008) and secured with a single skull screw and cranioplastic cement. Mice were allowed to recover for 7 days before testing.

On the day of training in the ORT, a 33 gauge injection cannula was inserted, and mice were administered vehicle, $\mathrm{H} 89$ or KT5823 using a syringe pump (KD 
Scientific, Holliston, MA) dispensing 5 ul over 5 min. The guide cannula was left in place for at least one additional min to allow diffusion and to minimize backflow into the guide cannula. At the end of the experiment, mice were injected with dye to confirm placement of the cannula; mice with incorrect cannula placement were excluded from analysis.

\subsubsection{Object Recognition Test}

Behavior in the Object Recognition Test (ORT) was assessed as previously described (Ennaceur and Delacour, 1988; Leger et al., 2013). As shown in Figure 2.1a, mice were trained and tested over 3 days. On the first day, mice were acclimated to the empty, square open field chamber for 5 min (T0: habituation). The next day, mice were placed in the field with 2 identical objects and allowed to explore for 10 min (T1: training). Twenty-four hrs later, mice were placed back into the open field with one familiar object (i.e., object used in T1) and one novel object and allowed to explore for 10 min (T2: testing). All objects used were of a size appropriate for exploration by mice (Fig 2.1b) and were placed at a diagonal in the box. Objects and object locations were counterbalanced for novel vs familiar use and orientation in the box. Between trials, the apparatus and each object was carefully cleaned with $95 \%$ ethanol to remove odor cues. All testing was done under low light conditions. Both T1 and T2 sessions were video recorded and time spent exploring the objects was later scored by an experimenter blinded to treatment conditions. For the testing phase, only the first $5 \mathrm{~min}$ of exploration were scored, or until the mouse reached the minimum exploration time. Mice that did not reach a minimum exploration time of 20 seconds during T1 or T2 were excluded from analysis. The discrimination index (DI) was calculated for each 
mouse during T2: $[\mathrm{DI}=$ (novel object exploration time - familiar object exploration time $) /($ novel object exploration time + familiar object exploration time)].

For dose-response analysis, individual cohorts of mice were given IP injections 30 min prior to training (T1) and memory was tested $24 \mathrm{hrs}$ later (T2). For time-course analysis, individual cohorts of mice were given IP injections of vehicle or Bay 60-7550 (3 mg/kg): $30,60,90,120$, or 180 min before training to asses memory acquisition; 0 , 1 or $3 \mathrm{hrs}$ after training to assess memory consolidation; or 30 min prior to testing to assess memory recall. Mice were tested $24 \mathrm{hrs}$ after T1.

For pathway inhibition studies, individual cohorts of mice were given an IP injection of the NOS inhibitor L-NAME $(20 \mathrm{mg} / \mathrm{kg})$, the sGC inhibitor ODQ $(20 \mathrm{mg} / \mathrm{kg})$, or corresponding vehicle, or an ICV injection of the PKG inhibitor KT5823 (2.5 ug), or the PKA inhibitor $\mathrm{H}-89$ (1 ug), or corresponding vehicle, 30 min prior to injection of vehicle, Bay 60-7550 (3 mg/kg), or ND7001 (3 mg/kg), which were administered immediately after T1. Mice were tested 24 hrs after T1.

\subsubsection{Immunoblot analysis}

Thirty minutes following an IP injection of vehicle or Bay 60-7550 (3 mg/kg), mice were decapitated, and brains were removed and quickly dissected on ice. Using a $1 \mathrm{~mm}$ coronal brain matrix (Kent Scientific, Torrington, Connecticut), the caudal most 2 $\mathrm{mm}$ of cortex were cut with a razor blade. From these coronal sections, the ventral portion of the tissue, roughly corresponding to the rhinal cortical areas, was dissected out. These boundaries were based on the previous literature and on the brain atlas of Paxinos and Franklin (Liu et al., 2003; Paxinos and Franklin, 2008; Suzuki, 1996; van Groen, 2001; Wan et al., 1999). Both whole hippocampi were then removed. 
Remaining subcortical structures were discarded and remaining cortex was used for analysis. Aliquots of supernatant from the hippocampus, rhinal cortex, and remaining cortex (70 ug/well) were separated using $4-12 \%$ NuPage gels, as previously described (Ding et al., 2014; Masood et al., 2008; Xu et al., 2013). Prestained protein molecular weight markers were run in parallel according to the specific molecular weight of the detected protein. Proteins from the gel were then transferred to PVDF $(0.25 \mathrm{uM}$ for pCREB \& pVASP; 0.44 uM for PDE2), and incubated with primary antibodies overnight at $4^{\circ} \mathrm{C}$. After 3 washes with PBST, blots were incubated with secondary goat andmouse or goat anti-rabbit antibodies (LI-COR Biosciences, Lincoln, NE) for $1 \mathrm{hr}$ at room temperature. Bands were detected using LI-COR infrared imaging system. Labeled protein bands were compared within individual blots and normalized as a fraction of control density for analysis between blots.

\subsubsection{Statistical Analysis}

Data are expressed as means \pm S.E.M. Comparisons among groups were first analyzed via one-way analysis of variance (ANOVA) followed by Bonferroni's multiple comparisons tests. A p value of less than 0.05 was considered significant. For analysis of the effects of PDE2 inhibitors on different learning and memory phases (acquisition, consolidation, or recall), each phase was analyzed using two-way ANOVA followed by Bonferroni's multiple comparisons tests, with the exception of recall, which only had one time point and was analyzed with an unpaired t-test. Group sizes varied based on exclusion criteria for the ORT. 


\subsection{Results}

\subsubsection{Dose-dependent memory enhancement using PDE2 inhibitors}

Both phosphodiesterase inhibitors Bay $60-7550(\mathrm{~F}(5,81)=7.15$, $\mathrm{P}<0.0001$; Fig 3.1a) and ND7001 $(F(5,75)=2.71, p<0.05$; Fig 3.1b) enhanced memory in the ORT in a dose-dependent manner. When given $30 \mathrm{~min}$ prior to training, $0.5 \mathrm{mg} / \mathrm{kg}(\mathrm{p}<0.05), 1$ $\mathrm{mg} / \mathrm{kg}(\mathrm{p}<0.001), 3 \mathrm{mg} / \mathrm{kg}(\mathrm{p}<0.0001)$, and $6 \mathrm{mg} / \mathrm{kg}(\mathrm{p}<0.001)$, but not $0.1 \mathrm{mg} / \mathrm{kg}$, of Bay 60-7550 significantly enhanced memory in the ORT when tested $24 \mathrm{hrs}$ after training (Fig 3.2a). For ND7001, $1 \mathrm{mg} / \mathrm{kg}(p=0.05), 3 \mathrm{mg} / \mathrm{kg}(p<0.05)$, and $6 \mathrm{mg} / \mathrm{kg}$ $(\mathrm{p}=0.05)$, but not 0.1 or $0.5, \mathrm{mg} / \mathrm{kg}$, given 30 min prior to training significantly enhanced memory in the ORT (Fig 3.1b). Because the most robust effects were at $3 \mathrm{mg} / \mathrm{kg}$ for both Bay60-7550 and ND7001, this dose was used for the subsequent experiments

a)

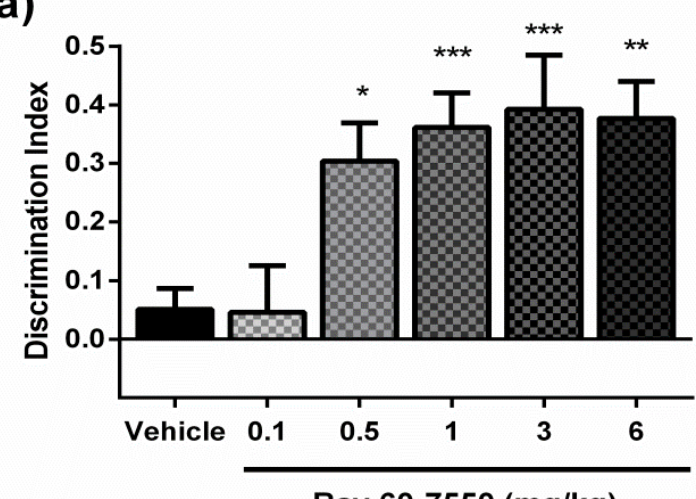

b)

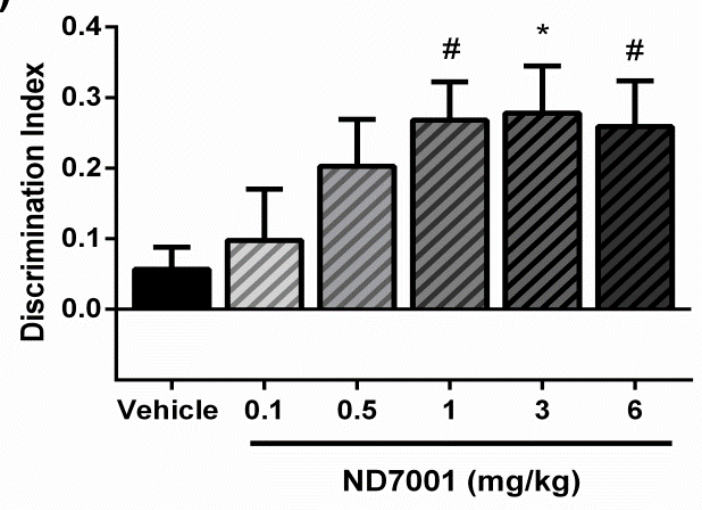

Figure 3.1 PDE2 inhibitors enhanced memory in the ORT. a, Bay 60-7550, when given 30 min prior to training, improved memory in a dose-dependent manner, as seen by an increase in the discrimination index (see Methods). b, ND7001, when given 30 min prior to training, improved memory in a dose-dependent manner, as seen by an increase in the discrimination index. Bars represent means \pm S.E.M.; $n=10-18$ per group. $\# p=0.05,{ }^{*} p<0.05,{ }^{* *} p<0.01,{ }^{* * *} p<0.001$ vs vehicle 


\subsubsection{PDE2 inhibition during acquisition, early consolidation, or recall}

\section{significantly enhances memory in the ORT.}

In order to understand the role of PDE2 at various phases of learning and memory, the PDE2 inhibitor Bay 60-7550 (3 mg/kg) was administered 30, 60, 90, or 120 min prior to training (acquisition), 0, 1, or $3 \mathrm{hrs}$ after training (consolidation), or immediately before testing (recall).

Bay 60-7550 significantly

enhanced memory when

administered during acquisition

(main effect, time of injection, $\mathrm{F}(4$, $132)=2.50, p<0.05 ;$ main effect,

treatment, $F(1,132)=14.50$, $p<0.001$; no interaction, time of injection $x$ treatment, $F(4,132)=$ $2.10, n s$ ), early consolidation (no main effect, time of injection, $\mathrm{F}(2$, $83)=1.74$, ns; main effect, treatment, $F(1,83)=6.22$, $p<0.05$; no interaction, time of injection $\mathrm{x}$ treatment, $\mathrm{F}(2,83)=$ $2.86, n s)$ or recall $(p<0.05)$. Mice treated with Bay 60-7550 30 min prior to training had significantly

a)

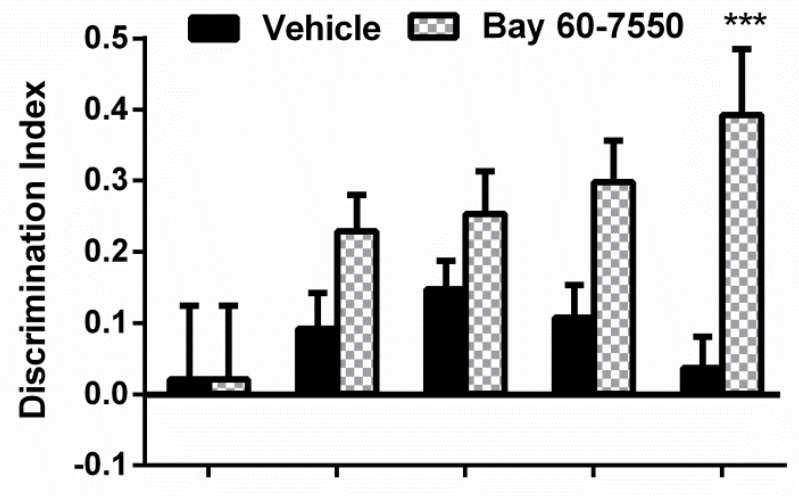

Injection T1: $-180 \mathrm{~min}-120 \mathrm{~min}-90 \mathrm{~min}-60 \mathrm{~min}-30 \mathrm{~min}$

b)

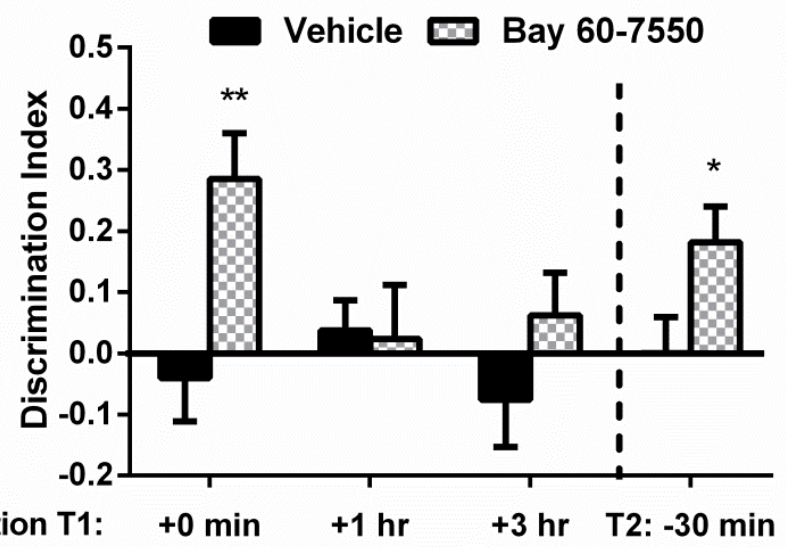

Figure 3.2 PDE2 inhibition during acquisition, early consolidation, or recall significantly enhanced memory in the ORT. a, Bay 60-7550 (3 $\mathrm{mg} / \mathrm{kg}$ ) significantly enhanced memory when given 30 min prior to training (acquisition). b. Bay 60-7550 (3 mg/kg) given immediately after training (consolidation) or $30 \mathrm{~min}$ prior to testing (recall) significantly enhanced memory, as seen by an increase in the discrimination index. Bars represent mean \pm S.E.M.; $n=10-18$ per group. 
enhanced memory in the ORT ( $p<0.001$; Fig 3.2a). Mice treated with Bay 60-7550 immediately after training, but not 1 or 3 hrs after training, had significantly enhanced memory in the ORT ( $p<0.01$, Fig 3.2b), as did mice treated with Bay 60-7550 30 min prior to recall testing $(p<0.05$; Fig 3.2b).

\subsubsection{Enhancement of memory in the ORT following PDE2 inhibition during early consolidation is mediated via NOS/cGMP/PKG pathway.}

To parse the roles of the cAMP vs cGMP pathways in Bay 60-7550 and ND7001 mediated memory enhancement during early consolidation, mice were pre-treated with pathway inhibitors in an attempt to block the effects of PDE2 inhibition. Each cohort of mice was pre-treated with one of the pathway inhibitors (or corresponding vehicle) 30 min prior to Bay 60-7550 (3 mg/kg) or ND7001 (3 mg/kg), which were given immediately after training (T1). Alone, the NOS inhibitor L-NAME $(20 \mathrm{mg} / \mathrm{kg})$ had no effect on memory, but blocked the effects of both Bay 60-7550 and ND7001 (F $(5,68)$ $=10.09, \mathrm{P}<0.0001$; Fig 3.3a). The sGC inhibitor ODQ (20 mg/kg), given $30 \mathrm{~min}$ prior to Bay 60-7550, had no effect alone, but blocked the memory-enhancing effects of both Bay 60-7550 and ND7001 $(F(5,67)=6.26, P<0.0001$; Fig 3.3b).

Next, the downstream actions of the cyclic nucleotides were examined by assessing the roles of PKA and PKG in PDE2 inhibitor-enhanced memory in the ORT. Mice were administered either the PKG inhibitor KT5823 (2.5 ug) or the PKA inhibitor $\mathrm{H}-89$ (1 ug). As compared to vehicle treated mice, KT5823 had no effect alone, but when given 30 min prior to Bay 60-7550 or ND7001, it significantly blocked the memory-enhancing effects of both PDE2 inhibitors $(F(5,74)=5.88, P<0.001$; Fig 3.3c). By comparison, the PKA inhibitor $\mathrm{H}-89$ did not block the effects of Bay $60-7550$ 
a)

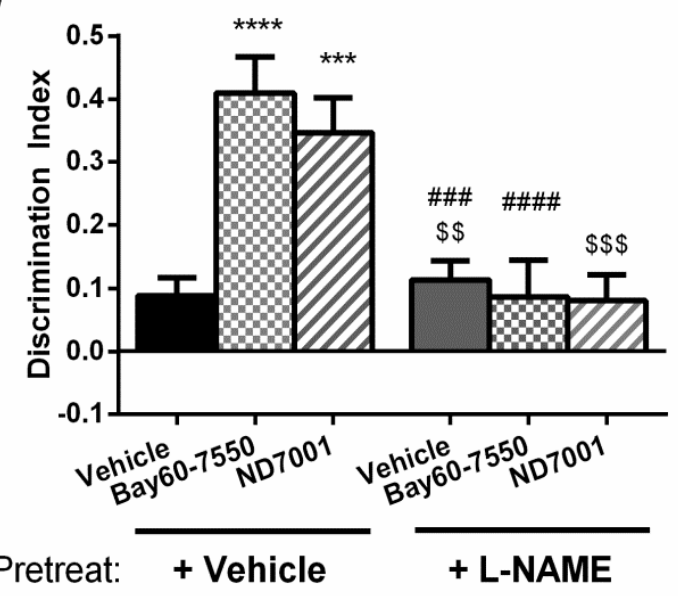

c)

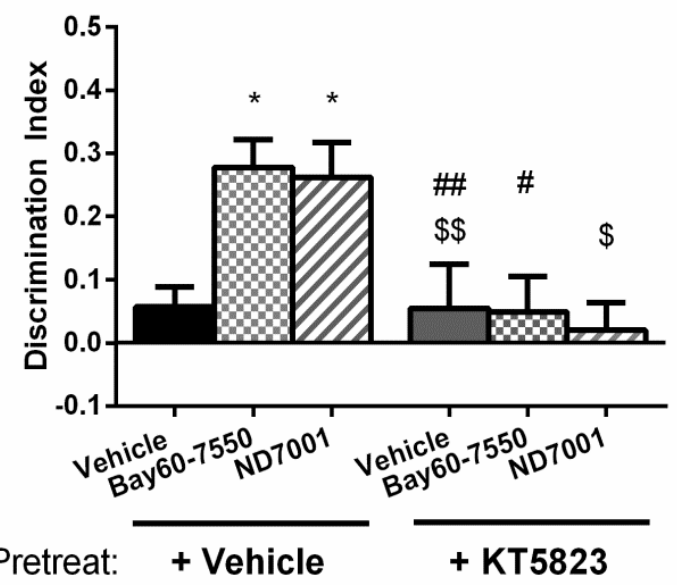

b)

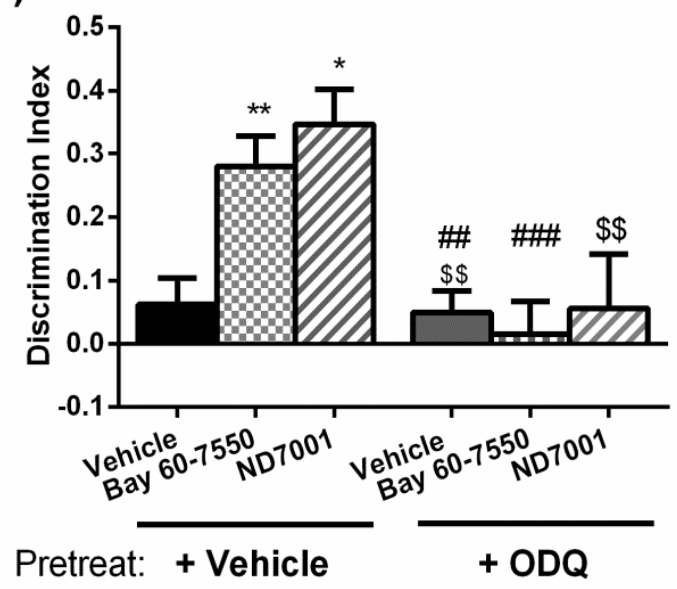

d)

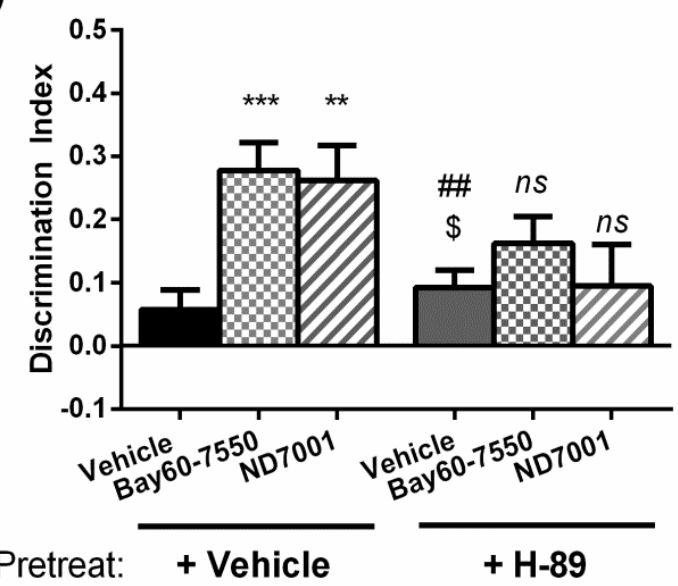

Figure 3.3 Inhibitors of the NOS/sGC/cGMP/PKG pathway blocked the memory-enhancing effects of PDE2 inhibition in the ORT. Mice were pretreated with an inhibitor of the CAMP or cGMP pathway $30 \mathrm{~min}$ prior to Bay 60-7550 (3 mg/kg) or ND7001 (3mg/kg), which were given immediately after training. For all panels, pre-treatment with vehicle and subsequent treatment with Bay 60-7550 or ND7001 significantly enhanced memory, as seen by an increase in the discrimination index. a, Pretreatment with the NOS inhibitor L-NAME (20 mg/kg) blocked the memory-enhancing effects of both Bay 60-7550 and ND7001. b. Pretreatment with the sGC inhibitor ODQ $(20 \mathrm{mg} / \mathrm{kg})$ blocked the memory-enhancing effects of both Bay 60-7550 and ND7001 c, Administration of PKG inhibitor KT5823 (2.5 ug) into the lateral ventricles also blocked the memory-enhancing of both PDE inhibitors . d, Administration of PKA inhibitor $\mathrm{H}-89$ (1 ug) into the lateral ventricles did not block the memory-enhancing effects of Bay 60-7550 or ND7001. $n=10-15$ per group. Bars represent mean \pm S.E.M.

${ }^{*} p<0.05,{ }^{* *} p<0.01,{ }^{* * *} p<0.001,{ }^{* * *} p<0.0001$ vs Vehicle pretreated, vehicle treated;

$\# p<0.05, \# \# p<0.01, \# \#$, 00.001 vs vehicle pretreated, Bay $60-7550$ treated;

$\$ p<0.05, \$ \$ p<0.01, \$ \$ \$ p<0.001$ vs vehicle pretreated, ND7001 treated.

ns vs vehicle pretreated, Bay 60-7550 or ND7001 treated.

$(p=0.42)$ or ND7001 ( $p=0.07$; Fig 3.3d) on memory in the ORT. It is important to note

that the lack of an effect of $\mathrm{H}-89$ does not rule out the possibility of a false-negative

finding. However, the dose of $\mathrm{H}-89$ used here has been shown to effectively inhibit 
PKA in vivo in numerous previous studies (Almeida et al., 2006; Cunha et al., 2014;

Wu et al., 2006; Xu et al., 2015, 2013).

\subsubsection{Bay 60-7550 enhanced CREB and VASP phosphorylation}

a)

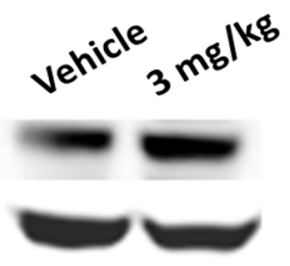

Rhinal Cortices

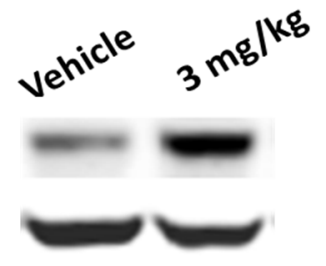

Cortex

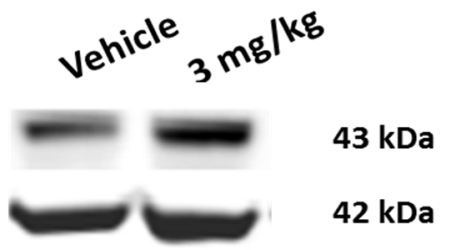

Hippocampus b)

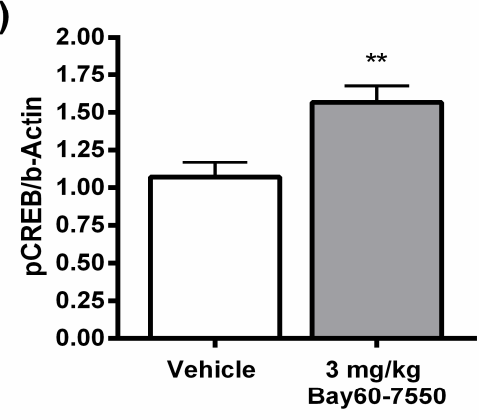

c)

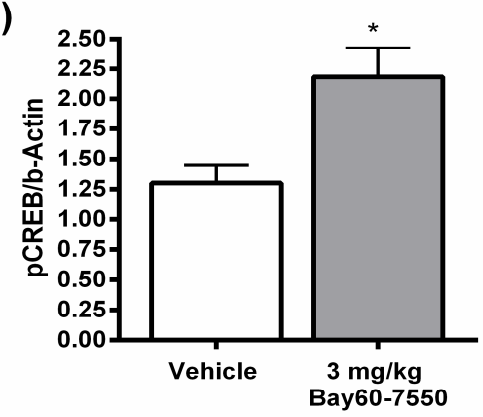

d)

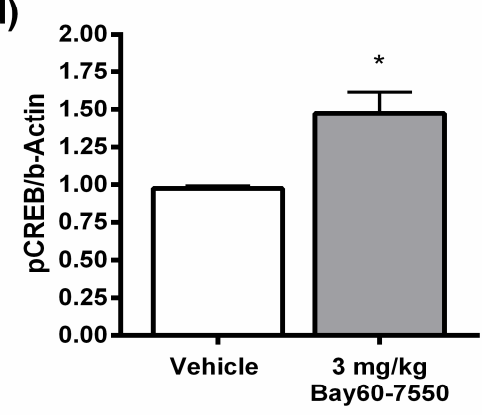

Figure 3.4 Bay 60-7550 significantly enhanced phosphorylation of CREB at Ser-133. Mice were treated with either vehicle or Bay 60-7550 (3 mg/kg) and sacrificed $30 \mathrm{~min}$ later. Brains were dissected into rhinal cortical areas, hippocampus, and remaining cortex. a, representative blot of each of the 3 brain regions probed. $b, 3 \mathrm{mg} / \mathrm{kg}$ Bay 60-7550 significantly enhanced pCREB levels in the rhinal cortex, $c$, the remaining cortex, $d$, and the hippocampus.

${ }^{*} p<0.05,{ }^{* *} p<0.01$ vs vehicle

Both PKA and PKG phosphorylate and activate the transcription factor CREB at

Ser-133, a necessary step in activation of the transcription machinery shown to be involved in rodent memory. Since memory in the ORT is thought to be mediated primarily by the rhinal cortex and partially by the hippocampus, these regions were examined for changes in the phosphorylation state of CREB ( $p C R E B$ ) following Bay 60-7550 administration (Fig 3.4a). Bay 60-7550 (3 mg/kg) significantly increased CREB phosphorylation at Ser-133 in the rhinal cortices ( $p<0.01$; Fig $3.4 b)$, as well as the cortex and hippocampus ( $<<0.05$ for both; Fig $3.4 c \& d)$. 
The NOS-cGMP-PKG pathway inhibitors, L-NAME, ODQ and KT5823, were able to block the memory-enhancing effects of PDE2 inhibition during early consolidation, suggesting that these effects are mediated via this pathway. To test the activity of PKG specifically, changes in phosphorylation of VASP, a target of PKG at Ser-239, were probed in all three brain regions (Fig 3.5a). The standard dose of Bay $60-7550(3 \mathrm{mg} / \mathrm{kg})$ increased pVASP in the rhinal cortex $(p<0.001$; Fig $3.5 \mathrm{~b})$, the remaining cortex ( $p<0.05$; Fig 3.5c), and the hippocampus ( $<<0.01$; Fig $3.5 d)$.

a)

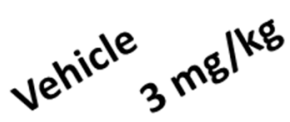

pVASP (Ser239)

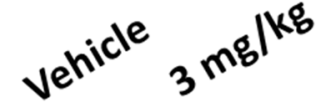

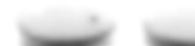

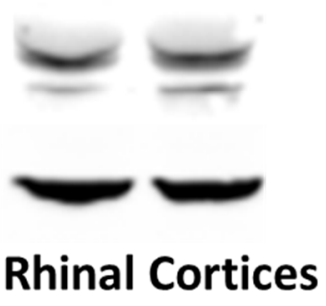

b-Actin
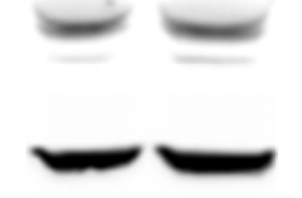

Cortex

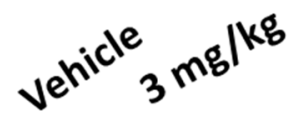

$47 \mathrm{kDa}$

$42 \mathrm{kDa}$ b)

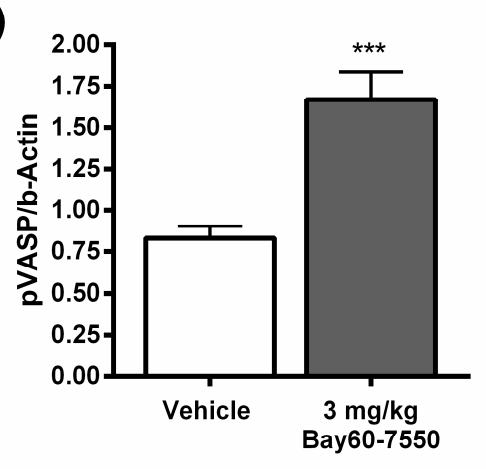

c)

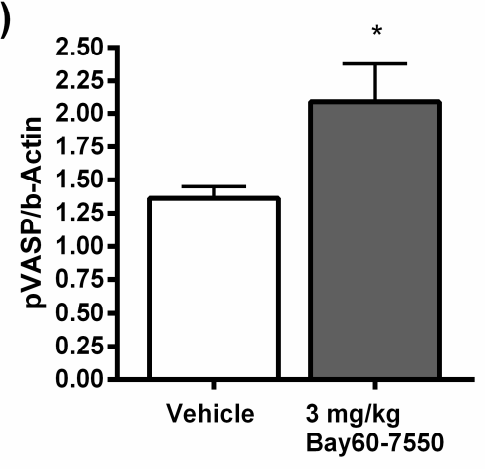

d)

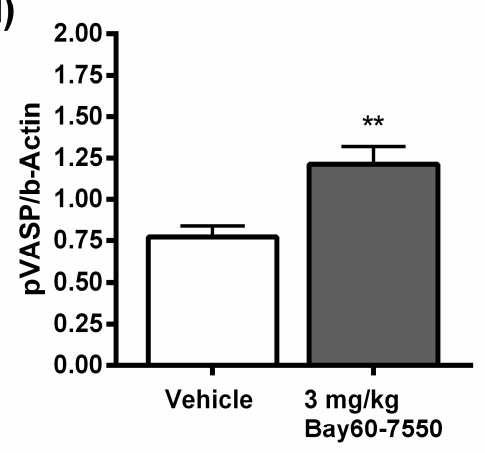

Figure 3.5 Bay 60-7550 significantly enhanced phosphorylation of VASP at Ser-239. Mice were treated with either vehicle or Bay 60-7550 (3 mg/kg) and sacrificed 30 min later. Brains were dissected into rhinal cortical areas, hippocampus, and remaining cortex. a, representative blot of each of the 3 brain regions. $b, 3 \mathrm{mg} / \mathrm{kg}$ of Bay 60-7550 significantly enhanced pVASP levels in the rhinal cortex, $c$, the remaining cortex, $d$, and the hippocampus. ${ }^{*} p<0.05,{ }^{* *} p<0.01,{ }^{* * *} p<0.001$ vs vehicle

\subsection{Discussion}

The PDE2 inhibitors Bay 60-7550 and ND7001, when administered 30 min prior to training, enhanced memory in the ORT in a dose-dependent manner in mice. Bay 
60-7550 also enhanced memory when administered immediately after training or prior to recall testing. This suggests that PDE2 is involved in signaling pathways that regulate memory during its acquisition, early consolidation, and recall. The early consolidation effects of PDE2 inhibition appear to be mediated via the NO/cGMP/PKG signaling cascade, since they were blocked by inhibitors of NOS, sGC, and PKG. We were able to confirm these findings with a second PDE2 inhibitor, ND7001, whose memory-enhancing effects were also blocked by inhibitors of the NO/cGMP/PKG pathway. These results are consistent with the current literature, which has shown similar effects of Bay 60-7550 during early consolidation (i.e., immediately after training) in the ORT in rats (Boess et al., 2004; Domek-Łopacińska and Strosznajder, 2008; Reneerkens et al., 2013a; Rutten et al., 2009, 2007; van Donkelaar et al., 2008). Additionally, we found that the PDE2 inhibitor Bay 60-7550 increased the phosphorylation of the transcription factor CREB at Ser-133 and VASP at Ser-239, both targets of PKG (Carlezon et al., 2005; Johannessen and Moens, 2007). While this does not preclude a role for CAMP/PKA in PDE2 inhibitor-enhanced learning and memory for the ORT, due to the fact that both PKA and PKG are able to phosphorylate CREB at Ser-133, the ability of Bay $60-7550$ to enhance phosphorylation of VASP at Ser-239 indicates that behaviorally relevant doses of Bay 60-7550 increase cGMP signaling in relevant brain regions.

Using mice, we have replicated and extended what has previously been shown with Bay 60-7550 in the ORT for rats (Boess et al., 2004; Bollen et al., 2014; DomekŁopacińska and Strosznajder, 2008; Prickaerts et al., 2002; Rutten et al., 2007; Suvarna and O'Donnell, 2002; van Staveren WC et al., 2001; Xu et al., 2015). Bollen 
and coworkers showed that injecting a PKG inhibitor directly into CA1 of the hippocampus blocked the memory-enhancing effects of Bay 60-7550, while a PKA inhibitor did not (Bollen et al., 2014). We were able to replicate this with not only a PKG inhibitor, but also inhibitors of NOS and sGC, which are upstream of PKG; this is consistent with NOS/sGC/PKG mediation of anxiolytic effects of these PDE2 inhibitors (Masood et al., 2009). One major difference between our findings and previously published reports involves the time-course for Bay 60-7550. Rutten and coworkers found Bay $60-7550$ to significantly enhance memory when given 0 or 3 hrs after training (Rutten et al., 2007). However, we found that Bay-60-7550 enhanced memory when given up to $30 \mathrm{~min}$ prior to training, immediately after training, and 30 min prior to recall, but not $3 \mathrm{hrs}$ after training. At present, the reason for this difference is unknown, but may indicate a species difference or be due to methodological differences discussed below.

While our findings in mice largely agree with the previous literature, it is important to note critical methodological differences between previously published work regarding PDE2 and enhanced memory in the ORT and the present study. First, because published protocols for the ORT vary greatly, we have adapted our protocol from Leger and coworkers, who carefully analyzed a number of different parameters for the use of ORT in mice, including frequency and duration of habituation, training and testing, as well as the length of the inter-trial interval, inclusion criteria, and also object characteristics and other environmental conditions (Leger et al., 2013). Based on their optimization of experimental conditions, mice in the present study only received one habituation exposure (5 $\mathrm{min})$ and one training exposure (10 $\mathrm{min})$. We also set a 
minimum criterion of 20 seconds of exploration for both training and testing. Following this protocol, we are able to reduce the number of animals needed per group without loss of power or significance, as compared to the previously published work.

Additionally, in contrast to previously published work, we have used naïve animals in a between-subjects design to reduce habituation to the test environment, as well as eliminate any potential crossover effect from multiple ORT exposures.

Secondly, the bulk of the research regarding the role of PDE2 in memory in the ORT has been conducted in singly housed rats (Akkerman et al., 2014a; Boess et al., 2004; Bollen et al., 2014; Domek-Łopacińska and Strosznajder, 2008; Prickaerts et al., 2002; Reneerkens et al., 2013a; Rodefer et al., 2012; Rutten et al., 2009, 2007; van Donkelaar et al., 2008). While research into the effects of social isolation on rodent behavior has varied somewhat based on sex, strain, and duration of isolation, it has been shown to result in numerous behavioral, neurochemical, and neurophysiological changes, as well as differential responses to psychotropic drugs, and has been used as a model for various psychiatric disorders, including schizophrenia (Akkerman et al., 2014b; Bianchi et al., 2006; Douglas et al., 2003; Hall, 1998; Lapiz et al., 2003;

Thorsell et al., 2006; Weiss et al., 2004). Of particular note, social isolation in rats has been shown to result in a hyperactive state with increased novelty seeking and increases in exploration time during the ORT, which complicates the interpretation of both behavioral and biochemical outcomes following PDE2 inhibition in these rats (Bianchi et al., 2006; Douglas et al., 2003; Thorsell et al., 2006). Additionally, social isolation leads to increased levels of anxiety-like behavior and results in altered hippocampal organization and hypothalamic-pituitary-adrenal axis function (Bianchi et 
al., 2006; Weiss et al., 2004). These changes are important to note because PDE2 inhibition is protective against stress-induced anxiety- and depression-like behavior, as well as stress-induced deficits in learning and memory, further complicating the interpretation of results in socially isolated rats (Ding et al., 2014; Masood et al., 2009, 2008; Xu et al., 2015, 2013). Also, while mice and rats are often used interchangeably in behavioral research, it is possible that the lack of an effect of Bay $60-7550$ when given at $3 \mathrm{~h}$ may be due to differences in the consolidation windows for cAMP, as suggested by early work in a mouse hippocampal slice preparation by Bollen and colleagues (Bollen et al., 2015).

Finally, when investigating the role of PDE2 in memory in the ORT, it is important to consider the expression of not only PDE2 in various brain regions, but also the expression of NMDA-mediated second messengers that may be involved in memory enhancement. Because PDE2 is able to hydrolyze and inactivate both cAMP and cGMP, either one or both may be responsible for enhancing memory. In primary rat cerebral cortical and hippocampal neuronal cultures, PDE2 is the primary PDE responsible for catalyzing the hydrolysis of cGMP (Zhang et al., 2002). Accordingly, both our research and previously published reports suggest that, for early consolidation, the NOS/cGMP/PKG pathway is primarily responsible for mediating the changes in memory that result from PDE2 inhibition (Boess et al., 2004; Bollen et al., 2014; Masood et al., 2009; Prickaerts et al., 2002; Rutten et al., 2007; Suvarna and O'Donnell, 2002; van Staveren WC et al., 2001; Xu et al., 2013). Furthermore, the ORT is thought to be mainly mediated via rhinal cortical areas (e.g., entorhinal, perirhinal, \& postrhinal cortex) (Antunes and Biala, 2012; Brown et al., 2012; Dere et 
al., 2007; Seoane et al., 2012). When looking at the differential expression of NOS in the hippocampus vs rhinal cortical areas, the entorhinal, perirhinal, postrhinal cortices have significantly higher levels of NOS than either dorsal or ventral hippocampus (Liu et al., 2003). Conversely, arginase activity is significantly higher in hippocampal areas as compared to rhinal cortices. Because NO is synthesized by NOS from L-arginine, higher concentrations of arginase will result in less available L-arginine as a substrate for NOS. However, previous work investigating the potential underlying neural mechanisms for PDE2-enhanced memory in the ORT has focused on the role of the hippocampus, specifically, with minimal consideration for the rhinal cortical areas (Bollen et al., 2014; Prickaerts et al., 2002). In this study, we have taken a step back and addressed a more global approach, injecting the PKA and PKG inhibitors into the lateral ventricles for widespread inhibition, rather than focusing on a specific region. Futures studies involving the use of the ORT, however, should consider shifting focus to more rhinal cortical areas, rather than hippocampal areas. It should be noted, however, that the brain regions thought to mediate behavior in the ORT vary based on the testing parameters. The apparatus used for much of the previous work with PDE2 and memory is reported as having distinct wall features that likely confer spatial information, making the task more hippocampal-dependent (Akkerman et al., 2015, 2014a; Boess et al., 2004; Bollen et al., 2014; Prickaerts et al., 2002; Reneerkens et al., 2013a; Rutten et al., 2009, 2007, 2006; van Donkelaar et al., 2008) while our apparatus minimized any spatial cues, and therefore may not be as hippocampaldependent. 
While non-specific changes in cyclic nucleotide concentrations act globally in terms of enhancing downstream signaling, targeting individual PDE subtypes may allow for a more fine-tuned approach based on the expression pattern of the PDE of interest, as well as the subcellular co-expression of other PDE family members and pre-existing cyclic nucleotide tone. Not only do individual brain regions have distinct combinations of PDE expression, but also, on a subcellular level, PDEs are differentially trafficked and likely involved in different aspects of signal modulation based on the subcellular compartmentalization (Beavo and Brunton, 2002; Bolger et al., 1994; Keravis and Lugnier, 2012; Kleppisch, 2009; Omori and Kotera, 2007). Adding an additional layer of complexity is the difference in expression of associated signaling molecules, such as differential expression of NOS in rhinal cortical areas vs hippocampal areas (Domek-Łopacińska and Strosznajder, 2008). Furthering the understanding of PDE2 on a global level, as well as within individual brain regions and at a molecular level, will aid future drug discovery efforts for enhancing memory and treating cognitive impairment associated with illnesses such as Alzheimer's disease.

\subsection{Contributions}

Lindsay Lueptow performed all behavioral testing, surgical procedures, drug administrations, and immunoblot analysis. Special thanks to members of the Zhang and O'Donnell labs for assistance during surgeries. Dr. James O'Donnell and Lindsay Lueptow were involved in the design of all experiments. Dr. Chang-Guo Zhan synthesized and generously donated ND7001. 


\section{CHAPTER 4}

\section{Conclusions and Future Studies}




\subsection{Summary and Conclusions}

Analysis of the effects of PDE2 inhibition on memory in the ORT revealed a dose-dependent relationship between both Bay 60-7550 and ND7001 with enhanced memory. Time-course assessment showed Bay 60-7550 enhanced memory when given 30 min prior to training, immediately after training, or 30 min prior to recall, indicating PDE2 inhibition affects memory during acquisition, early consolidation and recall. Using pathway inhibitors of cAMP and cGMP to block the effects of Bay 60-7550 or ND7001 revealed NOS/sGC/cGMP/PKG pathway primarily mediates PDE2-inhibitor enhanced memory. Immunoblot analysis revealed increases in pCREB at Ser133 and pVASP at Ser239, both downstream of PKG, further indicating a role of the cGMP pathway in PDE2-inhibitor mediated memory enhancement (Lueptow et al., 2015). However, PDE2 did not appear to play a significant role in anxiety- or depression-like behavior in nonstressed mice. Neither acute nor repeated treatment with the PDE2 inhibitor Bay 607550 altered behavior in the EPM, HB, FST or TST. Additionally, route of administration was not a factor since neither centrally or peripherally administered Bay 60-7550 altered behavior in the EPM, TST, or STPA. However, peripheral and central Bay 60-7550 significantly enhanced memory in the ORT.

Previous research has focused on the role of PDE2 in various stressed systems, including chemically-induced stress, restraint stress, chronic unpredictable stress, and singly-housed rats (Boess et al., 2004; Bollen et al., 2014; Ding et al., 2014; DomekŁopacińska and Strosznajder, 2008; Masood et al., 2009, 2008; Redrobe et al., 2014; Reneerkens et al., 2013a; Rodefer et al., 2012; Rutten et al., 2009; Sierksma et al., 2012; van Donkelaar et al., 2008; Xu et al., 2015, 2013). In a non-stressed system, the 
role of PDE2 is less clear. As shown previously in singly-housed rats, the current findings confirm PDE2 inhibition does play a significant role in learning and memory in non-stressed mice. However, these results do not suggest a role for PDE2 in baseline anxiety- or depression-like behaviors. Only one study has been published suggesting a role of PDE2 in anxiety-like behaviors in non-stressed mice, using the EPM and HB (Masood et al., 2009). The reason for the discrepancy is unknown and therefore requires further analysis and replication.

\subsection{Future Directions}

While the present studies certainly extend the current understanding PDE2 in mood and cognitive disorders, much more needs to be done to fully understand the role of PDE2 in rodent behavior. While the attempts to replicate the role of PDE2 inhibition in non-stressed mice in regards to anxiety and depression was not successful, PDE2 inhibition significantly and repeatedly enhanced memory in the object recognition test (Lueptow et al., 2015). These studies laid the groundwork for delving more deeply into the underlying mechanisms of learning and memory in the object recognition test, specifically in regards to the role of PDE2 in these processes. Time-course analysis revealed PDE2 inhibition to be important during acquisition, early consolidation, and recall. While the pathway analysis indicated the NOS/cGMP/PKG pathway was important for mediating PDE2-inhibitor enhanced memory during early consolidation (when Bay 60-7550 or ND7001 were given immediately after training), the other timepoints need to be investigated further. As Bollen and coworkers showed in rats, cGMP/PKG was important for mediating the effects of PDE2 inhibition and memory in early consolidation (immediately after training) but not at later consolidation ( $3 \mathrm{hrs}$ after 
training); instead, PKA/cAMP appeared to be more important at the later consolidation time point (Bollen et al., 2014). Using the set-up described here, the same analysis needs to be extended to the other time-points that were found to be significant in this study (e.g., acquisition and recall).

Additionally, while the Prickaerts group found PDE2 inhibition to play a role during early and later consolidation ( 0 and 3 hrs after training), here we showed PDE2 inhibition is only important immediately after training, but not at $3 \mathrm{hrs}$ (Lueptow et al., 2015; Rutten et al., 2007). While this is likely due to methodological or species related differences (see chapter 3 discussion), it is also possible that the critical periods for cAMP vs cGMP consolidation differ between mice and rats. Therefore, future studies using our methods should also include additional time-points, both between 1 and 3 hrs after training, as well as beyond $3 \mathrm{hrs}$ after training, to fully elucidate the potential timecourse differences between the mouse and what has been reported in the rat. From there, pathway analysis using various pathway inhibitors can be done, similar to what was shown in these studies, to elucidate the precise role and timing of cAMP/PKA vs cGMP/PKG pathways.

Furthermore, the bulk of research on PDE2 inhibition in mood and cognition has been carried out at the behavioral level. Some biochemical analysis has shown changes in various downstream targets of PDE2, including pCREB and pVASP (Lueptow et al., 2015). However, once again, this was only at one time point (30 min post Bay $60-7550$ administration) with only one inhibitor at one dose $(3 \mathrm{mg} / \mathrm{kg})$. Additional time points, doses, and inhibitors, including ND7001 should be used to verify these results. Pathway inhibitors should also be used to verify the role of NOS/cGMP/PKG over CAMP/PKA, as 
seen in the behavioral assay. Additional targets may also be investigated, including changes in known downstream targets of CREB, such as BDNF, which has been positively correlated with learning and memory (Carlezon et al., 2005; Mayr and Montminy, 2001). Other molecules known to target and phosphorylate CREB should also be tested, including the mitogen-activated protein kinase (MAPK) ERK 1 \& 2, which has been shown to be altered following corticosterone-induced cellular stress (Xu et al., 2013).

While focusing on one test of memory allows for a thorough development of an understanding of the role of PDE2 in learning and memory, additional domains of memory need to be explored. Object recognition memory is an aspect of declarative memory, and serves as an excellent test of such memory in rodents for the potential translation to humans. However, it is, of course, only testing one aspect of memory. Future studies should work to replicate precisely what has been done (and what is to be done) in the ORT using other test of memory. A simple variation of ORT is the object location test (OLT), which uses the same set-up and parameters as the ORT, but instead of introducing a novel object, one of the objects is moved to a new location in the box, shifting the task to spatial memory. Other tests for spatial memory include the MWM and RAM. Because of the protective role of PDE2 in stress-induced changes in anxiety, depression and memory, future studies should also consider making use of more fear- or stress- based tests, such as the STPA or other fear conditioning tests. In designing future studies, researchers should consider that the role of PDE2 in these different memory tasks may differ, as the underlying brain regions and molecular cascades involved may differ. It has already been suggested that making the ORT 
slightly more spatially-cued seems to shift the memory load from primarily rhinal regions to more hippocampal based regions (Akkerman et al., 2012; Brown et al., 2012; Dere et al., 2007; van Goethem et al., 2012; Wan et al., 1999). It is also possible that this may be shifting the critical periods for cAMP vs cGMP. This may also explain some of the differences seen between what has been reported here and what was reported by Bollen et al. (Bollen et al., 2014; Rutten et al., 2007). Furthermore, this may explain the lack of an effect following Bay 60-7550 administration 30 min prior to training in the STPA. Additional analysis should be done with administration of Bay $60-7550$ and other PDE2 inhibitors at earlier time points (i.e., $1 \mathrm{hr}$ prior to training) to rule out any role in acquisition, as well as later time points (i.e. 0-6 hrs after training and prior to recall) to fully elucidate the potential of PDE2 inhibition in fear-based memory of the STPA.

Additional behavioral analysis using a genetic system would greatly advance our current understanding of PDE2 in all of these behaviors. While a constitutive knockout of PDE2 is embryonic lethal, using more selective genetic approaches, such as Cre/Lox systems, would allow deletion of PDE2 in a narrower context. Global CNS knockout (but not peripheral PDE2 knockout) would allow for direct comparison and confirmation of what has been done using PDE2 inhibitors. Even more selective, brain-region specific approaches using viral-vector knockdowns would allow for neuro-anatomical analysis of where and when PDE2 is important in all of these behaviors.

Finally, though much of what has been shown here significantly contributes to the current understanding of PDE2 in anxiety, depression, and learning and memory, much more research is needed to come to a full understanding of PDE2, its role in mood and cognition, and the underlying mechanisms involved. Currently, PDE2 holds great 
potential as a novel therapeutic for the treatment of mood and cognitive disorders, and developing this understanding can only lead to better treatment options in the future. 


\section{References}

Aarsland, D., Andersen, K., Larsen, J.P., Lolk, A., Kragh-Sørensen, P., 2003.

Prevalence and characteristics of dementia in Parkinson disease: an 8-year prospective study. Arch. Neurol. 60, 387-392. doi:10.1001/archneur.60.3.387

Abarghaz, M., Biondi, S., Duranton, J., Limanton, E., Mondadori, C., Wagner, P., 2005. Cyclic nucleotide phosphodiesterase inhibitors, preparation and uses thereof. WO2005063723 A1; US 7410963 B2.

Adhikari, A., Topiwala, M. a, Gordon, J. a, 2010. Synchronized activity between the ventral hippocampus and the medial prefrontal cortex during anxiety. Neuron 65, 257-69. doi:10.1016/j.neuron.2009.12.002

Akkerman, S., Blokland, A., Prickaerts, J., 2014a. Mind the gap: delayed manifestation of long-term object memory improvement by phosphodiesterase inhibitors. Neurobiol. Learn. Mem. 109, 139-43. doi:10.1016/j.nlm.2014.01.006

Akkerman, S., Blokland, A., Reneerkens, O., van Goethem, N.P., Bollen, E., Gijselaers, H.J.M., Lieben, C.K.J., Steinbusch, H.W.M., Prickaerts, J., 2012. Object recognition testing: methodological considerations on exploration and discrimination measures. Behav. Brain Res. 232, 335-47. doi:10.1016/j.bbr.2012.03.022

Akkerman, S., Blokland, A., van Goethem, N.P., Cremers, P., Shaffer, C.L., Osgood, S.M., Steinbusch, H.W.M., Prickaerts, J., 2015. PDE5 inhibition improves acquisition processes after learning via a central mechanism. Neuropharmacology 97, 233-239. doi:10.1016/j.neuropharm.2015.04.019

Akkerman, S., Prickaerts, J., Bruder, A.K., Wolfs, K.H.M., De Vry, J., Vanmierlo, T., Blokland, A., 2014b. PDE5 inhibition improves object memory in standard housed rats but not in rats housed in an enriched environment: implications for memory models? PLoS One 9, e111692. doi:10.1371/journal.pone.0111692

Almeida, R.C., Souza, D.G., Soletti, R.C., López, M.G., Rodrigues, A.L.S., Gabilan, N.H., 2006. Involvement of PKA, MAPK/ERK and CaMKII, but not PKC in the acute antidepressant-like effect of memantine in mice. Neurosci. Lett. 395, 93-7. doi:10.1016/j.neulet.2005.10.057

Amer, M.S., 1977. Cyclic nucleotides as targets for drug design. Adv. Drug Res. 12, $1-$ 38.

American Psychiatric Association, 2013. Diagnostic and Statistical Manual of Mental Disorders, Arlington. doi:10.1176/appi.books.9780890425596.744053

Antunes, M., Biala, G., 2012. The novel object recognition memory: neurobiology, test procedure, and its modifications. Cogn. Process. 13, 93-110. doi:10.1007/s10339011-0430-z

Ashman, D.F., Lipton, R., Melicow, M.M., Price, T.D., 1963. Isolation of adenosine 3', 5'monophosphate and guanosine 3', 5'-monophosphate from rat urine. Biochem. Biophys. Res. Commun. 11, 330-4.

Balderas, I., Rodriguez-Ortiz, C.J., Bermudez-Rattoni, F., 2013. Retrieval and 
reconsolidation of object recognition memory are independent processes in the perirhinal cortex. Neuroscience 253, 398-405.

doi:10.1016/j.neuroscience.2013.09.001

Baxter, M.G., Murray, E.A., 2001. Opposite relationship of hippocampal and rhinal cortex damage to delayed nonmatching-to-sample deficits in monkeys. Hippocampus 11, 61-71. doi:10.1002/1098-1063(2001)11:1<61::AIDHIPO1021>3.0.CO;2-Z

Beavo, J. a, Brunton, L.L., 2002. Cyclic nucleotide research -- still expanding after half a century. Nat. Rev. Mol. Cell Biol. 3, 710-8. doi:10.1038/nrm911

Beavo, J. a, Hardman, J.G., Sutherland, E.W., 1970. Hydrolysis of cyclic guanosine and adenosine 3',5'-monophosphates by rat and bovine tissues. J. Biol. Chem. 245, 5649-55.

Bernabeu, R., Schmitz, P., Faillace, M.P., Izquierdo, I., Medina, J.H., 1996. Hippocampal cGMP and cAMP are differentially involved in memory processing of inhibitory avoidance learning. Neuroreport 7, 585-8.

Bianchi, M., Fone, K.F.C., Azmi, N., Heidbreder, C.A., Hagan, J.J., Marsden, C.A., 2006. Isolation rearing induces recognition memory deficits accompanied by cytoskeletal alterations in rat hippocampus. Eur. J. Neurosci. 24, 2894-902. doi:10.1111/j.1460-9568.2006.05170.x

Boess, F.G., Hendrix, M., van der Staay, F.-J., Erb, C., Schreiber, R., van Staveren, W., de Vente, J., Prickaerts, J., Blokland, A., Koenig, G., 2004. Inhibition of phosphodiesterase 2 increases neuronal cGMP, synaptic plasticity and memory performance. Neuropharmacology 47, 1081-92. doi:10.1016/j.neuropharm.2004.07.040

Boissier, J., Simon, P., 1964. Dissociation de deux composantes dans le compartment dinvestigation de la souris. Arch. Int. Pharmacodyn. 147, 372-387.

Boissier, J., Simon, P., 1962. La reaction dexploration chez la souris. Therapie 12251232.

Bolger, G.B., Rodgers, L., Riggs, M., 1994. Differential CNS expression of alternative mRNA isoforms of the mammalian genes encoding cAMP-specific phosphodiesterases. Gene 149, 237-44.

Bollen, E., Akkerman, S., Puzzo, D., Gulisano, W., Palmeri, A., D'Hooge, R., Balschun, D., Steinbusch, H.W.M., Blokland, A., Prickaerts, J., 2015. Object memory enhancement by combining sub-efficacious doses of specific phosphodiesterase inhibitors. Neuropharmacology 95, 361-366.

doi:10.1016/j.neuropharm.2015.04.008

Bollen, E., Puzzo, D., Rutten, K., Privitera, L., De Vry, J., Vanmierlo, T., Kenis, G., Palmeri, A., D'Hooge, R., Balschun, D., Steinbusch, H.W.M., Blokland, A., Prickaerts, J., 2014. Improved long-term memory via enhancing cGMP-PKG signaling requires CAMP-PKA signaling. Neuropsychopharmacology 4, 1-9. doi:10.1038/npp.2014.106 
Bourtchouladze, R., Abel, T., Berman, N., Gordon, R., Lapidus, K., Kandel, E.R., 1998. Different training procedures recruit either one or two critical periods for contextual memory consolidation, each of which requires protein synthesis and PKA. Learn. Mem. 5, 365-374. doi:10.1101/Im.5.4.365

Bourtchuladze, R., Frenguelli, B., Blendy, J., Cioffi, D., Schutz, G., Silva, a J., 1994. Deficient long-term memory in mice with a targeted mutation of the CAMPresponsive element-binding protein. Cell 79, 59-68. doi:10.1016/00928674(94)90400-6

Brown, M.W., Barker, G.R.I., Aggleton, J.P., Warburton, E.C., 2012. What pharmacological interventions indicate concerning the role of the perirhinal cortex in recognition memory. Neuropsychologia 50, 3122-3140. doi:10.1016/j.neuropsychologia.2012.07.034

Burgin, A.B., Magnusson, O.T., Singh, J., Witte, P., Staker, B.L., Bjornsson, J.M., Thorsteinsdottir, M., Hrafnsdottir, S., Hagen, T., Kiselyov, A.S., Stewart, L.J., Gurney, M.E., 2010. Design of phosphodiesterase 4D (PDE4D) allosteric modulators for enhancing cognition with improved safety. Nat. Biotechnol. 28, 6370. doi: $10.1038 / n b t .1598$

Carlezon, W. a., Duman, R.S., Nestler, E.J., 2005. The many faces of CREB. Trends Neurosci. 28, 436-445. doi:10.1016/j.tins.2005.06.005

Castellucci, V.F., Kandel, E.R., Schwartz, J.H., Wilson, F.D., Nairn, a C., Greengard, P., 1980. Intracellular injection of the catalytic subunit of cyclic AMP-dependent protein kinase simulates facilitation of transmitter release underlying behavioral sensitization in Aplysia. Proc. Natl. Acad. Sci. 77, 7492-7496. doi:10.1073/pnas.77.12.7492

Chien, W.-L., Liang, K.-C., Teng, C.-M., Kuo, S.-C., Lee, F.-Y., Fu, W.-M., 2005. Enhancement of learning behaviour by a potent nitric oxide-guanylate cyclase activator YC-1. Eur. J. Neurosci. 21, 1679-88. doi:10.1111/j.14609568.2005.03993.x

Chijiwa, T., Mishima, A., Hagiwara, M., Sano, M., Hayashi, K., Inoue, T., Naito, K., Toshioka, T., Hidaka, H., 1990. Inhibition of forskolin-induced neurite outgrowth and protein phosphorylation by a newly synthesized selective inhibitor of cyclic AMPdependent protein kinase, $\mathrm{N}$-[2-(p-bromocinnamylamino)ethyl]-5isoquinolinesulfonamide (H-89), of PC12D pheochromocytoma. J. Biol. Chem. 265, 5267-72.

Clark, R.E., Squire, L.R., 2010. An animal model of recognition memory and medial temporal lobe amnesia: History and current issues. Neuropsychologia. doi:10.1016/j.neuropsychologia.2010.02.004

Cryan, J.F., Holmes, A., 2005. The ascent of mouse: advances in modelling human depression and anxiety. Nat. Rev. Drug Discov. 4, 775-90. doi:10.1038/nrd1825

Cunha, M.P., Budni, J., Pazini, F.L., Oliveira, Á., Rosa, J.M., Lopes, M.W., Leal, R.B., Rodrigues, A.L.S., 2014. Involvement of PKA, PKC, CAMK-II and MEK1/2 in the 
acute antidepressant-like effect of creatine in mice. Pharmacol. Reports 66, 653659. doi:10.1016/j.pharep.2014.03.004

Deacon, R.M.J., Rawlins, J.N.P., 2005. Hippocampal lesions, species-typical behaviours and anxiety in mice. Behav. Brain Res. 156, 241-9.

doi:10.1016/j.bbr.2004.05.027

Deng, C., Wang, D., Bugaj-Gaweda, B., De Vivo, M., 2007. Assays for cyclic nucleotidespecific phosphodiesterases (PDEs) in the central nervous system (PDE1, PDE2, PDE4, and PDE10). Curr. Protoc. Neurosci. Chapter 7, Unit 7.21. doi:10.1002/0471142301.ns0721s38

Dere, E., Huston, J.P., De Souza Silva, M.A., 2007. The pharmacology, neuroanatomy and neurogenetics of one-trial object recognition in rodents. Neurosci. Biobehav. Rev. 31, 673-704. doi:10.1016/j.neubiorev.2007.01.005

Desgranges, B., 1998. The neural substrates of memory systems impairment in Alzheimer's disease. A PET study of resting brain glucose utilization. Brain 121, 611-631. doi:10.1093/brain/121.4.611

Ding, L., Zhang, C., Masood, A., Li, J., Sun, J., Nadeem, A., Zhang, H.-T., O'Donnell, J.M., Xu, Y., 2014. Protective effects of phosphodiesterase 2 inhibitor on depression- and anxiety-like behaviors: Involvement of antioxidant and antiapoptotic mechanisms. Behav. Brain Res. 268, 150-8.

doi:10.1016/j.bbr.2014.03.042

Domek-Łopacińska, K., Strosznajder, J.B., 2008. The effect of selective inhibition of cyclic GMP hydrolyzing phosphodiesterases 2 and 5 on learning and memory processes and nitric oxide synthase activity in brain during aging. Brain Res. 1216, 68-77. doi:10.1016/j.brainres.2008.02.108

Domek-Łopacińska, K.U., Strosznajder, J.B., 2010. Cyclic GMP and nitric oxide synthase in aging and Alzheimer's disease. Mol. Neurobiol. 41, 129-37. doi:10.1007/s12035-010-8104-x

Douglas, L.A., Varlinskaya, E.I., Spear, L.P., 2003. Novel-object place conditioning in adolescent and adult male and female rats: effects of social isolation. Physiol. Behav. 80, 317-25.

Dzirasa, K., Phillips, H.W., Sotnikova, T.D., Salahpour, A., Kumar, S., Gainetdinov, R.R., Caron, M.G., Nicolelis, M. a L., 2010. Noradrenergic control of cortico-striatothalamic and mesolimbic cross-structural synchrony. J. Neurosci. 30, 6387-97. doi:10.1523/JNEUROSCI.0764-10.2010

Engel, K., Bandelow, B., Gruber, O., Wedekind, D., 2009. Neuroimaging in anxiety disorders. J. Neural Transm. 116, 703-16. doi:10.1007/s00702-008-0077-9

Engin, E., Treit, D., 2007. The role of hippocampus in anxiety: intracerebral infusion studies. Behav. Pharmacol. 18, 365-74. doi:10.1097/FBP.0b013e3282de7929

Ennaceur, A., Delacour, J., 1988. A new one-trial test for neurobiological studies of memory in rats. 1: Behavioral data. Behav. Brain Res. 31, 47-59. 
Etkin, A., 2012. Neurobiology of anxiety: from neural circuits to novel solutions? Depress. Anxiety 29, 355-8. doi:10.1002/da.21957

Francis, S.H., Blount, M.A., Corbin, J.D., 2011a. Mammalian Cyclic Nucleotide Phosphodiesterases : Molecular Mechanisms and Physiological Functions. Physiol. Rev. 91, 651-690. doi:10.1152/physrev.00030.2010.

Francis, S.H., Houslay, M.D., Conti, M., 2011b. Phosphodiesterases as Drug Targets, Handbook of experimental pharmacology, Handbook of Experimental Pharmacology. Springer Berlin Heidelberg, Berlin, Heidelberg. doi:10.1007/978-3642-17969-3

Gabrieli, J.D.E., Fleischman, D.A., Keane, M.M., Reminger, S.L., Morrell, F., 1995. Double dissociation between memory systems underlying explicit and implicit memory in the human brain. Psychol. Sci. 6, 76-82. doi:10.1111/j.14679280.1995.tb00310.x

Gao, S.-F., Lu, Y.-R., Shi, L.-G., Wu, X.-Y., Sun, B., Fu, X.-Y., Luo, J.-H., Bao, A.-M., 2014. Nitric oxide synthase and nitric oxide alterations in chronically stressed rats: A model for nitric oxide in major depressive disorder. Psychoneuroendocrinology 47, 136-140. doi:10.1016/j.psyneuen.2014.05.009

Gesellchen, F., Zaccolo, M., 2011. Phosphodiesterase 2A, cGMP stimulated. UCSD Nat. Mol. Pages. doi:10.1038/mp.a001750.01

Golby, A., Silverberg, G., Race, E., Gabrieli, S., O'Shea, J., Knierim, K., Stebbins, G., Gabrieli, J., 2005. Memory encoding in Alzheimer's disease: an fMRI study of explicit and implicit memory. Brain 128, 773-87. doi:10.1093/brain/awh400

Goldman, J.G., Weintraub, D., 2015. Advances in the treatment of cognitive impairment in Parkinson's disease. Mov. Disord. 30, 1471-1489. doi:10.1002/mds.26352

Gomez, L., Breitenbucher, J.G., 2013. PDE2 inhibition: potential for the treatment of cognitive disorders. Bioorg. Med. Chem. Lett. 23, 6522-7.

doi:10.1016/j.bmcl.2013.10.014

Gorman, J.M., 2003. Treating generalized anxiety disorder. J. Clin. Psychiatry 64 Suppl 2, 24-9.

Greengard, P., 1976. Possible role for cyclic nucleotides and phosphorylated membrane proteins in postsynaptic actions of neurotransmitters. Nature 260, 101-8.

Hall, F.S., 1998. Social deprivation of neonatal, adolescent, and adult rats has distinct neurochemical and behavioral consequences. Crit. Rev. Neurobiol. 12, 129-62.

Haller, J., Alicki, M., 2012. Current animal models of anxiety, anxiety disorders, and anxiolytic drugs. Curr. Opin. Psychiatry 25, 59-64.

doi:10.1097/YCO.0b013e32834de34f

Hampstead, B.M., Khoshnoodi, M., Yan, W., Deshpande, G., Sathian, K., 2015. Patterns of effective connectivity during memory encoding and retrieval differ between patients with mild cognitive impairment and healthy older adults. Neuroimage. doi:10.1016/j.neuroimage.2015.10.002 
Handley, S.L., Mithani, S., 1984. Effects of alpha-adrenoceptor agonists and antagonists in a maze-exploration model of ?fear?-motivated behaviour. Naunyn. Schmiedebergs. Arch. Pharmacol. 327, 1-5. doi:10.1007/BF00504983

Harooni, H.E., Naghdi, N., Sepehri, H., Rohani, A.H., 2009. The role of hippocampal nitric oxide (NO) on learning and immediate, short- and long-term memory retrieval in inhibitory avoidance task in male adult rats. Behav. Brain Res. 201, 166-172. doi:10.1016/j.bbr.2009.02.011

Hebert, L.E., Scherr, P.A., Bienias, J.L., Bennett, D.A., Evans, D.A., 2003. Alzheimer disease in the US population: prevalence estimates using the 2000 census. Arch. Neurol. 60, 1119-22. doi:10.1001/archneur.60.8.1119

Hely, M.A., Reid, W.G.J., Adena, M.A., Halliday, G.M., Morris, J.G.L., 2008. The Sydney multicenter study of Parkinson's disease: The inevitability of dementia at 20 years. Mov. Disord. 23, 837-844. doi:10.1002/mds.21956

Hercher, C., Turecki, G., Mechawar, N., 2009. Through the looking glass: examining neuroanatomical evidence for cellular alterations in major depression. J. Psychiatr. Res. 43, 947-61. doi:10.1016/j.jpsychires.2009.01.006

Hettema, J.M., 2008. The nosologic relationship between generalized anxiety disorder and major depression. Depress. Anxiety 25, 300-16. doi:10.1002/da.20491

Hill, M.N., Hellemans, K.G.C., Verma, P., Gorzalka, B.B., Weinberg, J., 2012. Neurobiology of chronic mild stress: Parallels to major depression. Neurosci. Biobehav. Rev. 36, 2085-2117. doi:10.1016/j.neubiorev.2012.07.001

Hirschfeld, R.M., 2000. History and evolution of the monoamine hypothesis of depression. J. Clin. Psychiatry 61 Suppl 6, 4-6.

Holzschneider, K., Mulert, C., 2011. Neuroimaging in anxiety disorders. Dialogues Clin. Neurosci. 13, 453-61.

Hu, Y., Wu, D.-L., Luo, C.-X., Zhu, L.-J., Zhang, J., Wu, H.-Y., Zhu, D.-Y., 2012. Hippocampal nitric oxide contributes to sex difference in affective behaviors. Proc. Natl. Acad. Sci. U. S. A. 109, 14224-9. doi:10.1073/pnas.1207461109

Ignarro, L.J., Byrns, R.E., Wood, K.S., 1987. Endothelium-dependent modulation of cGMP levels and intrinsic smooth muscle tone in isolated bovine intrapulmonary artery and vein. Circ. Res. 60, 82-92.

Jarvik, M., Essman, W., 1960. A simple one-trial situation for mice. Psychol Rep 6, 290.

Jarvik, M.E., Kopp, R., 1967. An improved one-trial passive avoidance learning situation. Psychol. Rep. 21, 221-4. doi:10.2466/pr0.1967.21.1.221

Jobim, P.F.C., Pedroso, T.R., Werenicz, A., Christoff, R.R., Maurmann, N., Reolon, G.K., Schröder, N., Roesler, R., 2012. Impairment of object recognition memory by rapamycin inhibition of mTOR in the amygdala or hippocampus around the time of learning or reactivation. Behav. Brain Res. 228, 151-158.

doi:10.1016/j.bbr.2011.12.004 
Johannessen, M., Moens, U., 2007. Multisite phosphorylation of the cAMP response element-binding protein (CREB) by a diversity of protein kinases. Front. Biosci. 12, 1814-1832. doi: $10.2741 / 2190$

Kandel, E.R., 2012. The molecular biology of memory : cAMP, PKA ,CRE, CREB-1, CREB-2, and CPEB. Mol. Brain 5, 1-12. doi:10.1186/1756-6606-5-14

Karege, F., Vaudan, G., Schwald, M., Perroud, N., La Harpe, R., 2005. Neurotrophin levels in postmortem brains of suicide victims and the effects of antemortem diagnosis and psychotropic drugs. Mol. Brain Res. 136, 29-37. doi:10.1016/j.molbrainres.2004.12.020

Kawamoto, E.M., Vasconcelos, A.R., Degaspari, S., Böhmer, A.E., Scavone, C., Marcourakis, T., 2013. Age-related changes in nitric oxide activity, cyclic GMP, and TBARS levels in platelets and erythrocytes reflect the oxidative status in central nervous system. Age (Omaha). 35, 331-342. doi:10.1007/s11357-011-9365-7

Keravis, T., Lugnier, C., 2012. Cyclic nucleotide phosphodiesterase (PDE) isozymes as targets of the intracellular signalling network: benefits of PDE inhibitors in various diseases and perspectives for future therapeutic developments. Br. J. Pharmacol. 165, 1288-305. doi:10.1111/j.1476-5381.2011.01729.x

Kessler, R.C., Berglund, P., Demler, O., Jin, R., Merikangas, K.R., Walters, E.E., 2005. Lifetime prevalence and age-of-onset distributions of DSM-IV disorders in the National Comorbidity Survey replication. Arch Gen Psychiatry 62, 593-603.

Kheirbek, M. a, Drew, L.J., Burghardt, N.S., Costantini, D.O., Tannenholz, L., Ahmari, S.E., Zeng, H., Fenton, A. a, Hen, R., Ahmari, S.E., Zeng, H., 2013. Differential control of learning and anxiety along the dorsoventral axis of the dentate gyrus. Neuron 77, 955-68. doi:10.1016/j.neuron.2012.12.038

Kleppisch, T., 2009. Phosphodiesterases in the central nervous system. Handb. Exp. Pharmacol. 71-92. doi:10.1007/978-3-540-68964-5_5

Koen, N., Stein, D.J., 2011. Pharmacotherapy of anxiety disorders: a critical review. Dialogues Clin. Neurosci. 13, 423-37.

Krishnan, V., Nestler, E.J., 2010. Linking molecules to mood: new insight into the biology of depression. Am. J. Psychiatry 167, 1305-20. doi:10.1176/appi.ajp.2009.10030434

Kuhn, R., 1958. The treatment of depressive states with $\mathrm{G} 22355$ (imipramine hydrochloride). Am. J. Psychiatry 115, 459-64.

Kumar, A., Nisha, C.M., Silakari, C., Sharma, I., Anusha, K., Gupta, N., Nair, P., Tripathi, T., Kumar, A., 2015. Current and novel therapeutic molecules and targets in Alzheimer's disease. J. Formos. Med. Assoc. 1-8. doi:10.1016/j.jma.2015.04.001

Lakics, V., Karran, E.H., Boess, F.G., 2010. Quantitative Comparison Of Phosphodiesterase mRNA Distribution In Human Brain And Peripheral Tissues. Neuropharmacology 59, 367-374. doi:10.1016/j.neuropharm.2010.05.004 
Lapiz, M.D.S., Fulford, A., Muchimapura, S., Mason, R., Parker, T., Marsden, C.A., 2003. Influence of postweaning social isolation in the rat on brain development, conditioned behavior, and neurotransmission. Neurosci. Behav. Physiol. 33, 13-29. doi:10.1023/A:1021171129766

Laxman, S., Rascón, A., Beavo, J.A., 2005. Trypanosome cyclic nucleotide phosphodiesterase 2B binds CAMP through its GAF-A domain. J. Biol. Chem. 280, 3771-9. doi:10.1074/jbc.M408111200

Lee, B., Butcher, G.Q., Hoyt, K.R., Impey, S., Obrietan, K., 2005. Activity-dependent neuroprotection and CAMP response element-binding protein (CREB): kinase coupling, stimulus intensity, and temporal regulation of CREB phosphorylation at serine 133. J. Neurosci. 25, 1137-1148. doi:10.1523/JNEUROSCI.4288-04.2005

Lee, M.C., Smith, F.L., Stevens, D.L., Welch, S.P., 2003. The role of several kinases in mice tolerant to delta 9-tetrahydrocannabinol. J. Pharmacol. Experamental Ther. 305, 593-9. doi:10.1124/jpet.102.044446

Leger, M., Quiedeville, A., Bouet, V., Haelewyn, B., Boulouard, M., Schumann-Bard, P., Freret, T., 2013. Object recognition test in mice. Nat. Protoc. 8, 2531-7. doi:10.1038/nprot.2013.155

Lenze, E.J., Wetherell, J.L., 2011. A lifespan view of anxiety disorders. Dialogues Clin. Neurosci. 13, 381-399.

Li, Y.-C., Wang, F.-M., Pan, Y., Qiang, L.-Q., Cheng, G., Zhang, W.-Y., Kong, L.-D., 2009. Antidepressant-like effects of curcumin on serotonergic receptor-coupled ACcAMP pathway in chronic unpredictable mild stress of rats. Prog. Neuro-

Psychopharmacology Biol. Psychiatry 33, 435-449.

doi:10.1016/j.pnpbp.2009.01.006

Linden, M., Bandelow, B., Boerner, R.J., Brasser, M., Kasper, S., Möller, H.-J., Pyrkosch, L., Volz, H.-P., Wittchen, H.-U., 2012. The best next drug in the course of generalized anxiety disorders: The "PN-GAD-algorithm." Int. J. Psychiatry Clin. Pract. doi:10.3109/13651501.2012.722645

Liu, P., Smith, P.F., Appleton, I., Darlington, C.L., Bilkey, D.K., 2003. Nitric oxide synthase and arginase in the rat hippocampus and the entorhinal, perirhinal, postrhinal, and temporal cortices: Regional variations and age-related changes. Hippocampus 13, 859-867. doi:10.1002/hipo.10138

Lopez-Munoz, F., Alamo, C., 2009. Monoaminergic neurotransmission: The history of the discovery of antidepressants from 1950s until today. Curr. Pharm. Des. 15, 1563-1586.

Lueptow, L.M., Zhan, C.-G., O'Donnell, J.M., 2015. Cyclic GMP-mediated memory enhancement in the object recognition test by inhibitors of phosphodiesterase-2 in mice. Psychopharmacology (Berl). doi:10.1007/s00213-015-4129-1

Mak, E., Su, L., Williams, G.B., Firbank, M.J., Lawson, R.A., Yarnall, A.J., Duncan, G.W., Owen, A.M., Khoo, T.K., Brooks, D.J., Rowe, J.B., Barker, R.A., Burn, D.J., O'Brien, J.T., 2015. Baseline and longitudinal grey matter changes in newly 
diagnosed Parkinson's disease: ICICLE-PD study. Brain 138, 2974-2986. doi:10.1093/brain/awv211

Masood, A., Huang, Y., Hajjhussein, H., Xiao, L., Li, H., Wang, W., Hamza, A., Zhan, C., Donnell, J.M.O., 2009. Anxiolytic effects of phosphodiesterase-2 inhibitors associated with increased cGMP signaling. J. Pharmacol. Exp. Ther. 331, 690-699. doi:10.1124/jpet.109.156729.1993

Masood, A., Nadeem, A., Mustafa, S.J., Donnell, J.M.O., O'Donnell, J.M., Donnell, J.M.O., 2008. Reversal of oxidative stress-induced anxiety by inhibition of phosphodiesterase-2 in mice. J. Pharmacol. Experamental Ther. 326, 369-379. doi:10.1124/jpet.108.137208.be

Maurice, D.H., Ke, H., Ahmad, F., Wang, Y., Chung, J., Manganiello, V.C., 2014. Advances in targeting cyclic nucleotide phosphodiesterases. Nat. Rev. Drug Discov. 13, 290-314. doi:10.1038/nrd4228

Mayr, B., Montminy, M., 2001. Transcriptional regulation by the phosphorylationdependent factor CREB. Nat. Rev. Mol. Cell Biol. 2, 599-609. doi:10.1038/35085068

Menniti, F.S., Faraci, W.S., Schmidt, C.J., 2006. Phosphodiesterases in the CNS : targets for drug development. Nat. Rev. Drug Discov. 5, 660-670. doi:10.1038/nrd2058

Meyerhoff, J., Kant, G., Sessions, G., Mougey, E., Pennington, L., Lenox, R., 1985. Brain and pituitary cyclic nucleotide response to stress, in: Williams, R.B. (Ed.), Perspectives on Behavioral Medicine: Neuroendocrine Control and Behavior. Academic Press, pp. 53-70.

Muller, U., 2012. The Molecular Biology of Learning and Memory - Memory Phases and Signaling Cascades, in: Honeybee Neurobiology and Behavior: A Tribute to Randolf Menzel. pp. 409-421. doi:10.1007/978-94-007-2099-2

Nagel, D.J., Aizawa, T., Jeon, K.-I., Liu, W., Mohan, A., Wei, H., Miano, J.M., Florio, V.A., Gao, P., Korshunov, V.A., Berk, B.C., Yan, C., 2006. Role of nuclear $\mathrm{Ca} 2+/$ calmodulin-stimulated phosphodiesterase $1 \mathrm{~A}$ in vascular smooth muscle cell growth and survival. Circ. Res. 98, 777-84. doi:10.1161/01.RES.0000215576.27615.fd

Niewohner, U., Schauss, D., Hendrix, M., Konig, G., Boss, F.-G., van der Staay, F.-J., Schreiber, K., Schlemmer, K.-H., Grosser, R., 2003. Substituted imidazotriazinones.

Nonaka, M., Kim, R., Fukushima, H., Sasaki, K., Suzuki, K., Okamura, M., Ishii, Y., Kawashima, T., Kamijo, S., Takemoto-Kimura, S., Okuno, H., Kida, S., Bito, H., 2014. Region-specific activation of CRTC1-CREB signaling mediates long-term fear memory. Neuron 84, 92-106. doi:10.1016/j.neuron.2014.08.049

Norquist, G.S., 1998. National Institute of Mental Health. Med. Care 36, 1306-1308. doi:10.1097/00005650-199809000-00002 
Omori, K., Kotera, J., 2007. Overview of PDEs and their regulation. Circ. Res. 100, 309-27. doi:10.1161/01.RES.0000256354.95791.f1

Ossenkoppele, R., Cohn-Sheehy, B.I., La Joie, R., Vogel, J.W., Möller, C., Lehmann, M., van Berckel, B.N.M., Seeley, W.W., Pijnenburg, Y.A., Gorno-Tempini, M.L., Kramer, J.H., Barkhof, F., Rosen, H.J., van der Flier, W.M., Jagust, W.J., Miller, B.L., Scheltens, P., Rabinovici, G.D., 2015. Atrophy patterns in early clinical stages across distinct phenotypes of Alzheimer's disease. Hum. Brain Mapp. 4437, n/an/a. doi:10.1002/hbm.22927

Park, S., Ahmad, F., Philp, A., Baar, K., Williams, T., Ke, H., Rehmann, H., Taussig, R., Brown, A.L., Myung, K., Beaven, M.A., Burgin, A.B., Manganiello, V., Chung, J.H., 2012. Resveratrol ameliorates aging-related metabolic phenotypes by inhibiting cAMP phosphodiesterases. Cell 148, 421-433. doi:10.1016/j.cell.2012.01.017.Park

Paxinos, G., Franklin, K.B., 2008. The mouse brain in stereotaxic coordinates, compact, third edition: the coronal plates and diagrams, 3rd ed. Academic Press.

Pellow, S., Chopin, P., File, S.E., Briley, M., 1985. Validation of open:closed arm entries in an elevated plus-maze as a measure of anxiety in the rat. J. Neurosci. Methods $14,149-67$.

Petrovich, G.D., Canteras, N.S., Swanson, L.W., 2001. Combinatorial amygdalar inputs to hippocampal domains and hypothalamic behavior systems. Brain Res. 38, 24789.

Porsolt, R.D., 1977. Depression: a new animal model sensitive to antidepressant treatments. Nature 266, 730-732.

Prickaerts, J., De Vente, J., Honig, W., Steinbusch, H.W.M., Blokland, A., 2002. cGMP, but not cAMP, in rat hippocampus is involved in early stages of object memory consolidation. Eur. J. Pharmacol. 436, 83-87. doi:10.1016/S0014-2999(01)01614-4

Rafii, M.S., Aisen, P.S., 2015. Advances in Alzheimer's Disease Drug Development. BMC Med. 13, 62. doi:10.1186/s12916-015-0297-4

Rall, T., Sutherland, E.W., Berthet, J., 1956. The relationship of epinephrine and glucagon to liver phosphorylase. J. Biol. Chem. 224, 463-475. doi:10.1017/CBO9781107415324.004

Rascón, A., Soderling, S.H., Schaefer, J.B., Beavo, J.A., 2002. Cloning and characterization of a cAMP-specific phosphodiesterase (TbPDE2B) from Trypanosoma brucei. Proc. Natl. Acad. Sci. U. S. A. 99, 4714-9. doi:10.1073/pnas.002031599

Ravindran, L.N., Stein, M.B., 2010. The pharmacologic treatment of anxiety disorders: a review of progress. J. Clin. Psychiatry 71, 839-54. doi:10.4088/JCP.10r06218blu

Redrobe, J.P., Jørgensen, M., Christoffersen, C.T., Montezinho, L.P., Bastlund, J.F., Carnerup, M., Bundgaard, C., Lerdrup, L., Plath, N., 2014. In vitro and in vivo characterisation of Lu AF64280, a novel, brain penetrant phosphodiesterase (PDE) $2 \mathrm{~A}$ inhibitor: potential relevance to cognitive deficits in schizophrenia. 
Psychopharmacology (Berl). doi:10.1007/s00213-014-3492-7

Reinhold, J.A., Mandos, L.A., Rickels, K., Lohoff, F.W., 2011. Pharmacological treatment of generalized anxiety disorder. Expert Opin. Pharmacother. 12, 245767. doi:10.1517/14656566.2011.618496

Reneerkens, O., Rutten, K., Bollen, E., Hage, T., Blokland, A., Steinbusch, H.W.M., Prickaerts, J., 2013a. Inhibition of phoshodiesterase type 2 or type 10 reverses object memory deficits induced by scopolamine or MK-801. Behav. Brain Res. 236, 16-22. doi:10.1016/j.bbr.2012.08.019

Reneerkens, O., Sambeth, A., Blokland, A., Prickaerts, J., 2013b. PDE2 and PDE10, but not PDE5, inhibition affect basic auditory information processing in rats. Behav. Brain Res. 250, 251-6. doi:10.1016/j.bbr.2013.05.014

Repaske, D.R., Swinnen, J. V, Jin, S.L., Van Wyk, J.J., Conti, M., 1992. A polymerase chain reaction strategy to identify and clone cyclic nucleotide phosphodiesterase cDNAs. Molecular cloning of the cDNA encoding the 63-kDa calmodulin-dependent phosphodiesterase. J. Biol. Chem. 267, 18683-8.

Rodefer, J.S., Saland, S.K., Eckrich, S.J., 2012. Selective phosphodiesterase inhibitors improve performance on the ED/ID cognitive task in rats. Neuropharmacology 62, 1182-90. doi:10.1016/j.neuropharm.2011.08.008

Rosman, G.J., Martins, T.J., Sonnenburg, W.K., Beavo, J.A., Ferguson, K., Loughney, K., 1997. Isolation and characterization of human cDNAs encoding a cGMPstimulated 3',5'-cyclic nucleotide phosphodiesterase. Gene 191, 89-95.

Różyk-Myrta, A., 2015. Guidelines for prevention and treatment of cognitive impairment in the elderly. Med. Sci. Monit. 21, 585-597. doi:10.12659/MSM.892542

Rudolph, U., Knoflach, F., 2011. Beyond classical benzodiazepines: novel therapeutic potential of GABAA receptor subtypes. Nat. Rev. Drug Discov. 10, 685-97. doi:10.1038/nrd3502

Rutten, K., Prickaerts, J., Blokland, A., 2006. Rolipram reverses scopolamine-induced and time-dependent memory deficits in object recognition by different mechanisms of action. Neurobiol. Learn. Mem. 85, 132-138. doi:10.1016/j.nlm.2005.09.002

Rutten, K., Prickaerts, J., Hendrix, M., van der Staay, F.J., Sik, A., Blokland, A., 2007. Time-dependent involvement of cAMP and cGMP in consolidation of object memory: studies using selective phosphodiesterase type 2, 4 and 5 inhibitors. Eur. J. Pharmacol. 558, 107-12. doi:10.1016/j.ejphar.2006.11.041

Rutten, K., Van Donkelaar, E.L., Ferrington, L., Blokland, A., Bollen, E., Steinbusch, H.W., Kelly, P.A., Prickaerts, J., 2009. Phosphodiesterase inhibitors enhance object memory independent of cerebral blood flow and glucose utilization in rats. Neuropsychopharmacology 34, 1914-25. doi:10.1038/npp.2009.24

Schatzberg, A.F., Cole, J.O., DeBattista, C., 2007. Manual of Clinical Psychopharmacology, 7th ed. American Psychiatric Publishing.

Schildkraut, J., 1965. The catecholamine hypothesis of affective disorders: A review of 
supporting evidence. Am. J. Psychiatry 122, 509-522. doi:10.1176/ajp.122.5.509

Seoane, A., Tinsley, C.J., Brown, M.W., 2012. Interfering with Fos expression in rat perirhinal cortex impairs recognition memory. Hippocampus 22, 2101-2113. doi:10.1002/hipo.22028

Services, D. of H. and H., 2009. Anxiety Disorders: National Institute of Mental Health. doi:10.1037/e440272008-002

Shelton, C.I., 2004. Long-term management of major depressive disorder: are differences among antidepressant treatments meaningful? J. Clin. Psychiatry 65 Suppl 1, 29-33.

Sierksma, A.S.R., Rutten, K., Sydlik, S., Rostamian, S., Steinbusch, H.W.M., van den Hove, D.L. a, Prickaerts, J., 2012. Chronic phosphodiesterase type 2 inhibition improves memory in the APPswe/PS1dE9 mouse model of Alzheimer's disease. Neuropharmacology 1-13. doi:10.1016/j.neuropharm.2012.06.048

Sonnenburg, W.K., Mullaney, P.J., Beavo, J.A., 1991. Molecular Cloning of a Cyclic GMP-stimulated Cyclic Nucleotide Phosphodiesterase cDNA. J. Biol. Chem. 1.

Southam, E., Garthwaite, J., 1993. The nitric oxide-cyclic GMP signalling pathway in rat brain. Neuropharmacology 32, 1267-77.

Stephenson, D.T., Coskran, T.M., Wilhelms, M.B., Adamowicz, W.O., O'Donnell, M.M., Muravnick, K.B., Menniti, F.S., Kleiman, R.J., Morton, D., 2009.

Immunohistochemical localization of phosphodiesterase $2 \mathrm{~A}$ in multiple mammalian species. J. Histochem. Cytochem. 57, 933-49. doi:10.1369/jhc.2009.953471

Steru, L., Chermat, R., Thierry, B., Simon, P., 1985. The tail suspension test: a new method for screening antidepressants in mice. Psychopharmacology (Berl). 85, 367-70.

Strien, N.M. Van, Cappaert, N.L.M., Witter, M.P., 2009. The anatomy of memory: an interactive overview of the parahippocampal - hippocampal network. Nat. Rev. Neurosci. 10, 272-282. doi:10.1038/nrn2614

Stupien, G., Florian, C., Roullet, P., 2003. Involvement of the hippocampal CA3-region in acquisition and in memory consolidation of spatial but not in object information in mice. Neurobiol. Learn. Mem. 80, 32-41. doi:10.1016/S1074-7427(03)00022-4

Sutherland, E.W., Rall, T., 1958. Fractionation and characterization of a cyclic adenine ribonucleotide formed by tissue particles. J Biol Chem 232, 1077-1091.

Suvarna, N.U., O'Donnell, J.M., 2002. Hydrolysis of N-methyl-D-aspartate receptorstimulated cAMP and cGMP by PDE4 and PDE2 phosphodiesterases in primary neuronal cultures of rat cerebral cortex and hippocampus. J. Pharmacol. Experamental Ther. 302, 249-56.

Suzuki, W. a., 1996. The anatomy, physiology and functions of the perirhinal cortex. Curr. Opin. Neurobiol. 6, 179-186. doi:10.1016/S0959-4388(96)80071-7

Takeda, H., Tsuji, M., Matsumiya, T., 1998. Changes in head-dipping behavior in the 
hole-board test reflect the anxiogenic and/or anxiolytic state in mice. Eur. J. Pharmacol. 350, 21-29. doi:10.1016/S0014-2999(98)00223-4

Tanaka, T., Hockman, S., Moos, M., Taira, M., Meacci, E., Murashima, S., Manganiello, V.C., 1991. Comparison of putative cGMP-binding regions in bovine brain and cardiac cGMP-stimulated phosphodiesterases. Second Messengers Phosphoproteins 13, 87-98.

Thorsell, A., Slawecki, C.J., El Khoury, A., Mathe, A. a., Ehlers, C.L., 2006. The effects of social isolation on neuropeptide $Y$ levels, exploratory and anxiety-related behaviors in rats. Pharmacol. Biochem. Behav. 83, 28-34. doi:10.1016/j.pbb.2005.12.005

Tye, K.M., Prakash, R., Kim, S.-Y., Fenno, L.E., Grosenick, L., Zarabi, H., Thompson, K.R., Gradinaru, V., Ramakrishnan, C., Deisseroth, K., 2011. Amygdala circuitry mediating reversible and bidirectional control of anxiety. Nature 471, 358-62. doi:10.1038/nature09820

van Donkelaar, E.L., Rutten, K., Blokland, A., Akkerman, S., Steinbusch, H.W.M., Prickaerts, J., 2008. Phosphodiesterase 2 and 5 inhibition attenuates the object memory deficit induced by acute tryptophan depletion. Eur. J. Pharmacol. 600, 98104. doi:10.1016/j.ejphar.2008.10.027

van Goethem, N.P., Rutten, K., van der Staay, F.J., Jans, L. a W., Akkerman, S., Steinbusch, H.W.M., Blokland, A., van't Klooster, J., Prickaerts, J., 2012. Object recognition testing: Rodent species, strains, housing conditions, and estrous cycle. Behav. Brain Res. 232, 323-334. doi:10.1016/j.bbr.2012.03.023

van Groen, T., 2001. Entorhinal cortex of the mouse: cytoarchitectonical organization. Hippocampus 11, 397-407. doi:10.1002/hipo.1054

Van Staveren, W.C.G., Steinbusch, H.W.M., Markerink-Van Ittersum, M., Repaske, D.R., Goy, M.F., Kotera, J., Omori, K., Beavo, J. a, De Vente, J., 2003. mRNA expression patterns of the cGMP-hydrolyzing phosphodiesterases types 2, 5, and 9 during development of the rat brain. J. Comp. Neurol. 467, 566-80. doi:10.1002/cne.10955

van Staveren WC, Markerink-van Ittersum M, Steinbusch, H.W., de Vente J, 2001. The effects of phosphodiesterase inhibition on cyclic GMP and cyclic AMP accumulation in the hippocampus of the rat. Brain Res. 888, 275-286.

Videbech, P., Ravnkilde, B., 2004. Hippocampal volume and depression: a metaanalysis of MRI studies. Am. J. Psychiatry 161, 1957-66. doi:10.1176/appi.ajp.161.11.1957

Wan, H., Aggleton, J.P., Brown, M.W., 1999. Different contributions of the hippocampus and perirhinal cortex to recognition memory. J. Neurosci. 19, 1142-1148.

Wang, H., Hu, Y., Tsien, J.Z., 2006. Molecular and systems mechanisms of memory consolidation and storage. Prog. Neurobiol. 79, 123-135.

doi:10.1016/j.pneurobio.2006.06.004 
Warburton, E.C., Brown, M.W., 2010. Findings from animals concerning when interactions between perirhinal cortex, hippocampus and medial prefrontal cortex are necessary for recognition memory. Neuropsychologia 48, 2262-2272. doi:10.1016/j.neuropsychologia.2009.12.022

Weible, a. P., Rowland, D.C., Monaghan, C.K., Wolfgang, N.T., Kentros, C.G., 2012. Neural Correlates of Long-Term Object Memory in the Mouse Anterior Cingulate Cortex. J. Neurosci. 32, 5598-5608. doi:10.1523/JNEUROSCI.5265-11.2012

Weiss, I.C., Pryce, C.R., Jongen-Rêlo, A.L., Nanz-Bahr, N.I., Feldon, J., 2004. Effect of social isolation on stress-related behavioural and neuroendocrine state in the rat. Behav. Brain Res. 152, 279-295. doi:10.1016/j.bbr.2003.10.015

Winters, B.D., Bussey, T.J., 2005. Transient inactivation of perirhinal cortex disrupts encoding, retrieval, and consolidation of object recognition memory. J. Neurosci. 1, 52-61. doi:10.1523/JNEUROSCI.3827-04.2005

Winters, B.D., Saksida, L.M., Bussey, T.J., 2010. Implications of animal object memory research for human amnesia. Neuropsychologia 48, 2251-2261. doi:10.1016/j.neuropsychologia.2010.01.023

Winters, B.D., Saksida, L.M., Bussey, T.J., 2008. Object recognition memory: Neurobiological mechanisms of encoding, consolidation and retrieval. Neurosci. Biobehav. Rev. 32, 1055-1070. doi:10.1016/j.neubiorev.2008.04.004

Wu, Z.-Q., Li, M., Chen, J., Chi, Z.-Q., Liu, J.-G., 2006. Involvement of CAMP/cAMPdependent protein kinase signaling pathway in regulation of $\mathrm{Na}+\mathrm{K}+-\mathrm{ATPase}$ upon activation of opioid receptors by morphine. Mol. Pharmacol. 69, 866-76. doi:10.1124/mol.105.016501

Wykes, V., Bellamy, T.C., Garthwaite, J., 2002. Kinetics of nitric oxide-cyclic GMP signalling in CNS cells and its possible regulation by cyclic GMP. J. Neurochem. 83, 37-47.

Xu, Y., Pan, J., Chen, L., Zhang, C., Sun, J., Li, J., Nguyen, L., Nair, N., Zhang, H., O'Donnell, J.M., 2013. Phosphodiesterase-2 inhibitor reverses corticosteroneinduced neurotoxicity and related behavioural changes via cGMP/PKG dependent pathway. Int. J. Neuropsychopharmacol. 16, 835-47. doi:10.1017/S146114571200065X

Xu, Y., Pan, J., Sun, J., Ding, L., Ruan, L., Reed, M., Yu, X., Klabnik, J., Lin, D., Li, J., Chen, L., Zhang, C., Zhang, H., O'Donnell, J.M., 2015. Inhibition of phosphodiesterase 2 reverses impaired cognition and neuronal remodeling caused by chronic stress. Neurobiol. Aging 36, 955-970. doi:10.1016/j.neurobiolaging.2014.08.028

Xu, Y., Zhang, H., Donnell, J.M.O., 2011. Phosphodiesterase in the Central Nervous System: Implications in Mood and Cognitive Disorders, in: Francis, S.H., Conti, M., Houslay, M.D. (Eds.), Phosphodiesterase as Drug Targets, Handbook of Experimental Pharmacology. Springer Berlin Heidelberg, Berlin, Heidelberg, pp. 447-485. doi:10.1007/978-3-642-17969-3 
Yang, Q., Paskind, M., Bolger, G., Thompson, W.J., Repaske, D.R., Cutler, L.S., Epstein, P.M., 1994. A novel cyclic GMP stimulated phosphodiesterase from rat brain. Biochem. Biophys. Res. Commun. 205, 1850-8. doi:10.1006/bbrc.1994.2886

Zhang, H.-T., Huang, Y., Jin, S.-L., Frith, S. a, Suvarna, N., Conti, M., O'Donnell, J.M., 2002. Antidepressant-like profile and reduced sensitivity to rolipram in mice deficient in the PDE4D phosphodiesterase enzyme. Neuropsychopharmacology 27 , 587-95. doi:10.1016/S0893-133X(02)00344-5

Zhou, Q.-G., Zhu, L.-J., Chen, C., Wu, H.-Y., Luo, C.-X., Chang, L., Zhu, D.-Y., 2011. Hippocampal Neuronal Nitric Oxide Synthase Mediates the Stress-Related Depressive Behaviors of Glucocorticoids by Downregulating Glucocorticoid Receptor. J. Neurosci. 31, 7579-7590. doi:10.1523/JNEUROSCI.0004-11.2011

Zola, S.M., Squire, L.R., 2001. Relationship between magnitude of damage to the hippocampus and impaired recognition memory in monkeys. Hippocampus 11, $92-$ 8. doi:10.1002/hipo.1027 


\title{
Lindsay M. Lueptow, PhD
}

\section{Curriculum Vitae, December 2015}

\author{
West Virginia University Health Sciences Center \\ Department of Neurobiology and Anatomy \\ 1 Medical Drive \\ PO Box 9128 \\ Morgantown, WV 26506 \\ (304) 293-4782 \\ Imlueptow@mix.wvu.edu
}

\section{Education}

West Virginia University

Advisor: Dr. James M O'Donnell

$\mathrm{PhD}$, Neuroscience

2008- 2015

University of Wisconsin-Milwaukee

B.A. in Psychology, Minor in Comparative Literature

2005-2008

Wisconsin Lutheran College, Milwaukee, WI

2004-2005

\section{Research Experience}

Research Assistant - Center for Tobacco Research and Intervention - University of Wisconsin, Milwaukee Branch

August 2007-August 2008

Neuroscience Department Rotations - West Virginia University (Dr. James O'Donnell, Dr. Albert Berrebi, Dr. Bernard Schreurs)

August 2008-June 2009

Graduate Research Assistant - West Virginia University (Dr. James O'Donnell) June 2009-Present

\section{Publications}

Lueptow, LM, Xu,Y, O'Donnell, JM (2016). Role of PDE2 in CNS function. Phosphodiesterases: CNS Functions and Diseases. ed. O'Donnell, JM, Xu, Y, Zhang, HT. Springer. In preparation.

Lueptow, LM, Zhan, CG, O'Donnell, JM (2015). Cyclic GMP-Mediated Memory Enhancement in the Object Recognition Test by Inhibitors of Phosphodiesterase-2 in Mice.

Psychopharmacology. doi: 10.1007/s00213-015-4129-1

Lueptow, LM, Xu, Y, Zhang, HT, O'Donnell, JM (2015). Drugs used in Anxiety, Depression, and bipolar disorder. Craig and Stitzel's Modern Pharmacology, 7ed. New Deli, India: Jaypee Medical Publishers 
Zhang C, Yu Y, Ruan L, Wang C, Pan J, Klabnik J, Lueptow LM, Zhang HT, O'Donnell JM, Xu Y The Roles of Phosphodiesterase 2 in the Central Nervous and Peripheral Systems. Curr Pharm Des. 2014 Aug 26. [Epub ahead of print]

Lueptow, LM \& O'Donnell, JM (2011). Differential-reinforcement-of-low-rate behavior in rodents as a screen for antidepressant efficacy. ed Todd Gould. Mood \& Anxiety Related Phenotypes in Mice: characterization using behavioral tests. Volume II. Totowa, NJ: Humana Press.

\section{Poster Presentations}

Lueptow, LM, Xu, Y, O’Donnell, JM (2015) Cyclic Nucleotide PDE2 inhibition and Object Recognition Memory. 2015 Pharmacy Research Forum, Morgantown, WV. First Place Award.

Lueptow, LM, Xu, Y, O’Donnell, JM (2015) Effects of Cyclic Nucleotide Phosphodiesterase 2 (PDE2) on Object Recognition Memory in Mice. ASPET Annual Meeting at Experimental Biology, Boston, MA.

Lueptow, LM, Xu, Y, O’Donnell, JM (2015) Cyclic Nucleotide Phosphodiesterase 2 (PDE2) Inhibition Enhances Object Recognition Memory in Mice. Van Liere Research Day, WVU Health Science Center. First Place Award.

Lueptow, LM, Xu, Y, Kolandaivelu, S, Rammamurthy, V \& O’Donnell, JM (2013) Behavioral

Phenotype of the Conditional Phosphodiesterase-2 Knockout Mouse. Center for Neuroscience Annual Retreat. Stonewall Jackson Resort, WV.

Shockcor, N, Lueptow, LM, Kolandaivelu, S, Zhang, HT, Rammamurthy, V \& O'Donnell, JM (2012). Investigation of the role of phosphodiesterase 2 (PDE2) on mouse behavior:

Preliminary Findings. Center for Neuroscience Annual Retreat. Snoshoe, WV.

Lueptow, LM, Zhao, Z, O'Donnell, JM (2012). Regulation of Monoamine Transporters is important for Antidepressant-like Behavior in Rats. Linking Innovation, Industry, and Commercialization (LIINC) Event. Morgantown, WV.

Lueptow, LM, Zhao, Z, O’Donnell, JM (2010). Norepinephrine and Serotonin Transporter

Regulation is Important for Antidepressant-like Effects on Behavior in Rats.

Society for Neuroscience Meeting in San Diego, CA.

Lueptow, LM, Zhao, Z., O'Donnell, JM (2010). Down-regulation of Serotonin and

Norepinephrine Transporters Following Chronic Antidepressant Treatment. Van Liere Research Day, West Virginia University in Morgantown, WV.

Lueptow, LM, Zhao, Z, O'Donnell, JM (2010). The Effects of Antidepressant Treatment on Norepinephrine and Serotonin Transporters. West Virginia University School of Pharmacy Retreat in Morgantown, WV. 


\section{Invited Lectures and Symposia}

October 2015-WVU Neuroscience Seminar Series

March 2013 - Psychotropic Medication, Invited lecture WVU School of Social Work

March 2012 - WVU Neuroscience Student Seminar Series

May 2011 - Teaching Practicum: Principles of Neuroscience Lecture, Dept of Physiology, WVU

April 2011 - WVU Neuroscience Department: Qualifying Exam Seminar

April 2011 - WVU Neuroscience Department: Breakthrough Blitz

January 2010 - BBS T32 Meeting of the Behavioral and Biomedical Sciences, WVU

February 2010 - BBS T32 Meeting of the Behavioral and Biomedical Sciences, WVU

\section{Committee \& Journal Participation}

December 2011- Present

June - August 2014

November 2009 - May 2010

August 2009 -- August 2011

February 2010 - May 2010
Reviewer for Metabolic Brain Research Journal

Student Representative: Neuroscience Curriculum Development Committee

Chair: NIH/NIGMS T-32 Training Program, Behavioral and Biomedical Sciences (BBS T32) Training Scholarship Funding Committee

Organization for Meeting of Behavior \& Biomedical Sciences (MOBB) for NIH/NIGMS T-32 Training Program

Student Representative: First Year Biomedical Sciences Curriculum Committee

\section{Teaching Experience}

Volunteer -WVU Brain Awareness Program, Watson Elementary, Fairmont, WV October 2014

Invited Lecture - WVU School of Social Work Spring 2013 \& Spring 2014

Teaching Practicum - WVU Department of Physiology Spring 2011

Biochemistry Tutor - WVU first year graduate classes

Fall 2009

Writing Tutor - Wisconsin Lutheran College

Fall 2005

Undergraduate Teaching Assistant - Wisconsin Lutheran College Fall 2005

Site Coordinator - YMCA Milwaukee After School Program

August 2005- June 2007

\section{Awards}

2015 -- $1^{\text {st }}$ Place Poster Session, 2015 Pharmacy Research Forum, WVU

$2015-1^{\text {st }}$ Place Poster Session, Van Liere Research Day, WVU February 2015

2015 - WVU Office of Research and Grad Education Doctoral Travel Award for EB 2015 
$2009-2011$ NIH/NIGMS T-32 Training Program in the Behavioral \& Biomedical Sciences (BBS)

2008 - Graduated with Honors in Psychology, University of Wisconsin, Milwaukee

2008 - Graduated Summa Cum Laude, University of Wisconsin, Milwaukee

2004-2005 - Presidential Scholarship, Wisconsin Lutheran College

\section{Memberships}

American Association of Pharmeceutical Scientists

2013-Present

Society for Neuroscience

2009-Present

Psi Chi - National Honor Society for Psychology

2007-2008 